\title{
BIOLOGIA, NUTRIÇÃO E EXIGÊNCIAS TÉRMICAS DE D seudaletia sequax FrANCLEMONT, 1951 (LEPIDOPTERA, NoctUIDAE) EM DIETA ARTIFICIAL
}

JOSE ROBERTO SALVADORI

Engenheiro Agrônomo

Orientador: Prof. Dr. JOSÉ ROBERTO POSTALI PARRA

Tese apresentada à Escola Superior de Agricultura "Luiz de Queiroz", da Universidade de São Paulo, para obtenção do título de Doutor em Ciências - Área de Concentração: ENTOMOLOGIA.

\footnotetext{
PIR A C I A B A

Estado de São Paulo - Brasil

Fevereiro - 1987
} 


\title{
BIOLOGIA; NUTRIÇÃO E EXIGÊNCIAS TÉRMICAS DE Pseudaletia sequax FrancLEMONT, 1951 (LEPIDOPTERA; NOCTUIDAE) EM DIETA ARTIFICIAL
}

\author{
JOSÉ ROBERTO SALVADORI
}

APROVADA EM: 30.03 .87

COMISSÃO JULGADORA

Prof. Dr.'José Roberto Postali Parra . . . ESALQ/USP

Prof. Dr. Sinval Silveira Neto . . . . ESALQ/USP

Prof. Dr. José Djair Vendramin ..... ESALQ/USP

Dr. Flávio Moscardi. . . . . . . . CNPSo/EMBRAPA

Prof. Dr. Rogério Fernando Pires da Silva . Fac. Agronomia/UFRGS

Prof. Dr. José Roberto Postali Parra 
Aos meus pais

José e Eulālia,

AGRADEÇO

$\grave{A}$ Tania, minha esposa, e às nossas filhas Juliana e Carina, DEDICO 


\section{AGRADECIMENTOS}

Ao Dr. José Roberto Postali Parra, Professor adjunto do Departamento de Entomologia, da Escola Superior de Agricultura "Luiz de nueiroz" (ESALQ), da Universidade de São Paulo (USP), pela orientação e ajuda na condução desta pesquisa, pelos ensinamentos e amizade.

À Empresa Brasileira de Pesquisa Agropecuária (EMBRAPA) pela oportunidade de realização do Curso de Doutorado.

Aos Professores do Curso de Pós-Graduação em Entomologia da ESALQ/USP pelos conhecimentos transmitidos, especialmente aos Drs. Sinval Silveira Neto, Evôneo Berti Filho e Roberto Antônio zucchi pela colaboração direta em diferentes etapas deste trabalho.

Ao Professor Décio Barbin (ESALQ/USP), ao Engenheiro Agrônomo MS em Estatistica, Carlos Henrique Mattioli (Centro de Informática da Agricultura/USP) e à Dra. Marinéia de Lara Haddad, pelo suporte estatístico.

Às bibliotecárias Marialice M. Poggiani (Instituo de Pes quisas e Estudos Florestais) e Odair T. M. de Paris (ESALQ/USP) pela revisão das referências bibliográficas.

$\bar{A}$ todos os que auxiliaram na realização deste trabalho, em especial aos colegas Willy R. V. Chiarevalle, Rosá ria M. S. de Almeida e Roseli do Carmo Estevam, aos laboratoristas João Marcelo Lopes e Neide G. Maria e à desenhista Liciane T. Duda (Centro Nacional de Pesquisa de Trigo/EMBRAPA). 


\section{INDICE}

Página

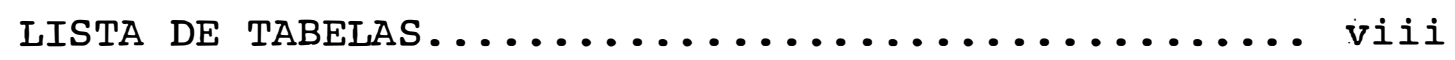

LISTA DE FIGURAS..................... xv

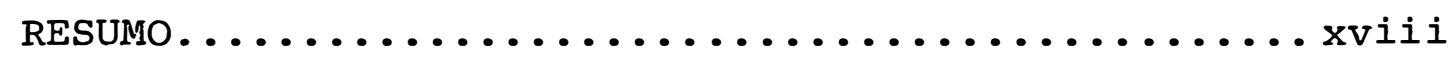

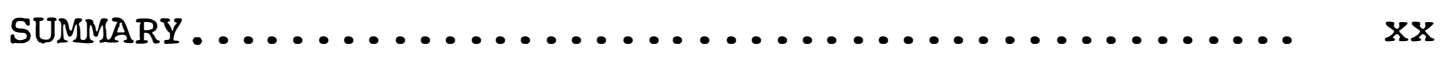

1. INTRODUÇÃO........................... 1

2. REVISÃo DE LITERATURA.................. 3

2.1. Nutrição e dietas artificiais........... 6

2.2. Parâmetros biológicos............... 10

2.2.1. Espeécies do "grupo unipuncta"..... 10

:2.2.2. M. separata.................... 12

2.2.3. L. Loreyi.Dup................ 13

2.2.4. P. adultera................ 13

2.2.5. P. sequax.................. 14

2.3. Influência da temperatura no crescimento e desenvolvimento.................. 16

3. MAtERial E MÉtodos...................... 21

3.1. Procedimentos gerais............... 21

3.2. Estudo de dietas artificiais para $P$. sequax 23

3.2.1. Seleção de dietas artificiais...... 24

3.2.2. Avaliação de três dietas seleciona-

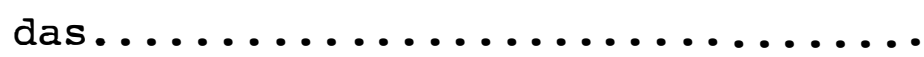


3.2.2.1. Efeito de três dietas arti ficiais sobre parāmetros biológicos..............

3.2.2.2. Comparação das três dietas artificiais quanto ao consumo e utilização de àlimento.................

3.2.2.3. Custo do inseto produzido nas três dietas artificiais.

3.3. Biologia comparada de $P$. sequax em dietas natural e artificial.............. 30

3.4. Efeito da temperatura na biologia de $P$. se quax em dieta artificial............ 32

4. RESUltados E discussão................. 34

4.1. Estudo de dietas artificiais para a criação de Pseudaletia sequax Franclemont, 1951

4.1.1. Seleção de dietas artificias.......

4.1.2. Avaliação das três dietas artificiais selecionadas............... 4.1.2.1. Efeito das dietas artificiais sobre parâmetros bio lógicos do inseto......... 
Pāgina

4.1.2.2. Comparação das dietas artificiais quanto ao seu consu mo e utilização pelos insetos.................. 54

4.1.2.3. Custo do inseto produzido nas dietas artificiais.....

4.2. Biologia comparada de $P$. sequax em dietas

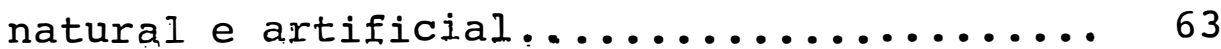
4.2.1. Viabilidade das fases imaturas..... 63 4.2.2. Duração do desenvolvimento........ 67 4.2.3. Razão sexual................ 70 4.2.4. Peso de Dupas................... 71 4.2 .5 . Adu 1 to..................... 73

4.2.6. Deformação de pupas e adultos...... 79 4.2.7. Contaminação das dietas artificias por microrganismos............ 79

4.2.8. Tabelas de vida de fertilidade..... 80

4.3. Efeito da temperatura na biologia e exigências térmicas de $P$. sequax.............. 82

4.3.1. Sobrevivência das fases imaturas.... 82

4.3.2. Duração do desenvolvimento........ 84

4.3.3. Peso de pupa................... 89

4.3.4. Adulto..................... 89 
.viii.

Página

4.3.5. Deformação de pupas e adultos......

4.3.6. Contaminação das dietas artificias por microrganismos.............

4.4. Considerações sobre uma criação massal de

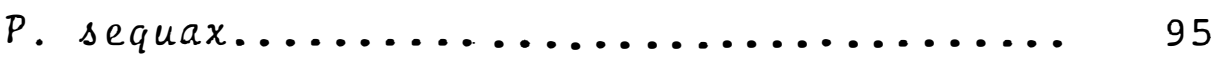

4.4.1. Dieta artificial.............. 96

4.4.2. Temperatura de criação.......... 102

4.4.3. Outros conhecimentos necessários à

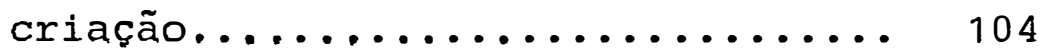

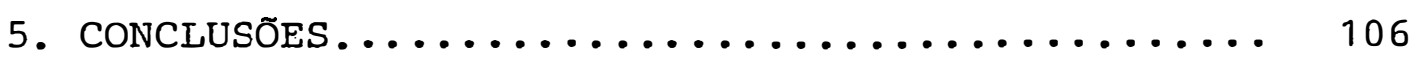

6. REFERÊNCIAS BIBLIOGRÁFICAS................ 108 


\section{LISTA DE TABELAS}

Tabela

Página

Principais citações de Cirphis unipuncta, Pseudaletia adultera e P. unipuncta em diverșos Estados do Brasil até $1976 \ldots \ldots \ldots \ldots \ldots \ldots \ldots$

Composição $(\mathrm{g} / 1000 \mathrm{~g})$ de dezesseis dietas artificiais avaliadas para a criação de Pseudaletia sequax Franc.

Viabilidade e duração das fases larval e pupal e peso de pupas de Pseu. daletia sequax Franc., 1951, criada! em dezesseis dietas artificiais (tem peratura: $25 \pm 2^{\circ} \mathrm{C}$; UR: $60 \pm 10 \%$, fo tofase: $14 \mathrm{~h}) \ldots . . \ldots \ldots \ldots \ldots . . . . .$.

Efeito de três dietas artificiais so bre parâmetros biológicos na primeira geração de Pseudaletia sequax Franc., 1951 (temperatura: $25 \pm 2^{\circ} \mathrm{C}$; UR: $60 \pm 10 \%$, fotofase: $14 \mathrm{~h}) \ldots .$. 
Efeito de três dietas artificiais so bre parāmetros biológicos na segunda geração de Pseudaletia sequax Franc., 1951 (temperatura: $25 \pm 2^{\circ} \mathrm{C}$; UR: 60 $\pm 10 \%$; fotofase: $1 \dot{4} \mathrm{~h}) \ldots \ldots \ldots \ldots \ldots$

Efeito de três dietas artificiais so bre parāmetros biológicos na terceira geração de Pseudaletia sequax Franc. 1951 (temperatura: $25 \pm 2^{\circ} \mathrm{C}$; UR: 60 $\pm 10 \%$; fotofase: $14 \mathrm{~h}) \ldots \ldots \ldots \ldots \ldots \ldots$

Viabilidade e duração do período lagarta-pupa de Pseudaletia sequax Franc., 1951, criada em três dietas artificiais, por três gerações suces sivas (temperatura $25 \pm 2^{\circ} \mathrm{C}$; UR: 60 $\pm 10 \%$; fotofase: $14 \mathrm{~h}) \ldots \ldots \ldots \ldots \ldots$

Peso de puñas e razão sexual de Pseu daletia sequax Franc., 1951, criada em três dietas artificiciais, por três gerações sucessivas itemperatura: 25

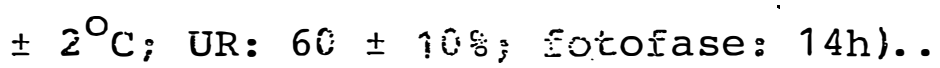


Deformação (\%) de pupas e adultos de Pseudaletia sequax Franc., 1951, cria da em três dietas artificiais, por três gerações sucessivas (temperatura: $25 \pm 2^{\circ} \mathrm{C}$; UR: $60 \pm 10 \%$; fotofase: $14 \mathrm{~h})$

Alimento ingerido (I), fezes produzi das $(F)$, alimento assimilado $(I-F), \underline{a}$ limento metabolizado (H) e ganho de biomassa (B) no período larval de Pseudaletia sequax Franc., 1951. em três dietas artificiais (temperatura: $26^{\circ} \mathrm{C}$; UR: $60 \pm 10 \%$ : fotofase: $14 \mathrm{~h})$

Taxa de consumo relativo ( $R C R)$, taxa de crescimento relativo (RGR), taxa metabólica relativa (RMR), digestibi lidade aproximada (AD), eficiência de conversão do alimento ingerido (ECI) e do digerido (ECD) no período larval de Pseudaletia sequax Franc., 
1951, em três dietas artificiais (tem peratura: $26^{\circ} \mathrm{C}$; UR: $60 \pm 10 \%$; fotofa se: $14 \mathrm{~h}) \ldots \ldots \ldots \ldots \ldots \ldots \ldots$

Consumo e custo de produção de Pseu_ daletia sequax Franc., 1951, em três dietas artificias................

Viabilidade (\%) das fases imaturas de Pseudaletia sequax Franc., 1951, submetida a diferentes dietas no pe ríođo larval (temperatura: $25 \pm 2^{\circ} \mathrm{C}$; UR: $60 \pm 10 \%$; fotofase: $14 \mathrm{~h}) \ldots . .$.

Duração (diass) das fases imaturas de Pseudaletia sequax Franc., 1951, submetida a diferentes dietas no periodo larval (temperatura: $25 \pm 2^{\circ} \mathrm{C}$; UR: $60 \pm 10 \%$; fotofase: $14 \mathrm{~h}) \ldots \ldots$.

Razão sexual e peso de pupas de Pseu daletia sequax Franc., 1951, submeti da a diferentes dietas no período lar val (temperatura: $25 \pm 2{ }^{\circ} \mathrm{C}$; UR: $60 \pm 10^{\circ}$

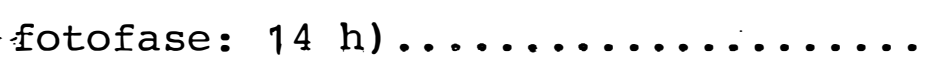


Períodos de pré-oviposição e oviposi ção, longevidade e capacidade de pos tura de adultos de Pseudaletia sequax., 1951, submetida a diferentes dietas no periodo larval (UR: $60 \pm 10 \%$;

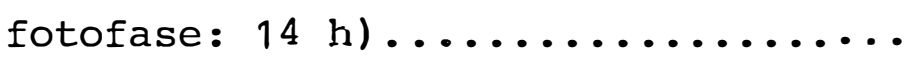

Deformação de pupas e adultos de Pseudaletia sequax Franc., 1951, sub metida a diferentes dietas no período larval e contaminação das dietas artificiais

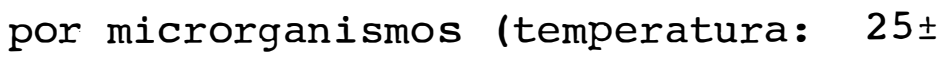
$2^{\circ} \mathrm{C}$; UR: $60 \pm 10 \%$; fotofase: $\left.14 \mathrm{~h}\right) \ldots$

Taxa lî́quida de reprodução (Ro), duração mêdia de cada geração ( $T$ ), can pacidade inata de aumentar em número (rm) e razão finita de aumento $(\lambda)$ de Pseudaletia sequax Franc., 1951, em diferentes dietas (temperatura: $\underline{\text { fa }}$ ses imaturas $-25: \pm 2{ }^{\circ} \mathrm{C}$, adultos-médias de $25 \pm 2{ }^{\circ} \mathrm{C}$ e $28 \pm 2{ }^{\circ} \mathrm{C}$; UR: $60 \pm$ $10 \%$; fotofase: $14 \mathrm{~h}) \ldots . \ldots \ldots \ldots$ 
Sobrevivência (\%) das fases imaturas de Pseudaletia sequax Franc., 1951, submetida a diferentes temperaturas: (UR: $60 \pm 10 \%$; fotofase: $14 \mathrm{~h}$ )......

Duração (dial das fases imaturas de Pseudaletia sequax Franc., 1951, sub metida a diferentes temperaturas (UR: $60 \pm 10 \%$; fotofase: $14 \mathrm{~h}) \ldots . . . \ldots$

Temperatura base (Tb), constante tēr mica (K), equạação da velocidade do desenvolvimento $(1 / D)$ e : respectivo coeficiente de determinação $\left(R^{2}\right)$ para as fases imaturas de Pseudaletia sequax Franc., 1951, criada em dieta

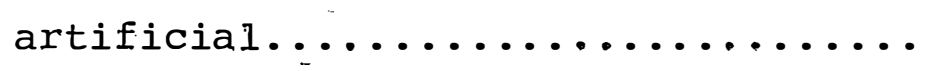

Longevidade (dia) de Pseudaletia se quax Franc., 1951, submetida a diferentes temperaturas constantes desde a fase larval e não alimentada na fa se adulta (UR: $60 \pm 10 \%$; fotofase:

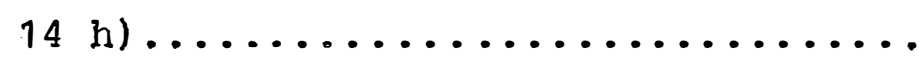


Períodos de oré-ovinosição, ovip̣osição, longevidade e capacidade de pos tura de adultos de Pseudaletia sequax Franc., 1951, alimentados com solução de mel a 10\%; em duas condições de temperaturas (UR: $60 \pm 10 \%$ fo tofase: $14 \mathrm{~h}) \ldots . . \ldots \ldots \ldots . . . . .$.

Peso de pupas, deformação de pupas e adultos de Pseudaletia sequax Franc., 1951 e contaminação da dieta artificial, oor microrganismos em diferentes temperaturas constantes (UR: -.60 $\pm 10 \%$; fotofase: $14 \mathrm{~h}) \ldots . . . \ldots \ldots$. 


\section{IISTA DE FIGURAS}

Figura

Pāgina

Viabilidade do período larva-pupa de Pseudaletia sequax Franc., 1951 cria da em três dietas artificiais, por três gerações sucessivas (temperatura: $25 \pm 2^{\circ} \mathrm{C}$; UR: $60 \pm 10 \%$; fotofase: $14 \mathrm{~h}) \ldots \ldots \ldots \ldots \ldots \ldots \ldots \ldots$

Duração do período larva-pupa de Pseu daletia sequax Franc., 1951 .. criada em três dietas artificias, por três gerações suicessivas (temperatura: 25 $\pm 2^{\circ} \mathrm{C}$; UR: $60 \pm 10 \%$; fotfase: $\left.14 \mathrm{~h}\right) \ldots$

Peso de pupas de Pseudaletia sequax Franc., 1951 criada em três dietas artificiais, por três gerações suces sivas (temperatura: $25 \pm 2{ }^{\circ} \mathrm{C}$; UR: 60 $\pm 10 \%$; fotofase: $14 \mathrm{~h}$ )............ 
Taxa de consumo ( $R C R$ ), de crescimento (RGR) e de metabolismo (RMR) rela tivos (em g/g.dia) e digestibilidade aproximada (AD), eficiência de oonversão do ingerido (ECI) e eficiên cia de conversão do digerido (ECD) em : de Pseudaletia sequax Franc., 1951, em três dietas artificiais (tem peratura: $26^{\circ} \mathrm{C}$; UR: $60 \pm 10 \%$; fotofa se: $14 \mathrm{~h}) \ldots \ldots \ldots \ldots \ldots \ldots \ldots . . . . .$.

Duração de diferentes etapas do ciclo biológico de Pseudaletia sequax Franc., 1951 criada em três dietas artificiais (A, K e N) e em trigo (T) (temperatura: fases imaturas $-25 \pm 2 \mathrm{C}$; adultos: médias de $25 \pm 2$ e $28 \pm 2^{\circ} \mathrm{C}$; $\mathrm{UR}: 60 \pm 10 \%$; fotofase: $14 \mathrm{~h}$ )...... 
Relação da temperatura com a duração (-) e com a velocidade de desenvolvimento (---) de diferentes fases do ciclo biológico de Pseudaletia sequax Franc., 1951 (UR: $60 \pm 10$; foto fase $114 \mathrm{~h}) \ldots \ldots \ldots \ldots \ldots \ldots \ldots \ldots$

Relação entre temperatura e longevi dade (mêdia de machos e fêmeas) de Pseudaletia sequax Franc., 1951 (UR: $60 \pm 10 \%$; fotofase: $14 \mathrm{~h}) \ldots . . . .$.

Viabilidade e duração das fases imaturas de Pseudaletia sequax Franc., 1951 criada em três dietas ! artificiais $(A, K$ e N) e em trigo (T) (tem peratura: $25 \pm 2{ }^{\circ} \mathrm{C}$; UR: $60 \pm 10 \%$; tofase: $14 \mathrm{~h}) \ldots \ldots \ldots \ldots \ldots . . . . . .$.

Sobrevivência e duração das fases ima turas de Pseudahetia sequax Franc., 1951 submetida a diferentes temperaturas (UR: $60 \pm 10 \%$; fotofase: 14h).. 


\section{BIOLOGIA, NUTRIÇÃO E EXIGENCIAS TÉRMICAS DE Pseudaletia sequax Franclemont, 1951 (Lepidoptera, NoctuidaE) EM DIETA ARTIFICIAL}

Autor: José Roberto Salvadori

Orientador: Prof. Dr. José Roberto Postali Parra

\section{RESUMO}

Com o objetivo de se obterem informações sobre a biologia e as exigências nutricionais e térmicas de $P$. sequax Franc., 1951, com vistas à sua criação em dieta artifi cial, conduzirarn-se estudos no Laboratório de Biologia do Departamento de Entomologia da Escola Superior de Agricultura. "Luiz de Queiroz" da Universidade de São Paulo (USP). As condiçōes de temperatura foram controlachas, porém em niveis variàveis nas diferentes etapas do trabalho; a umidade relati va foi de $60 \pm 10 \%$ e a fotofase de 14 horas.

O trabalho constou, basicamente, de três etapas: 1.a) Estudo de dietas artificiais no qual, através de parâmetros biológicos, foram comparadas dezesseis dietas; as dietas selecionadas desta forma, foram avaīia das mais detalhadamente através de seu efeito na biologia (por três gerações sucessivas), consumo e utilização do alimento e custo dos insetos produzidos; 2a) Biologia comparada em dietas natural (folhas de trigo) e artificiais e 3.) Efeito da temperatura $\left(18,20,22,26,30\right.$ e $\left.32^{\circ} \mathrm{C}\right)$ na biologia, em dieta artificial.

Concluiu-se que duas dietas artificiais, uㅡ ma à base de feijão, caseína, farinha de soja, germe de trigo e levedura de cerveja (dieta A) e outra à base de 
feijão, germe de trigo e levedura de cerveja (dieta K) ,po dem ser utilizadas em substituição ao trigo para a criação de $P$. sequax. A condição térmica mais adequada para a criação deste inseto foi entre 25 e $26^{\circ} \mathrm{C}$.

Verificou-se que o alimento ingerido na fase la val afetou a viabilidade de ovos, lagartas e pupas, a duração das fa ses larval e pupal, o peso das pupas, a taxa líquida de reprodução (Ro) e a razão finita de aumento $(\lambda)$. Não teve efeito, porém, sobre a razão sexual, longevidade de machos e de fêmeas, duração dos perío dos de pré-oviposição e de oviposição e na capacidade de postura. Constatou-se tambejn, que as lagartas consumiram e utilizaram as dietas artificiais de forma quantitativamente diferente, havendo uma menor eficiência de conversão do alimento menos adequado.

Durante as fases de desenvolvimento, a temperaturateve influência na sobrevivência e na duração. A velocidade do desenvolvimento aumentou linearmente com 0 incremento da temperatura, na faixa de 20 a $30^{\circ} \mathrm{C}$ para a fase de ovo, e de 18 a $30^{\circ} \mathrm{C}$ para as fases larval e pupal. Para que fossem completadas as fases de ovo, lagarta e pupa, P. sequax exigiu 34,4 GD, 505,9 GD e 180,6 GD, respectivamente; para todo o período de desenvolvimento foram exigi dos 804,4 GD.

Na fase adulta, observou-se çue a temperatú ra afetou a longevidade, a duração dos períodos de pré-ovi posição e de oviposição e a capacidace de postura. Com relação a estes parâmetros, a condição de $25 \pm 2{ }^{\circ} \mathrm{C}$ foi mais favorável à espécie do que $28 \pm 2{ }^{\circ} \mathrm{C}$. 


\section{BIOLOGY, NUTRITION AND THERMAL REQUIREMENTS OF Pseudale- tia sequax FranCLEMONT, 1951 (LEPIDOPTERA, NoctuIDAE) ON ARTIFICIAL DIET.}

Author: José Roberto Salvadori

Adviser: Prof. José Roberto Postali Parra

\section{SUPMARY}

This research was carried out in laboratory in order to obtain data on the biology, nutrition and thermal requirements of Pseudaletia sequax Franclemont, 1951, aiming at the insect rearing on artificial diet. The food ingested in the larval stage did affect the viability of eggs, larvae and pupae, the length of larval and pupal stages and pupal weigth. The temperature influenced on the survival and developmental time of immature stages. The species required 804.4 degree days to complete its development. As to the adults, the temperature did affect the longevity, the preoviposition and oviposition periods as well as the of laying eggs capacity. Two artificial diets were most suitables; one composed by beans, casein soybean flour, wheat germ and yeast, and the other composed by beans, wheat germ and yeast, which may substitute the natural diet (wheat leaves) for $P$. sequax rearing. The most suitable thermal condition for this insect was found to be.. between 25 and $26^{\circ} \mathrm{C}$. 


\section{INTRODUC,ÃO}

Pseudaletia sequax Franclemont, 1951' (Lepidoptera, Noctuidae) é um inseto polífago, que se alimen ta de várias plantas de interesse econômico (BIEZAnKo e RUFFINELLI, 1971; BIEZANKO et alii, 1974 e CRUZ e FOERSTER, 1986).

Segundo FRANCLEMONT (1951) esta espécie pą rece ser comum entre os trópicos americanos, ocorrendo desde o México até o norte da Argentina.

No Brasil, sua ocorrência já foi citada nos Estados de São Paulo (LARA et alii, 1977), Paraná (PEREIRA, 1980), Mato Grosso do Sul (SALVADORI et alii, 1983) e Rio Grande do Sul (GASSEN, 1983). Denominada vulgarmente de lagarta-do-trigo, é considerada uma importante praga desta cultura (GALLO et alii, 1978; NAKANO etalii, 1981 e GASSEN, 1984), pois pode causar prejuizos significativos através da destruição de folhas e espigas.

A literatura nacional e internacional é ex tremamente carente em publicações a respeito de $P$. sequax. Muito pouco se conhece sobre sua biologia, nutrição e exi gências térmicas. Não consta na literatura científica nenhuma informação sobre as exigências nutricionais desta espécie, com vistas à sua criação en dieta artificial.

A realização de pesquisas básicas e aplicą das com esta espécie está condicionada, atualmente, à sua ocorrência natural, que se restringe a curtos períodos ao longo do ciclo de cereais de inverno e cuja intensidade 
tem variado de ano para ano.

o conhecimento de técnicas de criação em dieta artificial é fundamental para a produção contínua de insetos. Isto agilizaria o processo de obtenção de informaçōes sobre a bioecologia e o desenvolvimento de métó dos de controle, especialmente biológicos (parasitóides, pre dadores e patógenos), que dependem da disponibilidade constante de insetos.

Em vista do exposto, conduziu-se o presente trabalho com o objetivo de se obterem conhecimentos so bre a biologia e as exigências nutricionais e térmicas de $P$. sequax, os quais poderão servir de subsídio à criação desta espécie em dieta artificial. 


\section{REVISÃO DE LITERATURA}

Espécies de Cirphis, Leucánia, Mythimna e Pseudaletia constituem um grupo de pragas de característi cas biológicas e comportamentais semelhantes. As lagartas são extremamente vorazes, especialmente no último instar, quando podem apresentar hábitos migratórios sendo, por is so, chamadas de lagartas-militares. Também têm em comum a ampla faixa de hospedeiros, composta principalmente de gra míneas cultivadas ou não.

o "grupo unipuncta" foi revisado por FRANCLEMONT (1951), que discutiu os nomes genéricos das lagar tas-militares das Américas e criou o gênero Pseudaletia, onde incluiu diversas espécies de Cirphis e de Leucania. Para as espécies que ocorrem no Brasil, o autor definiu a seguinte nomenclatura:

Pseudaletia unipuncta (Haworth, 1809). Fran clemont, 1951

sinonimia: Noctua unipuncta Haworth

Leucania impuncta Stephens

Leucania extranea Guenée

Pseudaletia roraimae Franclemont, 1951

Pseudaletia adultera (Schaus, 1894) Franclemont, 1951

sinonimia: Leucania adultera Schaus

Pseudaletia sequax Franclemont, 1951

A primeira vez que a denominação $P$. sequax apareceu na bibliografia nacional foi no trabalho de LARA et alii, (1977). Conforme ZUCCHI e SILVEIRA NETO*, foi O Dr. *ZUCCHI, R.A. e SILVEIRA NETO, S. (Escola Superior de Agricultura "Luiz de Queiroz"/Universidade de São Paulo). Comunicação Pessoal, 1984. 
Vitor Becker (EMBRAPA/CENTRO DE PESQUISA AGROPECUARIA DOS CERRADOS (CPAC) - Planaltina-DF) que en 1976, examinando o material do Museu do Departamento de Entomologia da ESALQ/USP, constatou que os exemplares que estavam registrados como $P$. adultera, eram na verdade $P$. sequax.

No entanto, cabe ser mencionado que a deno minação Cirphis sequax Franc., embora não conste na revisão de FRANCLEMONT (1951), já fora utilizada para uma espécie encontrada no Rio Grande do Sul (BERTELS, 1956; BER TELS, 1970; BERTELS e FERREIRA, 1973 e CORSEUIL e CRUZ, 1975).

GASSEN (1983) examinou exemplares de Pseudaletia de coleções do Rio Grande do Sul e concluiu que naquele Estado ocorre tanto $P$. adultera como $P$. sequax. Es te autor ressaltou a semelhança com $P$. sequax, das descri: ções de P. unipuncta punctulata e de C. : unipuncta feitas por CORSEUIL (1958) e VERNALHA et alii, (1968).

No cuarto Catálogo: dos Insetos que Vivem nas Plantas do Brasil, seus Parasitos e Predadores, SILVA et alii (1968) registraram apenas $P$. adultera e, como sinônimos, C. unipuncta auct.nec. Haworth, 1809 e P. unipuncta auct.nec. Haworth, 1809. Na realidade, tudo indica '. qué, conforme conclusão de GASSEN (1983), muitos trabalhos antigos não possuem a nomenclatura correta de $P$. adultera. Na Tabela 1, são apresentadas as principais citações deC. unipuncta, P. adultera e P. unipuncta feitas no Brasil atē 1976.

A nivel internacional, constata-se que fora do Continente Americano utiliza-se de forma generaliza 
Tabela 1 - Principais citações de Cirphis unipuncta, Pseudaletia adultera e P. unipuncta em diversos Estados do Brasil até 1976.

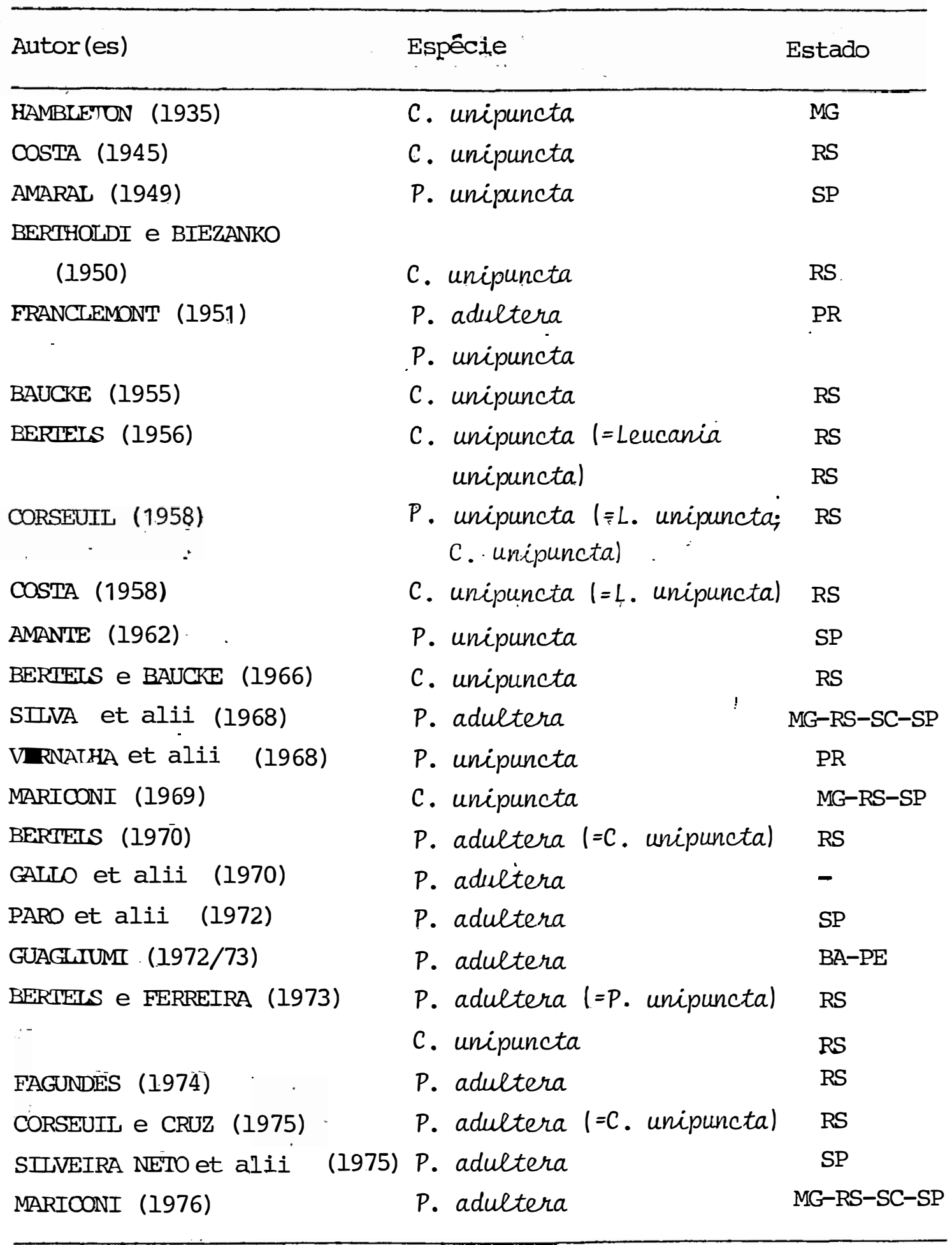


da o gênero Mythimna ao invés de Pseudaletia, que é consi derado como sinônimo.

Diante do reduzido volume de informações sobre $P$. sequax bem como dos aspectos de semelhança, sinoní mia e possibilidade de erros de nomenclatura nas referências brasileiras anteriormente citados, incluíram-se nesta revisão espécies de Cirphis, Leucania, Pseudaletia e Mythimna.

\subsection{NutriçÃo E DietAS ARTIFICIAIS}

(1928), BRUES (1946) e FRAENKEL (1953), a nutrição de insetos tem sido objeto da atenção de estudiosos jā há algum tempo. Existe atualmente um volume considerável de co nhecimentos nesta área. Aceita-se que os requisitos nutri cionais de diferentes insetos são qualitativamente semelhantes (HOUSE, 1974), porém, que espécies próximas podem apresentar exigências quantitativamente distintas.

No entanto, se por um lado muito é conhecí do em termos de nutrição qualitativa dos insetos, o mesmo não ocorre em relação ao consumo e utilização dó alimento (PARRA, 1980), pois são poucos os trabalhos realizados nesta área.

A importância da ecologia nutricional na interpretação apropriada de fenômenos biológicos dos inse tos foi ressaltada por SCRIBER e SLANSKY (1981). Estes autores conceituaram a nutrição quantitativa como a medição da quantidade de alimento consumido, digerido e assimilado, excretado, metabolizado e convertido em biomassa. A a 
nálise destes dados revela como o organismo responde a di ferentes alimentos.

A metodologia para estudos de nutrição quan titativa foi revisada por WALDBAUER (1968) que propôs a padronização dos indices de consumo e utilização do alimento pelos insetos. SCRIBER e SLANSKY (1981) propuseram algumas alterações na terminologia estabelecida por WALDBAUER (1968).

Os Índices de consumo e utilização de alimentos por insetos têm sido empregados como critério de a nálise e interpretação em trabalhos em diferentes áreas de estudo. KOGAN e PARRA (1981) apontaram sua aplicação em estudos de fluxo energético em comunidades, de comportamento, de resistência de plantas, de controle de pragas e de nutrição, especialmente como indicadores da adequação de dietas a insetos.

Como uma conseqüência do conhecimento acumulado sobre nutrição e hābitos alimentares, as técnicas de criação de insetos em meios artificiaís tiveram uma grande evolução. Uma prova disto, é o livro de: SINGH (1977) que compilou na literatura dietas artificiais para a cria ção dé 750 espécies, aproximadamente. Mais recentemente, SINGH (1985) registrou que este número cresceu para mais de 1.300 espécies de insetos.

A importância da criação de insetos e suas aplicações foram ressaltadas por KOGAN (1980), o qual enfatizou que o uso de insetos criados em meios artificiais têm permitido grandes avanços tanto em pesquisas básicas como aplicadas.

A grande maioria dos trabalhos sobre nutri 
ção dos gêneros de Noctuidae objetos desta revisão, restringe-se à determinação da capacidade de consumo foliar das lagartas. Um aspecto comum ao comportamento alimentar destas lagartas, é que cerca de $80 \%$ ou mais do consumo to tal é realizado no último ou nos dois ültimos instares (DAVIS e SATTERTHWAIT, 1916; ALAM, 1961; FRANZMANN, 1973 e ETCHECHURY et alii, 1985). A despeito disso, a capacidade de consumo foliar é variāvel com a espécie e influenciada por diversos fatores. Assim, P. adultera pode consumir uma maior ou menor área foliar, de acordo com o estádio fe nológico e com a adubação nitrogenada na cultura do trigo (ETCHECHURY et alii, 1985). Conforme DAVIS e SATTERTHWAIT (1916) .. C. unipuncta consome $267 \mathrm{~cm}^{2}$ de folhas de milho e, segundo LESCHE (1984), 'P. sequax ingere cerca de 146 $\mathrm{cm}^{2}$ de folhas de trigo.

o desenvolvimento e o crescimento de uma lagarta estão relacionados com a taxa de ingestão e utili zação do alimento, sendo evidente a necessidade de que um certo limiar energético deva ser atingido, para que estes processos ocorram normalmente. MUKERJI e GUPPY (1970) verificaram que $P$. unipuncta desenvolve-se precariamente, a presentando ecdises adicionais e menor fecundidade, quando a taxa de ingestão de folhas de milho não atinge deter minado nível.

Quanto aos indices de consumo e utilização do alimento, neste mesmo trabalho, MUKERJI e GUPPY (1970) constataram que a digestibilidade aproximada é maior no primeiro instar e diminui gradualmente com o aumento da idade. Nos instares iniciais, a lagarta digere melhor o alimento por não ingerir nervuras mas, por tomá-lo em quantidades bastante pequenas, utiliza-o quase que totalmente para energia de manutenção, canalizando muito pouco para conversão em substância corporal. Assim a efi- 
ciência de conversão do ingerido (ECI) aumenta até o quin to instar, e a do digerido (ECD) mostra relação inversa à $A D$, tendência esta observada na grande maioria dos inse tos.

Em termos de criação em dietas artificiais, não há nenhum registro na bibliografia em relação à $P$. sequax. Porēm, para espécies afins, a literatura é relativamente abundante. Assim, a criação de M. separata (Wlk.) é mencionado por NEELGUND e MATHAD (1974), HIRAI (1976), KOJIMA E NAKAYAMA (1979), HATTORI e ATSUSANA (1980), BE (1981) e SINGH (1983). A utilização bem sucedida de dietas artificiais para a criação de $P$. unipuncta foi referida por SHOREY e HALE (1965) e GOODWIN (1966).

A composição destas dietas é muito variāvel. Para M. separata, NEELGUND e MATHAD (1974) utilizaram uma dieta composta de feijão, caseína, levedura, saca rose, óleo de germe de trigo, ácido ascórbico, ágar e anticontaminantes; enquanto que a dieta descrita por HIRAI (1976), em termos gerais e qualitativos, pouco difere desta, pois contém farinha de milho e óleo de linho, ao invés de feijão e óleo de germe de trigo, além de não conter sacarose. Já a dieta desenvolvida por HATTORI e ATSUSAWA (1980), caracteriza-se pela simplicidade e baixo cus to, contendo ração comercial para herbívoros, germe de trigo, levedura, óleo de soja, ácido propiônico, ágar e á gua. A dieta de SINGH (1983) é mais complexa que as demais e além de $M$. separata, permitiu a criação de $L$. $\ell$ reyimina (Rungs) e de 40 outras espécies de insetos de di ferentes ordens. E composta de caseina, germe de trigo, sacarose, glucose, colesterol, ácido linoléico, sais de Wesson, vitaminas, anticontaminantes, celulose, $\mathrm{kOH}$, agar e água. 
Para $P$. unipuncta, a dieta citada por sHoREY e HALE (1965) é de composição relativamente simples: feijão, levedura, ácido ascórbico, anticontaminantes, ágar e água. A desenvolvida por GOODWIN (1966), no entanto, é mais complexa pois contém caseina, germe de trigo, vitaminas, sais minerais, óleo de linho, colesterol, $\beta-s \underline{i}$ tosterol, ácido ascórbico, $\alpha$-tocoferol, ácido fólico, sacarose, celulose, polisorbato 80 , ágar e água.

\subsection{Parâmetros biológicos}

\subsubsection{ESPÉCIES DO "GRUPO unipuncta"}

Os trabalhos mais completos sobre a biologia destes insetos foram realizados nos E.U.A. por DAVIS e SATTERTHWAIT. (1916), BREELAND (1958) e POND (1960), e no Canadá por GUPPY (1961). No Brasil, há registros feitos por AMARAL (1949), BAUCKE (1955) e COSTA (1958).

Quanto ao ciclo de vida de $C$. unipuncta, $\mathrm{D}$ A VIS e SATTERTHWAIT (1916) constataram que em milho o mesmo é de 53 dias, e pode variar com a época do ano. Esse período resultou da duração de 6,26 e 21 dias para as fases de ovo, lagarta e pupa, respectivamente. As lagartas apresentaram seis instares e a fecundidade pode ser de até 446 ovos por fêmea. AMARAL (1949) criou esta espécie em laboratório, alimentando as lagartas com folhas de arroz, capim quicuio, centeio e trigo; registrou um ciclo de vida de 56 dias e capacidade de postura superior a 600 ovos por fêmea.

Para P. unipuncta, BREELAND (1958) encontrou um perínodo de incubação de 3,6 dias a $24,8^{\circ} \mathrm{C}$, e via- 
bilidade de $67,5 \%$ para a fase de ovo. A longevidade foi de 10 dias, em média, mas os adultos viveram até 27 dias, e as fêmeas viveram mais que os machos.

O estudo de POND (1960) foi conduzido em laboratório, a $22^{\circ} \mathrm{C}$, com $P$. unipuncta alimentada com cereais na fase larval e com solução de mel a $10 \%$, na fase adulta. As fases de ovo, lagarta e pupa foram de 6, 26 e 15 dias, respectivamente. A longevidade das fêmeas (18 dias) foi o dobro da dos machoṣ. o período de pré-oviposição foi extremamente variāvel ( 1 a 15 dias) e o mesmo ocorreu com a fecundidade, que oscilou entre 363 e 1.420 ovos por fêmea (940 ovos, em média). Em condiçōes de falta de alimen to ou de baixas temperaturas, ocorreram instares larvais adicionais.

GUPPY (1961) pesquisou por: seis anos, em gaiolas de campo, a biologia de $P$. unipuricta mantida em trigo e aveia. Exceto em um dos anos, onde ocorreu o inicio da terceira geração, nos demais registraram-se duas gerações anuais. A duração do ciclo de vida variou tanto com o ano, como com a geração. Assim, o período de incuba ção variou de 3 a 33 dias (mêdia de 8 dias), as lagartas de primeira geração tiveram, em mêdia, uma duração de 30 dias no outono e, em média, de 18,3 dias no verão. A longevidade dos adultos alimentados com solução de glucose e sacarose a $12,5 \%$, foi de 19,3 dias (27 dias, no máximo) para machos e 17,2 (29 dias, no máximo) para fêmeas, superior a dos adultos que receberam apenas água (média de 14 dias). o período de pré-oviposição variou de 4 a 14 dias (média de 6,9 dias) e o de oviposição de 3 a 12 dias (média de 8,7 dias). A alimentação da fase adulta mostrou-se essencial para a produção normal de ovos e, possivelmente, para o acasalamento. Fêmeas que não receberam a solução açu 
carada, colocaram poucos ovos e inférteis. Fêmeas não aca saladas, em geral não ovipositaram ou o fizeram em nümero de ovos insignificante. A capacidade de postura foi bastante variável e sofreu a influência da densidade de casais nas gaiolas. Em casais isolados, o nûmero de ovos por fêmea ficou entre 252 e 1.887 (média de 967 ovos), o qual foi cerca de $33 \%$ superior em gaiolas com vários ca sais.

Neste mesmo trabalho o autor chamou atenção para $\circ$ fato que $50 \%$ das mariposas acasaladas individualmente, por razões desconhecidas, não ovipositaram ou colo caram apenas alguns poucos ovos. Além disso, ocasionalmen te, o macho não conseguiu retirar o endofalo após o acasalamento, e o casal permaneceu acoplado até a morte. : Este último aspecto, foi discutido por CALLAHAN e CHAPIN (1960).

De acordo com ALAM (1961), em iavouras de arroz no Paquistão, P. unipuncta apresenta períodos de in cubação de 5 a 13 dias, larval de 20 a 48 dias e pupal de 7 a 29 dias, dependendo da temperatura. A fecundidade média é d'e 106 ovos por fểmea, com uma variação de 84 a 232 ovos.

\subsubsection{M. separata}

Esta espécie tem sido estudada principalmente na India onde é apontada como importante praga de cereais (BINDRA e SINGH, 1973 e SINGH e RAI, 1977).

Na natureza, a duração do ciclo de vida vá ria com a época do ano, ocorrendo no entanto quatro gerações anuais (BINDRA e SINGH, 1973). 
Em laboratório, SINGH e RAI (1977) registraram que a duração média em arroz, foi de 2,0 dias para o período embrionário, 16,4 dias para a fase larval e 8,6 dias para a fase pupal. A longevidade foi de 9,8 dias para os machos e de 12,8 dias para as fêmeas, ambos alimentados com solução de mel a 10\%. O nûmero de ovos por fêmea foi de 745 e o período de oviposição variou de 3 a 7 dias.

\section{$2,2,3$, L. Loreyi Dup.}

EL-SHERIF (1972) pesquisou, no Egito, aspectos biológicos desta espécie. Constatou que a duração do ciclo de vida depende da época do ano, e que ao longo deste ocorrem sete gerações completas e o início de uma oitava. Em laboratório, a $29^{\circ} \mathrm{C}$ e $70 \%$ de UR, as lagartas a limentadas com milho, apresentaram 6 instares. As fêmeas acasaladas e alimentadas com solução de açúcar a 10\%, .colocaram de 327 a 939 ovos/fêmẹ̦, numa mẻdia de 554 ovos.

\section{$2,2,4, P$. adultera}

Informações sobre a biologia de $P$. adultera foram obtidas no Uruguai (TERRA e ZERBINO, 1983a e b e ETCHECHURY et alii, 1985).

TERRA e ZERBINO (1983a) investigaram 0 efeito do alimento sobre alguns parâmetros biológicos da espécie, a $26,4 \pm 10^{\circ} \mathrm{C}$ e $61,1 \pm 5 \%$ UR. Quando alimentadas com folhas-bandeira de trigo, as lagartas apresentaram maior duração e menor sobrevivência, e as pupas originadas foram mais pesadas e demoraram mais para completar seu desenvolvimento,em relação ao que ocorreu quando as lagar- 
tas foram mantidas com folhas tenras de trigo. O alimento fornecido aos adultos afetou a fecundidade, a fertilidade e a longevidade dos mesmos, sendo que a solução de mel foi mais adequada do que a de açúcar. o período de incuba ção foi de 3,5 dias, enquanto que o desenvolvimento larval foi de 21,46 a 28,28 dias e o pupal de 9,06 a 9,50 dias. Alimentados com mel, fêmeas e machos viveram, respectivamente, 9,67 e 10,0 dias. Estas fêmeas colocaram de 137 a 1.416 ovos, os quais apresentaram uma viabilidade de $46 \%$.

ETCHECHURY et alii (1985) observaram que a $21 \pm 1{ }^{\circ} \mathrm{C}$ e $69 \pm 12 \%$ de UR, os parâmetros biológicos de $\mathrm{P}$. adultera foram afetados pela qualidade do alimento forneci do às lagartas (estado fenológico e adubação nitrogenada recebida pelas plantas de trigo). Em termos médios, o período de incubação foi de 9 dias, o período larval de 27 dias e o pupal de 17 dias. A fecundidade média foi de 677 ovos por fêmea, variando entre 53 e 1.763 ovos.

\subsubsection{P. sequax}

As poucas informaçōes disponîveis sobre a biologia de $P$. sequax são provenientes de trabalhos brasi leiros (PEREIRA, 1978; PADIAL, 1980; PEREIRA, 1980; IESCHE, 1984 e CRUZ e FOERSTER; 1986).

As pesquisas de PEREIRA (1978), realizadas a temperatura de $25 \pm 1{ }^{\circ} \mathrm{C}$, umidade relativa do ar de $75 \pm 5 \%$ e $12 \mathrm{~h}$ de fotofase, permitiram concluir que o capim quicuio é um alimento mais adequado do que trigo e cevada, para esta espêcie. Em capim quicuio houve maior sobrevivência larval e menor duração do período larval. Em trigo e cevada ocorreu um instar adicional (o 79), em 33\% e 35\% 
das lagartas, respectivamente. Quando criadas em trigo as lagartas apresentaram uma sobrevivência de $60 \%$ e duração de 31 a 34 dias; o período pupal foi de 11,21 dias e o de incubação 4 dias; a proporção sexual foi de 1:l. Os adultos originados de lagartas criadas em capim quicuio, vive ram cerca de 22. (machos) a 26 dias (fêmeas), com períodos de prê-oviposição, oviposição e pós-oviposição de, aproxi madamente, 14,10 e 2 dias, respectivamente. Assim como os demais parâmetros relativos aos adultos, o número de . vos por fêmea foi bastante variāvel, atingindo 872 ovos, em média. A fertilidade destes ovos foi de $89,91 \%$ e cerca de 26\% do total de ovos que uma fêmea foi capaz de pro duzir, ficou retido no interior da mesma.

O efeito do alimento (folhas de trigo, mitho e capim quicuio) das lagartas no desenvolvimento de $P$. sequax foi estudadọ por PADIAL (1980), em laboratório $\left(25^{\circ} \mathrm{C}, 75 \pm 5 \%\right.$ de UR e $\exists 2 \mathrm{~h}$ de fotofase). Ficou demonstrado que o alimento influenciou na duração, largura da cápsula cefálica e sobrevivência das lagartas, além da duração e peso das pupas. A fecundidade, a fertilidade e a longevidade dos adultos não foram afetadas pelo alimento ingerído na fase larval. A proporção sexual foi pouco afetada pelo alimento ficando, em geral, em torno de l:l. Em rela çao aos insetos criad̄os em trigo, o autor constatou um nūmero de machos um pouco superior ao de fêmeas $(1,45: 1)$. 0 período larval variou de 23,77 (6 instares) a 24,58 dias ( 7 instares), e apresentou uma viabilidade de 81,5\%. 0 pe ríodo pupal foi de 16,06 dias e as pupas atingiram um peso médio de $453,31 \mathrm{mg}$. Foram bastante variáveis os valores de fecundidade ( 5 a 2.535 ovos por fêmea) e de fertilidade $(0$ a $98,5 \%)$. O nümero médio de ovos por fêmea foi de $1.248,36$ e a viabilidade média de 53,17\%. Cada fêmea reteve no abdome 101,73 ovos, em mêdia. As fêmeas viveram um pouco mais que os machos, e a longevidade média esteve 
em torno de 13 dias; a duração dos períodos de pré-oviposição, oviposição e pós-oviposição foi cerca de 3,1; 8,0 e 3,4 dias, respectivamente.

Um trabalho de laboratório sobre a biologia de $P$. sequax em trigo, foi realizado por IESCHE (1984). Para as condições desta pesquisa $\left(20 \pm 5^{\circ} \mathrm{C}, 70 \pm 5 \%\right.$ de UR e $12 \mathrm{~h}$ de fotofase) o período de incubação foi de 6,6 dias, o período larval de 24,4 dias e o pupal de 15,8 dias. 0 pe, so das pupas alcançou $340 \mathrm{mg}$ nas fêmeas e $320 \mathrm{mg}$ nos machos. A proporção entre fêmeas e machos foi de $1: 1,4$, sen do que as fêmeas viveram 13,1 dias e os machos 12,5 dias. Os períodos de pré-oviposição e de pós-oviposição duraram, pela ordem, 3,5 e 2,5 dias. Durante os 7,1 dias do período de oviposição as fêmeas colocaram, em média, 564 ovos cuja viabilidade foi de $77,1 \%$

\subsection{INFLUÊNCIA DA TEMPERATURA NO CRESCIMENTO E DESEN- VOLVIMENTO}

Os insetos são animais pecilotérmicos é a temperatura ambiental influi sobre eles de maneira indi reta, afetando suas fontes de alimento e, diretamente, in fluenciando seu crescimento, desenvolvimento e comportamento.

Segundo SILVEIRA NETO et alii (1976) os in setos reagem diferentemente à temperatura de tal foima que as espécies apresentam exigências tērmicas que determinam a velocidade de seu desenvolvimento e sua prolificidade. Desta maneira, em função dos requisitos de temperatura de cada espécie, uma dada região poderá ser mais ou menos fa vorāvel ao seu crescimento populacional. 
Diversos estudos já demonstraram a importância da temperatura para espêcies de Cirphis, Leucania, Mythimna e Pseudaletia. A maior parte das pesquisas foi realizada com $P$. unipuncta.

Hâ evidências de uma relação inversa entre a duração das diferentes fases do desenvolvimento desta espécie e a temperatura, dentro de certos limites, confor me se depreende dos trabalhos de BREELAND (11958), POND (1960) e GUPPY (1961 e 1969).

BREELAND (1958) e GUPPY (1969) registraram que $\circ$ aumento do período larval de $P$. unipuncta em função de baixas temperaturas, é acompanhado pelo incremento do número de instares. Este fato também foi observado por POND (1960), que acrescentou que is to tambêm pode ocorrer em conseqüência de falta de alimento. MUKERJI e GUPPY (1970) sugeriram que a ocorrência de ecdises adicionais está mais relacionada à menor ingestão de alimento, em conseqüência da baixa temperatura. Nesta situação adversa, o crescimento e o desenvolvimento são reduzidos para garantir a sobrevivência.

GUPPY (1969) verificou um aumento linear da largura da câpsula cefálica de lagartas de P. unipuncta com o incremento da temperatura na faixa de 13 a $29^{\circ} \mathrm{C}$. No mesmo trabalho, estudando o efeito da temperatura (13, $17,21,25$ e $29^{\circ} \mathrm{C}$ ) sobre a velocidade de desenvolvimento nas fases de ovo, lagarta e pupa, encontrou como resultado gráfico uma sigmóide, sendo que a máxima taxa de desen volvimento ocorreu prôximo à $29^{\circ} \mathrm{C}$, em todas as fases.

A existência de limites térmicos para a $\underline{\mathbf{s}}$. brevivência de $P$. unipuncta já foi evidenciada em diversos trabalhos. Para a fase de ovo, foi constatada a mor- 
te dos embriões quando os ovos foram mantidos a $5^{\circ} \mathrm{C}$ (GUPPY, 1969) e também a 170 C (POND, 1960). MCLAUGHLIN (1962) observou que a mortalidade larval aumentou com o acréscimo da temperatura entre 22,2 e $35^{\circ} \mathrm{C}$, bem como com 0 tempo de exposição; a mortalidade como conseqüência deste fator, foi mais expressiva no 6 \% Instar, que é significativamente mais longo que os demais. GUPPY (1969) registrou uma alta sobrevivência larval a 13, 17, 21 e $25^{\circ} \mathrm{C}$, mas a $29^{\circ} \mathrm{C}$ a mesma caiu devido à grande mortalidade das lagartas de último instar; quando submetidas a temperaturas de 10 e de $31^{\circ} \mathrm{C}$, nenhuma lagarta atingiu a fase pupal.

Muitos autores rejortaram-se à influência da temperatura no número de gerações anuais da espécie, em função da duração do ciclo e da sobrevivência nas diferen tes estações do ano: No Canadá, a oeste de ontário, P. unipuncta não sobrevive ao inverno e a primeira geração re sulta de adultos que migram de regiões mais meridionais (GUPPY, 1961). No Tennessee (E.U.A.) 0 insetø passa $\circ$ in verno na forma de lagarta em desenvolvimento continuo e lento (BREELAND, 1958). Na Louisiana (E.U.A.), a população desaparece completamente no verão e è abundante na primavera e no outono (CALLAHAN e CHAPIN, 1960). Em Illinois (E.U.A.), as baixas populações estã॰ associadas a altas temperaturas (McLAUGHLIN, 1962).

Em relação ao comportamento, POND (1960) re gistrou a importância das condições de temperatura para que $P$. unipuncta copule e oviposite', em laboratório.

Para outras espêcies, as informações, embo ra menos numerosas, confirmam o mesmo tipo de influência da temperatura já relatada para $P$. unipuncta, em relação ao desenvolvimento e à sobrevivência. 
SINCHA.ISRI e SÕGAWA (1969), no Japão, cons tataram que o desenvolvimento de ovos, lagartas e pupas

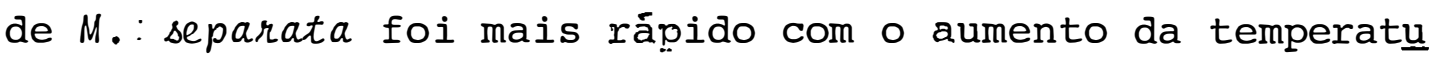
ra, na faixa estudada $\left(15,20,25\right.$ e $\left.30^{\circ} \mathrm{C}\right)$. A longevidade e a fecundidade foram mais elevadas a $20^{\circ} \mathrm{C}$. A existência de uma faixa ótima de desenvolvimento foi evidenciada pelo fato da sobrevivencia e da fecundidade terem atingido menor valor a 15 e a $30^{\circ} \mathrm{C}$. Com os dados obtidos os auto res estimaram a temperatura base $(\mathrm{Tb})$ e a constante térmi ca (GD) para as fases de ovo, lagarta e pupa.

Ainda no Japão e para esta espécie, HIRAI (1975) concluiu que a faixa ótima para o desenvolvimento está entre 20 e $25^{\circ} \mathrm{C}$. A partir da Tb e dos GD, estimou o número de gerações anuais e constatou que 0 inseto passa o inverno na forma de lagarta.

Na India, o efeito letal das altas tempera turas de verão e das baixas temperaturas de inverno é fator chave na flutuação das populações de M.: separata. Esta foi a conclusão de DHALIWAL e BAINS (1978) que estudaram a biologia da espécie a 15, 20, 25, 30 e $35^{\circ} \mathrm{C}$. Os autores utilizaram-se de indices obtidos em tabelas de ví da de fertilidade para concluírem sobre a faixa de temperatura mais favorável à multiplicação deste inseto. Por outro lado, determinaram que'a $4 T_{50}$ a $40^{\circ} \mathrm{C}$ foi de 63,24 dias para larvas e de 104,7 minutos para pupas.

Também para L. Loreyi, as pesquisas demons traram que a duração do ciclo de vida varia inversamente com a temperatura (EL-SHERIF, 1972 e HIRAI, 1975).

As informações sobre o efeito da temperatura na biologia de $P$. sequax, restringen-se ao trabalho realizado no Brasil por PALIAL (1980). Trabalhanoo com temperaturas de 
20 e $25^{\circ} \mathrm{C}$ o autor não encontrou diferença em termos de via bilidade larval, pois em ambas as temperaturas a mortalidade foi de $70 \%$. Os períodos larval e pupal variaram inversamente com a temperatura, durando de 23,83 a 27,08 dias e de 12,60 a 14,89 dias, respectivamente. No entanto, a maior porcentagem de instares adicionais $(57,10 \%)$ ocorreu a $25^{\circ} \mathrm{C}$. O peso de pupas no segundo dia após a pupação, foi de $438,55 \mathrm{mg}$ a $20^{\circ} \mathrm{C}$ e de $500,69 \mathrm{mg}$ a $25^{\circ} \mathrm{C}$. A proporção sexual (o: $0^{\circ}$ ) foi de $1: 1$ a $20^{\circ} \mathrm{C}$ e $1,3: 1$ a $25^{\circ} \mathrm{C}$. Somen te a $25^{\circ} \mathrm{C}$ é que ocorreu mortalidade pupal. O autor afirmou não ter sido possivel concluir qual a temperatura mais favorável ao desenvolvimento de $P$. sequax. 


\section{MATERIAL E MÉTODOS}

o presente trabalho foi desenvolvido no la boratório de Biologia do Departamento de Entomologia, da Escola Superior de Agricultura "Luiz de Queiroz", da Universidade de São Paulo, em Piracicaba, SP, com a espécie Pseudaletia sequax Franclemont, 1951 (Lepidoptera, Noctui dae).

\subsection{PROCEDIMENTOS GERAIS}

- Material estoque: os experimentos foram conduzidos com insetos oriundos de fêmeas capturadas em armadilha luminosa, em Piracicaba, exceto o experimento do "item 3.2.1. Neste caso, foi utilizado material procedente de Passo Fundo, RS. A identificação da espécie foi feita pelo Dr. Vitor Becker (EMBRAPA/CPAC - Planaltina, DF).

- Técnica de criação: 'as lagartas foram cria das individualmente em tubos de vidros com fundo chato $(2,3 \mathrm{~cm}$ de diâmetro $\times 8,5 \mathrm{~cm}$ de comprimento), fechados com a ĺgodão hidrófugo. Antes de receberem o alimento, os tubos já fechados, foram esterilizados em estufa a $1500^{C}$ por 1 hora. As dietas foram transferidas ainda quentes, para os tubos e, após o resfriamento, foram "inoculadas" com lagartas recém-eclodidas, com auxilio de um pequeno pincel. Esta operação foi realizada em câmara asséptica, mode lo PLANALSUCAR (MENDES, 1980), antecedida pela exposição do material (tubos com dieta, pincel, etc., por 1 hora, e as lagartas durante 10 minutos) à lâmpada germicida (ultravioleta), no interior da câmara asséptica. Após a "ino culação", os tubos foram colocados em prateleiras, em po- 
sição levemente inclinada (com a tampa de algodão voltada para baixo, para facilitar o escoamento de água e diminuir a contaminação por microrganismos), onde os insetos foram mantidos até a pupação.

Para dar condições à emergência dos adultos, as pupas foram individualizadas em copos plásticos $(5,5 \mathrm{~cm}$ de altura $\times 5,5 \mathrm{~cm}$ de diâmetro na abertura $\times$ 4,0 $\mathrm{cm}$ de diâmetro no fundo). Estes foram emborcados sobre ban dejas forradas com papel de filtro, umedecido diariamente. Adultos emergidos no mesmo dia foram acasalados, e ca da casal colocado em gaiola cilindrica de PVC $110 \mathrm{~cm}$ de diâmetro x $20 \mathrm{~cm}$ de altura) e alimentado com solução aquo sa de mel a $10 \%$ o alimento foi colocado em um pequeno recipiente de vidro $(3,0 \mathrm{~cm}$ de diâmetro $\mathrm{x}$ 4,0 $\mathrm{cm}$ de altura) e fornecido aos insetos por meio de um pavio de algodão, inserido atravês de um orifício na tampa do recipien te. As gaiolas, fechadas na abertura superior com filó, fo ram colocadas sobre tampas de placas de Petri $1.15 \mathrm{~cm}$ de diâmetrol, forradas com papel de filtro. Diariamente, pro cedeu-se à troca do alimento e ao umedecimento do papel de filtro. Como substrato de' postura utilizou-se um peque no feixe de tiras de papel de filtro (medindo cerca de 10,0 $\mathrm{cm} \times 0,5 \mathrm{~cm})$ que, para ser mantido em posição vertical, teve uma extremidade (cerca de $3,0 \mathrm{~cm}$ ) introduzida em um re cipiente de vidro $(4,0 \mathrm{~cm}$ de altura e abertura de $1,0 \mathrm{~cm}$ de diâmetrol.

A criação dos insetos foi desenvolvida na condição de $25 \pm 2^{\circ} \mathrm{C}, 60 \pm 10 \%$ de UR e $\uparrow 4 \mathrm{~h}$ de fotofase.

- Preparo das dietas: as dietas foram preparadas conforme descrito por PARRA (1979). A quantidade de água utilizada para dissolver o ágar e para misturar os demais ingredientes, variou em cada dieta. Geralmente, 
o ágar foi dissolvido em quantidade equivalente a 30-70\% da água total. O feijão utilizado em algumas dietas foi cozido previamente, e a água da cocção foi utilizada no preparo da dieta.

- Obtenção e análise dos dados: os registros dos experimentos decornemam de observações diárias. Em todos os casos, a pesagem das pupas foi realizada 24 horas após a pupação. A sexagem dos insetos foi realizada nas pupas e a razão sexual calculada por $\frac{q}{++0^{*}}$.

Os dados experimentais foram submetidos à análise da variância, segundo delineamento completamente casualizado. Para o estabelecimento das repetições, cujo número variou em cada caso, os insetos em suas formas imaturas foram tomados em grupos, seguindo-se a ordem numé rica dos tubos ou copinhos. Para as observações na fase a dulta cada casal foi considerado uma repetição. Os dados de deformação de pupas e adultos, e de.contaminação de die tas não foram submetidos à análise de variância.

Apôs o teste $F$, as diférenças entre médias foram comparadas pelo teste de Tukey, ao nível de 5\% de probabildade.

As variações nestes procedimentos gerais serão especificadas em cada experimento.

\subsection{ESTUDO DE DIETAS ARTIFICIAIS PARA $P$.. sequax}

Este estudo foi executado para se identifi car uma ou mais dietas adequadas ao desenvolvimento da es pêcie e que, ao mesmo tempo, reunissem características de simplicidade de composição e economicidade. Em seqüência, 
as dietas seleclonadas foram avaliadas mais detalhadamente.

\subsubsection{SELEĈ̃O DE DIETAS ARTIFICIAIS}

Foram avaliadas dezesseis dietas, sendo es tudadas a viabilidade e duração dos periodos larval e pupal, e o peso de pupas. Para cada dieta utilizaram-se cinquenta tubos, cada um com duas lagartas. A emergência dos adultos ocorreu em tubos iguais aos utilizados para o for necimento das dietas (item 3.1.).

Na definição das dietas a serem avaliadas, consideraram-se três citadas na literatura para espécies de Pseudaletia: dietas de GOODWIN (1966) para $P$. unipuncta (Haw.) e de NEELGUND e MATHAD (1974) e de SINGH (1983), para $P \therefore$ separata (WIk.). Além destas, foram incluỉdas cinco dietas, que são utilizadas no Brasil para criação de outras espécies de Noctuidae e Pyralidae. Estas foram as dietas de BOWLING (1967), HENSLEY e HAMMOND (1968), BURTON (1969), GREENE et alii (1976) e MIHSFELDT (1985).

Nestas oito dietas básicas procederam - se algumas modificações na composição, de forma a se totalizar as dezesseis dietas estudadas. As modificações foram, basicamente, de três tipos: 19) adição de um ou mais ingre dientes, com base em uma pressuposta carência, o que ocon reu em relação a lipídeos, esteróis, vitaminas e anticontaminantes; 20) substituição de componentes por alternati vas de menor custo e/ou de mais fácil aquisição no mercado nacional; e 39) modificações quantitativas, principalmente nos conteúdos de água, ágar e celulose para viabilizar o preparo adequado das dietas (características físicas). 
A composição das dietas estudadas é apresentada na Tabela 2. Cada dieta foi idenfificada por uma letra, identificação que se manteve ao longo de todo o tra balho:

A - dieta de GREENE et alii (1976)

B e C - dieta de GREENE et alii (1976), modificada

D e E - dieta de GOODWIN (1966), modificada

F - dieta de SINGH (1983), modificada

G - dieta de MIHSFELDT (1985)

$\mathrm{H}$, I e J - dieta de MIHSFELDT (1985), modificada

K - dieta de BURTON (1969)

L e M - dieta de BURTON (1969), modificada

N- dieta de BOWLING (1967)

0 - dieta de NEELGUND e MATHAD (197.4), modificada

P - dieta de HENSLEY e HAMMOND (1968)

O feijão utilizado foi das cultivares Carioca (dietas $A, B$ e C) e Rosinha (dietas $K, L, M, N$ e 0 ), e o milho, que entrou na composição das dietas $G, H, I$ e J, foi da cultivar Piranão-opaco 2. Como farinha de soja, utilizou-se o produto comercial Sojinha Superbom. Nas dietas que levariam alfacel (D, E e F) utilizaram-se em substituição, lậninas de celulose de Eucalyptus sp., sulfato branqueadas e trituradas em liquidificador (VENDRAMIN et alii, 1982). As misturas de vitaminas e de sais minerais utilizadas. foram as citadas por PARRA (1979) e KOGAN (1980), respectivamente.

Como critério para seleção das dietas que continuariam nas próximas etapas do trabalho, consideraram-se as médias dos parâmetros avaliados. As dietas que proporcionaram dados suficientes foram comparadas através da análise da variância e teste de Tukey, a 5\% de pro babilidade. 


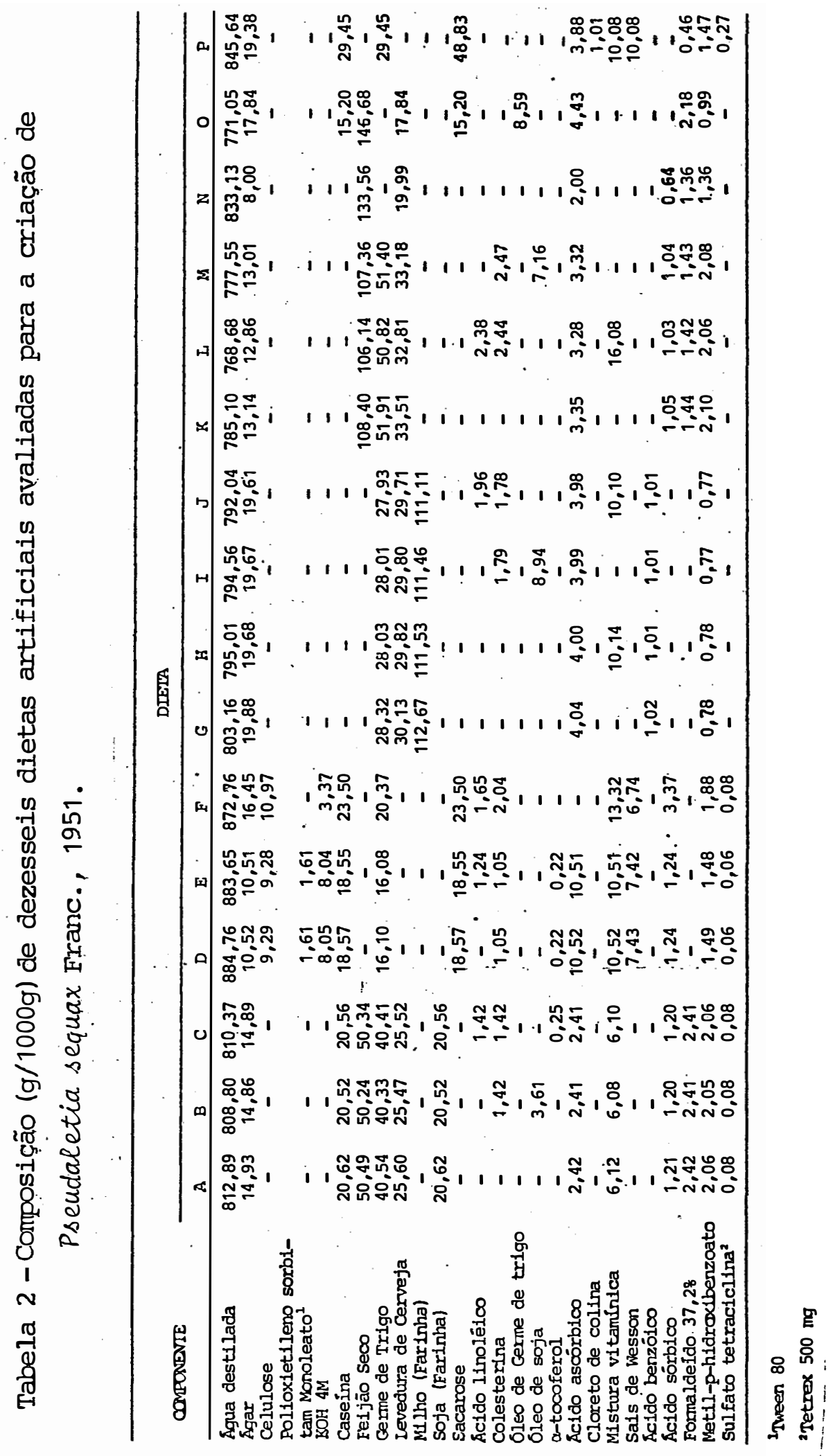




\subsubsection{AVALIAÇÃO DE TRES DIETAS SELEC IONADAS}

Nesta etapa estabeleceu-se uma competição entre as dietas $A, K$ e $N$, para uma avaliação mais detalha da, baseando-se em critérios biológicos, nutricionais e e conômicos.

3.2.2.1. Efeito de três dietas artificiais sobre parâmetros biológicos

Conduziu-se a criação de $P$.: sequax nas die tas $A, K$ e N, avaliando-se viabilidade e duração das fa ses de lagarta e pupa, peso de pupas razão sexual e defor mação de pupas e adultos, por três gerações consecutivas.

- Primeira geração: o experimento foi iniciado com 190, 146 e 188 lagjartas nas dietas $A, K$ e $N$, res pectivamente. Neste teste, foram colocadas duas lagartas por tubo, e a emergência do adulto ocorreu em tubos nos quais as pupas foram individualizadas, por ocasião da pesagem. Para efeito de análise estatística, os insetos de cada tratamento foram agrupados em 10 repetições.

- Segumda geiração: foram utilizados 90 tubos para a dieta $A, 40$ para a $K$ e 70 para a N. Na análise. estatística, estes foram reunidos em 9,5 e 7 repetições, respectivamente.

- Terceira geração: utilizaram-se 98, 91 e 83 tubos para as dietas $A, K$ e $N$, pela ordem, os quais fo ram reunidos em 10 repetições em cada dieta.

- Gerações sucessivas: añém da análise den tro de cada geração, analisou-se tambēm o efeito de três 
gerações sucessivas em cada uma das dietas. Para tanto, con siderou-se como $F_{1}$, a geração do item 3.3.

\subsubsection{Comparação das três dietas artifí ciais quanto ao consumo e utiliza ção de alimento}

Para a determinação dos indices de nutrição quantitativa dos insetos, adotou-se a metodologia pro posta por WALDBAUER (1968) e modificada por SCRIBER e SLANS KY (1981). Foram medidos os seguintes parâmetros:

$$
\begin{aligned}
T= & \text { duração (dias) do periodo de alimentação } \\
A f= & \text { peso }(\mathrm{g}) \text { do alimento fornecido ao inseto } \\
A r= & \text { Peso }(\mathrm{g}) \text { do restante do alimento fornecido ao } \\
& \text { inseto, após } T \\
F= & \text { peso }(\mathrm{g}) \text { das fezes preduzidas durante } T \cdot \\
P= & \text { peso }(\mathrm{g}) \text { do insetọ ao final de } T
\end{aligned}
$$

Os dados acima foram obtidos através do mé todo gravimétrico (PARRA, 1980), com base no peso seco dos alimentos, dos insetos e das fezes.

O experimento foi conduzido à temperatura'constante de $26^{\circ} \mathrm{C}$, umidade relativa de $60 \pm 10 \%$ e $14 \mathrm{~h}$ de fotofase. Em cada dieta foram utilizadas 13 lagartas (consideradas repetições), individualizadas em tubos ơue foram pesados antes e após a co locação da dieta. Ao atingirem o tamanho máximo, no ültimo instar, as lagartas foram retiradas dos tubos, pesadas e mortas por congelamento; as fezes foram cuidadosamente se paradas da dieta restante. Em seguida, lagartas, fezes e restos de dieta foram levados à estufa $\left(55-60^{\circ} \mathrm{C}\right)$ até completa desidratação (peso constante). 
Paralelamente, estabeleceu-se uma alíquota de 10 tubos, sem lagarta, para cada dieta, os quais foram devidamente pesados antes e após a colocação desta, e mantidos em estufa $\left(55-60^{\circ} \mathrm{C}\right)$ para o secamento até o peso cons tante de seus conteúdos. Com os pesos fresco e seco da die ta contida nos tubos, calculou-se um fator de correção que permitiu estimar o peso seco inicial da dieta, a partir do peso fresco conhèciđo.

Assim, considerando-se desprezível o :peso inicial do inseto, determinou-se o peso do alimento ingerido (I), o ganho de biomassa do inseto (B), o peso médio do inseto $(\bar{B})$ e o peso do alimento assimilado (I-F) e do metabolizado $(\mathrm{M})$, em $\mathrm{g}$, durante $\mathrm{T}$ :

$$
\begin{aligned}
& I=A \Gamma-A f \\
& B=P-O \\
& \dot{\bar{B}}=\frac{P-O}{2} \\
& M=(I-F)-B
\end{aligned}
$$

De posse destes parâmetros, determinaram-se os índices de consumo e utilização para cada dieta, através das seguintes fórmulas:

$$
\text { Taxa de consumo relativo (g/g.dia) ou RCR }=\frac{I}{\bar{B} \cdot T}
$$$$
\text { Taxa de crescimento relativo (g/g.dia) ou RGR }=\frac{B}{\bar{B} \cdot T}
$$$$
\text { Taxa metabólica relativa ( } \dot{g} / \mathrm{g} \text {.dia) ou RMR }=\frac{M}{\bar{B} \cdot T}
$$ 


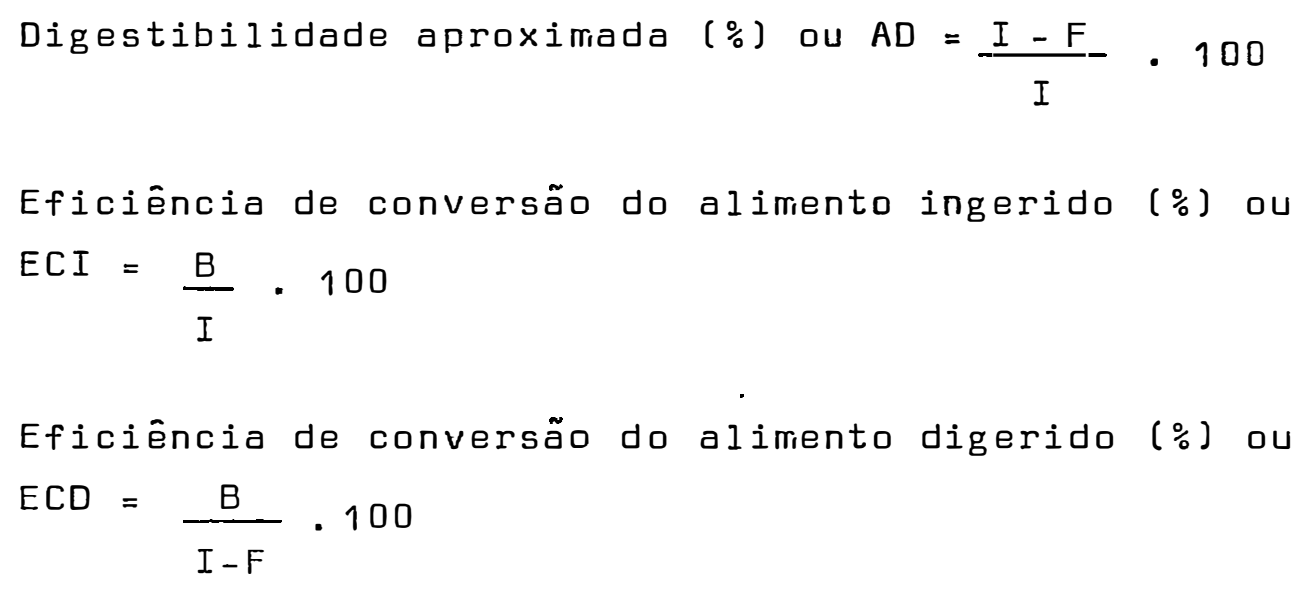

3.2.2.3. Custo do inseto produzido nas três dietas artificiais

Com base no preço comercial dos componentes em setembro de 1986, e no consumo das lagartas, calculou -se o custo do inseto produzido em cada dieta artificial.

\subsection{BIOLOGIA COMPARADA DE P. sequax EM DIETAS NATURAL E ARTIFICIÄIS}

Estudou-se a biologia nas dietas $A, k$ e $N$ e em folhas de trigo (cultivar IAC-5-Maringá).

O alimento natural foi fornecido às lagartas em tubos, da mesma forma que as dietas artificiais. Antes do trigo, cada tubo recebeu um segmento retangular 11,5 $x 7,0 \mathrm{~cm})$ de papel de filtro embebido em água destilada. Pe daços de folhas de trigo, aproximadamente deste mesmo tama nho, após terem sido lavados e permanecido em água destila da por uma hora, foram colocados nos tubos. Diariamente ou a cada 2 dias, trocaram-se o alimento, o tubo e o papel de filtro. Os tubos permaneceram fechados com algodão hidrófí lo umedecido. Com estes procedimentos, foị possivel evita- 
rem-se problemas de ressecamento das folhas e também de ex cesso de umidade.

Para cada um dos quatro tratamentos iniciou -se com 150 tubos, nos quais anotaram-se o grau de contami nação por microrganismos e os seguintes parâmetros biológicos: "pegamento" inicial (viabilidade do 10 'instar), so brevivência e duração das fases larval e pupal, peso de pupas, deformação de pupas e adultos e razão sexual. Para análise estatística, estes tubos foram reunidos em grupos para se obterem 10 repetições por tratamento.

Visando a obtenção de dados de longevidade, duração dos períodos de pré-oviposição e oviposição, e de capacidade de postura, casais (repetições) emergidos no mesmo dia, foram mantidos em duas condições ambientais dis tintas: 10) $25 \pm 2{ }^{\circ} \mathrm{C}$, umidade relativa de $60 \pm 10 \%$ e fotofase de 14 horas lcom $6,5,6$ e 4 casais, provenientes das dietas $\mathrm{A}, \mathrm{K}, \mathrm{N}$ e trigo, respectivamente); e 20 ) $28 \pm 2{ }^{\circ} \mathrm{C}$, umidade relativa de $60 \pm 10 \%$ e fotofase de 14 horas (com $9,5,6$. e 10 casais, provenientes das dietas $A, K, N$ e tri go, respectivamente). Os ovos colocados, foram retirados e contados a cada dois dias.

Para se verificar a viabilidade te ovos e o período de incubaçã̃o consideraram-se duas posturas consecutivas por casal, a partir da primeira postura com mais de 50 ovos. Uma amostra de cada postura, contendo de 50 a 100 ovos foi separada, recortando-se o substrato de oviposição, e submetida à esterilização superficial (imersão em formal deído 10\% por 75 segundos e lavagem em água destilada durante 3 minutos). Os ovos assim tratados, foram colocados em placas de Petri, sobre papel de filtro umedecido diariamente e mantidos a $25 \pm 2^{\circ} \mathrm{C}$ e 14 horas de fotofase. O número de repetições (média de duas posturas) variou de 5 a 7 
para cada tratamento.

Além de serem submetidas a análise da variância, os dados foram utilizados para a elaboração de tabela de ví da de fertilidade para cada dieta artificial e para o trigo. Para isto, determinaram-se conforme SILVEIRA NETO et alii (1976), os valores de:

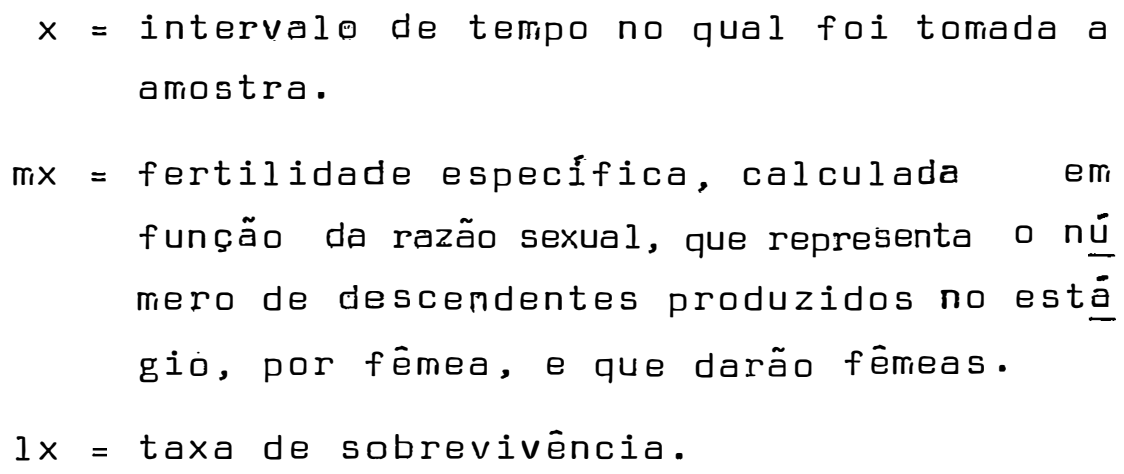

A partir destes dados calcularam-se os seguintes indices:

- Taxa líquida de reprodução - Ro = $\sum m x \cdot I x$

- Duração média de uma geração - $T=\underline{\sum m x} \cdot \underline{I x} \cdot \underline{x}$

, Ro

- Capacidade inata de aumientar emi número - $r_{m_{1}}=\frac{\text { l'Ro }}{T}$

- Razão finita de aumento da população $-\lambda=e^{\mathrm{rm}}$

\subsection{EFEITO DA TEMPERATURA NA BIOLOGIA DE P. sequax EM DIETA ARTIFICIAL}

Quarenta e cinco tubos contendo a dieta $K$ e "inoculados" com lagartas recém-eclodidas, foram colocados em cada uma das seguintes temperaturas: $18,20,22,26$, 30 e $32^{\circ} \mathrm{C}$, mantidas constantes em câmaras climatizadas. A 
umidade relativa no interior das câmaras foi de $60 \pm 10 \%$ e a fotofase de $14 \mathrm{~h}$.

Após a emergência, os adultos permaneceram em copinhos plásticos emborcados sobre papel de filtro, onde haviam sido individualizadas as pupas. A estes adultos não foi fornecido alimento. o papel de filtro foi umedecido diariamente.

Para as diferentes temperaturas anotaram-se a sobrevivência e duração das fases larval e pupal, peso de pupas, longevidade de adultos não alimentados, deformação de pupas e adultos, e contaminação das dietas por microrganismos. Na análise estatística consideraram-se 5 repe tições para cada tratamento, exceto em relação à longevida de, onde cada inseto foi considerado como repetição.

A viabilidade dos ovos foi avaliada a 18, $20,22,26,30$ e $32^{\circ} \mathrm{C}$, e a duração do período de incubação a. $20,22,26$ e $30^{\circ} \mathrm{C}$. Utilizaram-se para tanto, ovos pro cedentes de adultos criados em dietas artificiais (A e K). A metodologia seguida foi a mesma descrita no item 3.3..

Além de submeter os dados obtidos à análise - de variância, os mesmos foram utilizados para se estimar a constante térmica $(\mathrm{K})$, para as fases de ovo, lagarta e pupa e ciclo total. (ovo à emergência do adulto). Para tal, em pregou-se a metodologia descrita por HADDAD e PARRA (1984), sendo que a temperatura base (Tb) foi estimada pelo método da . hipérbole.

Para se verificar o efeito das temperaturas de $25 \pm 2{ }^{\circ} \mathrm{C}$ e $28 \pm 2{ }^{\circ} \mathrm{C}$ na longevidade, duração dos períodos de pré-oviposição e de oviposição, e na capacidade de postura de adultos alimentados, utilizaram-se os dados do item 3.3 . 


\section{RESULTADOS E DISCUSSÃO}

\subsection{ESTUDO DE DIETAS ARTIFICIAIS PARA A CRIAÇÃO DE Pseudaletia: sequax Franclemont, 1951.}

\subsubsection{SELEÇ̃̃O DE DIETAS ARTIFICIAIS}

Os resultados obtidos na avaliação de dezes seis dietas artificiais estão expressos na Tabela 3 , em or dem decrescente quanto à viabilidade acumulada nas fases larval e pupal (viabilidade total).

A viabilidade dos insetos foi extremamente variável nas dietas estudadas: Para a fase larval, sem 0 cômputo do primeiro instar, a viabilidade oscilou de 0 a 100\%; para a fase pupal a viabilidade máxima foi de 75\% na dieta $A$, seguida pela dieta $K$ com $71 \%$. O maior número de insetos que atingiram a fase adulta, foi constatado nas dietas A $(72 \%), \mathrm{K}(71 \%)$ e N (61\%).

Em algumas dietas (D, E, F, G, H, I, J, L e O), a alta mortalidade impediu que se obtivessem insetos em número suficiente para a aplicação da análise da variân cia para as mêdias dos parâmetros registrados. Desta forma, foram comparadas atravēs deste tipo de análise as dietas $A, B, C, K, M, N$ e $P$, nas quais a viabilidade larval foi superior a $70 \%$. 
Tabela 3 - Viabilidade e đuração das fases larval e pupal e peso de pupas de Pseudaletia: sequax Franc., 1951, criada en dezesseis dietas artificiais (temperatura: $25 \pm 2^{\circ} \mathrm{C}$; UR: $60 \pm$ 10; fotofase: $14 \mathrm{~h}$ ).

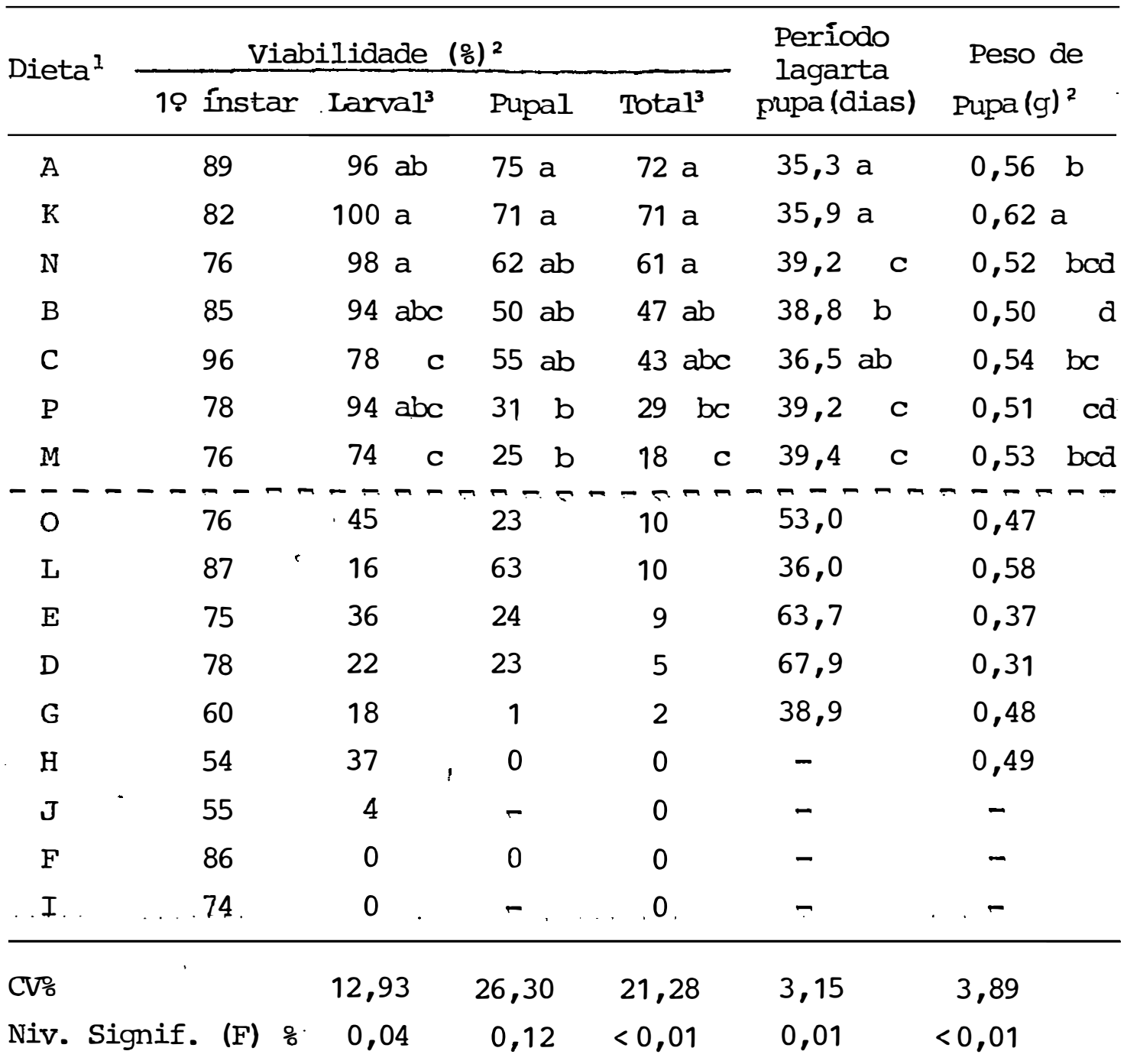

IAs dietas $O, L, E, D, G, H, J, F$ e I não foram incluîdas na análise da variância por insuficiência de dados.

${ }^{2}$ Para cada parâmetro, médias seguidas da mesma letra não diferem esta tisticamente entre si (Tukey, 5\%); os dados de viabilidade : foram transformados para arco seno $\sqrt{\bar{x}} / \overline{100,}$ na análise da variância.

${ }^{3}$ Exceto a do 19 Instar. 
Nenhuma das dietas proporcionou valor de 75\% . de viabilidade total, preconizado por SINGH (1983) como o mínimo exigido em dietas artificiais. Convém destacar, no entanto, que estes valores não foram tomados isoladamente, uma vez que o objetivo nesta etapa do trabatho foi identificar as dietas mais adequadas entre as dezesseis testadas, para uma posterior avaliação. mais completa. Além disto, outros fatores podem estar senvolvidos quanto às causas das mortalidades observadas, além da composição das dietas.

A criação de duas lagartas por tubo de dieta determinou, em alguns casos, a necessidade de separá-las no último instar larval, para se evitar a competição por espaço e alimento. Tanto esta competição, desde que não evitada ao tempo certo, bem como a manipulação para separação, podem ter colaborado para a diminuição da viabilidade. Outro fator que pode ter interferido negativamente na sobrevivência decorreu, provavelmente, da falta de uma com pleta familiarização com outros procedimentos empregados (preparo das dietas, "inoculação" das lagartas, etc). Assim, este ensaio, na condição de primeira etapa do trabalho teve, também, um caráter de exploração e aperfeiçoamen to quanto às técnicas que foram adotadas nos experimentos subseqüentes.

Entre as dietas comparadas estatisticamente destacaram-se a $A, B, K, N$ e $P$ com viabilidade larval supe rior a $90 \%$, sendo que as dietas $\mathrm{K} \cdot \mathrm{e} N$, apresentaram os mais altcs valores numéricos.

Quanto à viabilidade pupal, as melhores foram as dietas $A$ e $K$. Considerando-se a viabilidade nas fases larval e pupal, verificou-se que as dietas $A, K$ e $N$ fo 
ram superiores às demais.

A duração do período lagarta-pupa, nas dietas submetidas à análise da variância (Tabela 3) variou de 35,3 a 39,4 dias, e foi menor nas dietas A e K. Sendo as sim, estas dietas, por terem proporcionado maior velocidade de desenvolvimento e maior viabilidade, podem ser consideradas mais adequadas à espécie que as demais.

- Entre as sete dietas em questão, o maior peso de pupas foi constatado na dieta $\mathrm{K}(0,62 \mathrm{~g})$, indicando um acúmulo de biomassa mais elevado, enquanto que as pupas menos pesadas foram registradas na dieta $B(0,50 \mathrm{~g})$. No entanto, o peso de pupas foi superior àqueles citados por PADIAL (1980), que foi de $0,45 \mathrm{~g}$, e por LESCHE (1984), que foi de $0,32 \mathrm{~g}$ para machos e $0,34 \mathrm{~g}$ para fêmeas de $P$. sequax, cria das em trigo.

Com relaçãoàs modificações feitas nas dietas $A$ e $K$, não se encontraram resultados positivos para os parâmetros analisados. As dietas B e C não superaram a die t ta original (dieta $A$ ), ficando claro que a adição de óleo de soja e colesterina (dieta B) ou de a-tocoferol,ácido li noléico e colesterina (dieta $\mathrm{C}$ ), não significou uma melhoria da dieta $A$. Fato semelhante pode ser relatado para as dietas resultantes de modificações da dieta $k$, pela adição de ácido linoléico, colesterina e vitaminas (dieta L), ou de óleo de soja e colesterina (dieta M), que se mostraram inferiores à que lhes deu origem. Considerando-se apenas os resultados das fases imaturas, estes não confirmam a hí

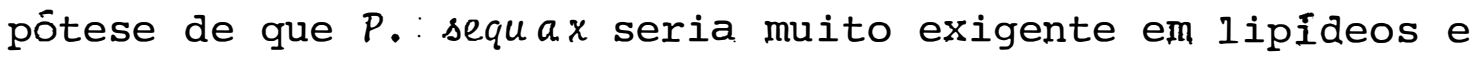
esteróis. Esta suposição, levantada a partir da composição da dieta de GOODWIN (1966) para $P$. unipuncta (Haw.); serviu de fundamentação na formulação de algumas das. dietas estudadas. 
Quanto às dietas D, E, F, G, H, I, L e O, não incluídas na análise de variância, a despeito de não terem apresentado resultados convincentes, principalmente quanto à sobrevivência dos insetos, não se pode concluir so bre a inadequação qualitativa das mesmas, para a criação da lagarta de $P$. sequax. Esta afirmação também é válida para as dietas B, C e M, oriundas da modificação de outras dietas e que, embora tenham proporcionado resultados satis fatórios em alguns parâmetros avaliados, não chegaram a superar a dieta que lhes serviu de base.

De modo geral, as modificações realizadas nas dietas originais, podem ter determinado inadequação ou desbalanceamento quantitativo, ou ainda, inadequação das dietas resultantes, quando às suas caracteristicas físicas. A rigor, em testes desta natureza, antes de seu inicio efetivo, seria necessário obter-se completo domínio e familiarização com o preparo de cada dieta de forma a avaliá-las a partir de uma condição física considerada satisfatória para todas: Subseqüentemente, então, poderia ser feito um trabalho de desenvolvimento e aperfeiçoamento das dietas através de ajustes necessários na composição. Para tanto, seria necessário uma avaliação mais completa das dietas, incluindo-se também, parâmetros nutricionais e indices de fecundidade e de fertilidade.

No presente ensaio, pôde-se constatar alguns dos problemas discutidos anteriormente. Assim, as die tas F, G, H, I e J apresentaram caracteristicas físicas im próprias decorrentes do preparo ou da quantidade em que al guns ingredientes foram a elas adicionados.

Nas dietas $\mathrm{D}$ e $\mathrm{E}$, somente cerca de 5 e 9\% dos insetos atingiram a fase adulta, respectivamente, como resultado da mortalidade ocorrida, tanto na fase larval co mo na fase pupal (Tabela 3). Estas dietas resultam de modí 
ficações na dieta de GOODWIN (1966), especialmente a adição de anticontaminantes, substituição de lipídeos e substitui ção do alfacel por folhas de celulose trituradas. Aparente mente, as duas dietas resultantes destas modificações apre sentaram inadequação de composição ou de balanceamento nutricional, pois não se registrou nenhum problema acentuado quanto às características físicas das mesmas.

Na dieta F, após un "pegamento inicial" de 86\% (Tabela 3), todas as lagartas restantes morreram no 20 e 3 instares. Isto pode ter sido causado pela inadequa ção física da dieta. A substituição do alfacel da dieta original por folhas decelulose trituradas, provavelmente, alterou o balanço entre componentes sólidos e líquidos, de modo que a dieta ficou demasiadamente seca e endurecida. A relativa insuficiência de água desta dieta pôde ser consta tada através das fezes visivelmente ressecadas das lagartas. Outra possivel conseqüência do uso de cèlulose em quantidade excessiva, seria a diluição dos nutrientes na dieta. Outro fator a ser considerado entre as possiveis cau sas de insucesso desta dieta, refere-se à quantidade de ácido sórbico utilizada $(3,37 \%)$. A relação entre o ácido sórbico,na concentração de $0,24 \%$,com a deformação de pupas e de adultos, foi registrada por HIRAI (1976), em dieta artificial, para Leucania separata wik.

De forma isolada ou conjunta, todos estes fatores podem ter afetado a alimentação ou o desenvolvimen to das lagartas, determinando completa mortalidade na dieta F.

A dieta $G$ e as decorrentes de sua modificação (dietas H, I e J) apresentaram problemas quanto ao con teúdo relativo entre as frações sôlida e líquida. Consta- 
tou-se um acúmulo de líquido sobre as dietas, especialmente junto às paredes dos tubos, o qual pode ter sido o prin cipal responsável pela alta mortalidade na fase larval. Res salte-se que os menores indices de "pegamento inicial", foram registrados nestas quatro dietas (Tabela 3 ).

Os maus resultados obtidos na dieta 0 , espe cialmente em termos de sobrevivência e velocidade de desen volvimento (Tabela 3) não têm uma explicação razoável e evidente. Talvez, possam ser atribuídos à consistência obtida na dieta após as modificações. Para viabilizar o preparo da dieta foi necessário alterar as quantidades de água e ágar, em relação a composição original, resultando num meio demasiadamente duro.

Em função dos resultados obtidos neste expe rimento, selecioṇaram-se as dietas $A, K$ e $N$ para se dar continuidade ao trabalho. Estas dietas, além de terem apre sentado as maiores viabilidades, proporcionaram uma duração para as fases larval e pupal, compatível com a citada na literatura para $P$. sequax criada em trigo (PEREIRA, 1978; PADIAL, 1980 e LESCHE, 1984). 


\subsubsection{AVALIAÇÃO DAS TRES DIETAS ARTIFICIAIS SELE- CIONADAS}

4.1.2.1. Efeito das dietas artificiais sobre parâmetros biológicos do inseto

- Primeira geração

Pelos resultados obtidos na avaliação das dietas $A, K$ e $N$ na primeira geração de $P$. sequax (Tabela 4), verificou-se que as mesmas não diferiram entre si quan to à viabilidade das fases larval e pupal.

No entanto a duração do período lagarta-pupa foi afetado pelas dietas. Este período foi cerca de 3 dias mais longo nos indivíduos criados na dieta $\mathrm{N}$, sendo que este efeito diferencial existiu apenas na fase larval. Esta maior velocidade de desenvolvimento constatada nas die tas $A$ e $K$ indicam, provavelmente, uma melhor adequação nutri cional das mesmas para $P$. sequa $x$.

o peso de pupas também foi afetado pelos diferentes tratamentos, sendo que as pupas provenientes da dieta $\mathrm{K}$ foram mais pesadas que as demais.

\section{- Segunda geração}

Na segunda geração (Tabela 5), houve efeí to das dietas na viabilidade ṕupal, a qual se refletiu na viabilidade do periodo lagarta-pupa, evidenciando uma supe rioridade das dietas $A$ e $K$, em relação à dieta $N$.

A duração do período lagarta-pupa e o peso 


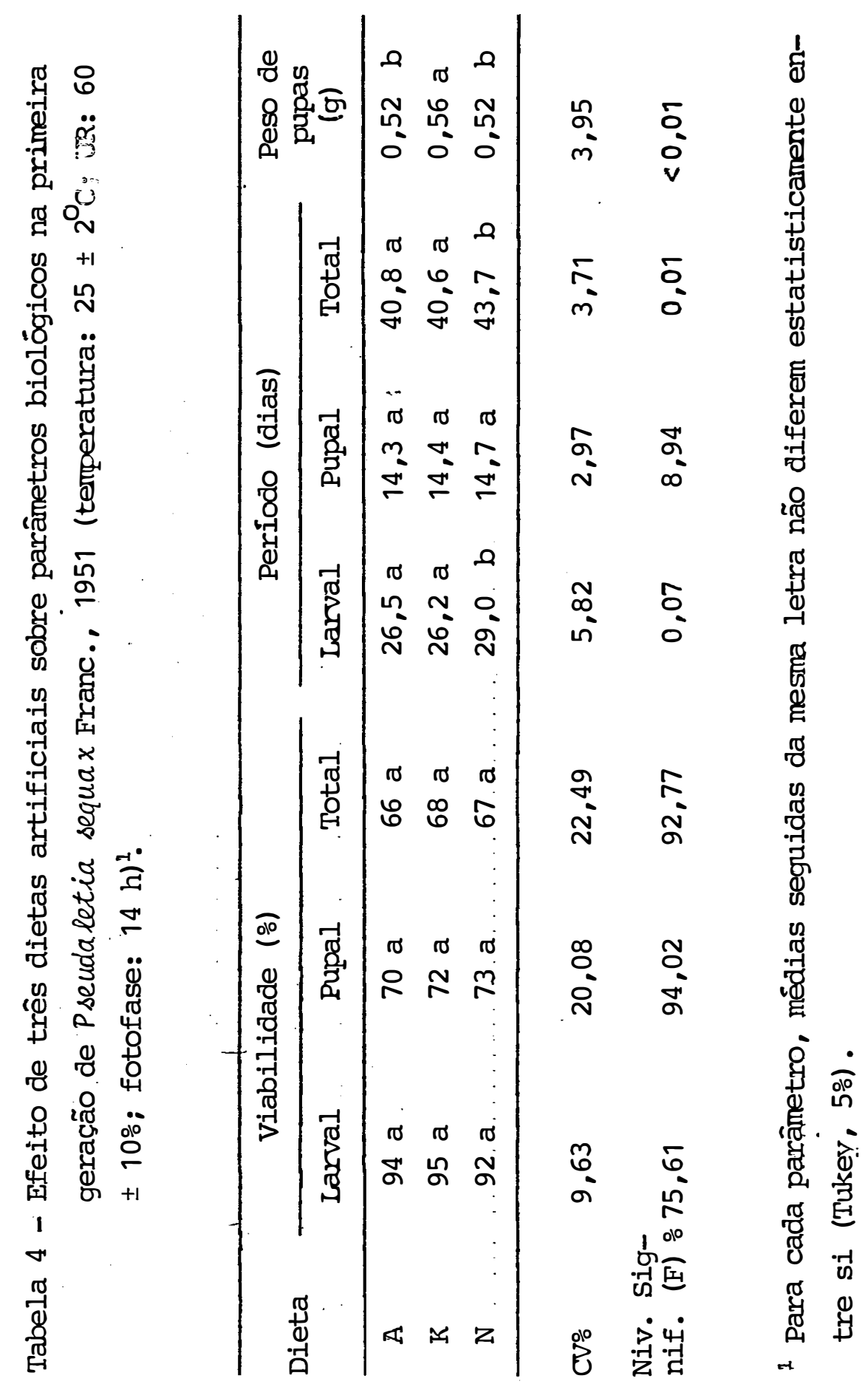



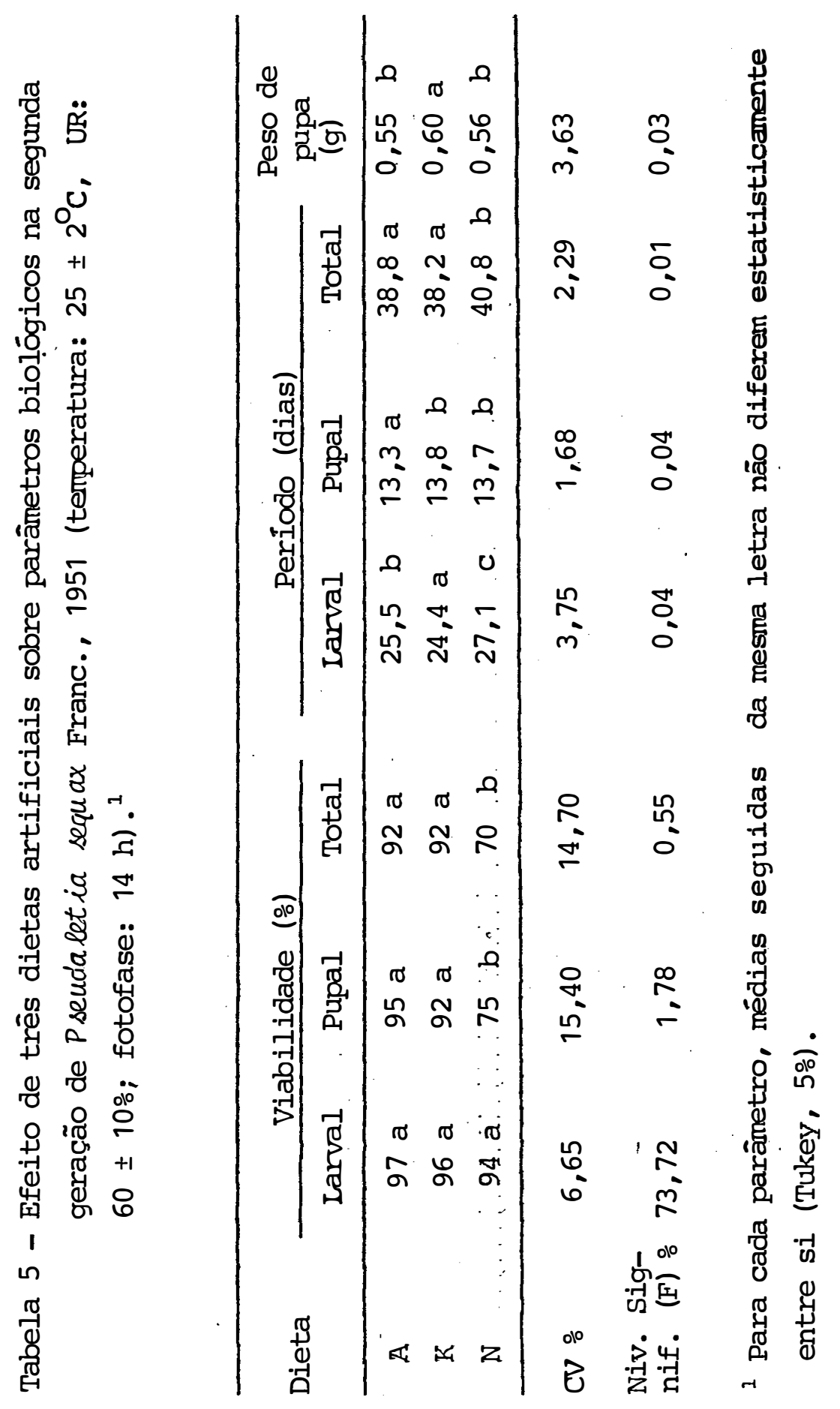
de pupas foram influenciados pelo alimento ingerido pelas lagartas, confirmando os resultados do experimento conduzi do com insetos de primeira geração.

Também nesta geração, as dietas A e $\mathrm{K}$ mostraram superioridade à $\mathrm{N}$, para a criação da lagarta do tri go.

\section{- Terceira geração}

A avaliação das dietas $A, K$ e $N$ com indivíduos de terceira geração (Tabela 6), também demonstrou efeitos significativos das mesmas na viabilidade e duração do período lagarta-pupa, bem como no peso de pupas.

Considerando-se a viabilidade do período la garta-pupa, observou-se uma maior adequação da dieta $\mathrm{K}$ em relação às outras duas dietas. Este resultado deveu-se ao efeito do alimento sobre a mortalidade de pupas, uma vez que as dietas proporcionaram viabilidades larvais que não diferiram estatisticamente entre si.

Os dados relativos à duração do período lagarta-pupa e ao peso de pupa, ratificaram os resultados en contrados nos experimentos na primeira e segunda gerações. A velocidade de desenvolvimento foi superior nas dietas A e $\mathrm{K}$, e o peso de pupas foi maior quando os insetos foram criados nesta última dieta. 


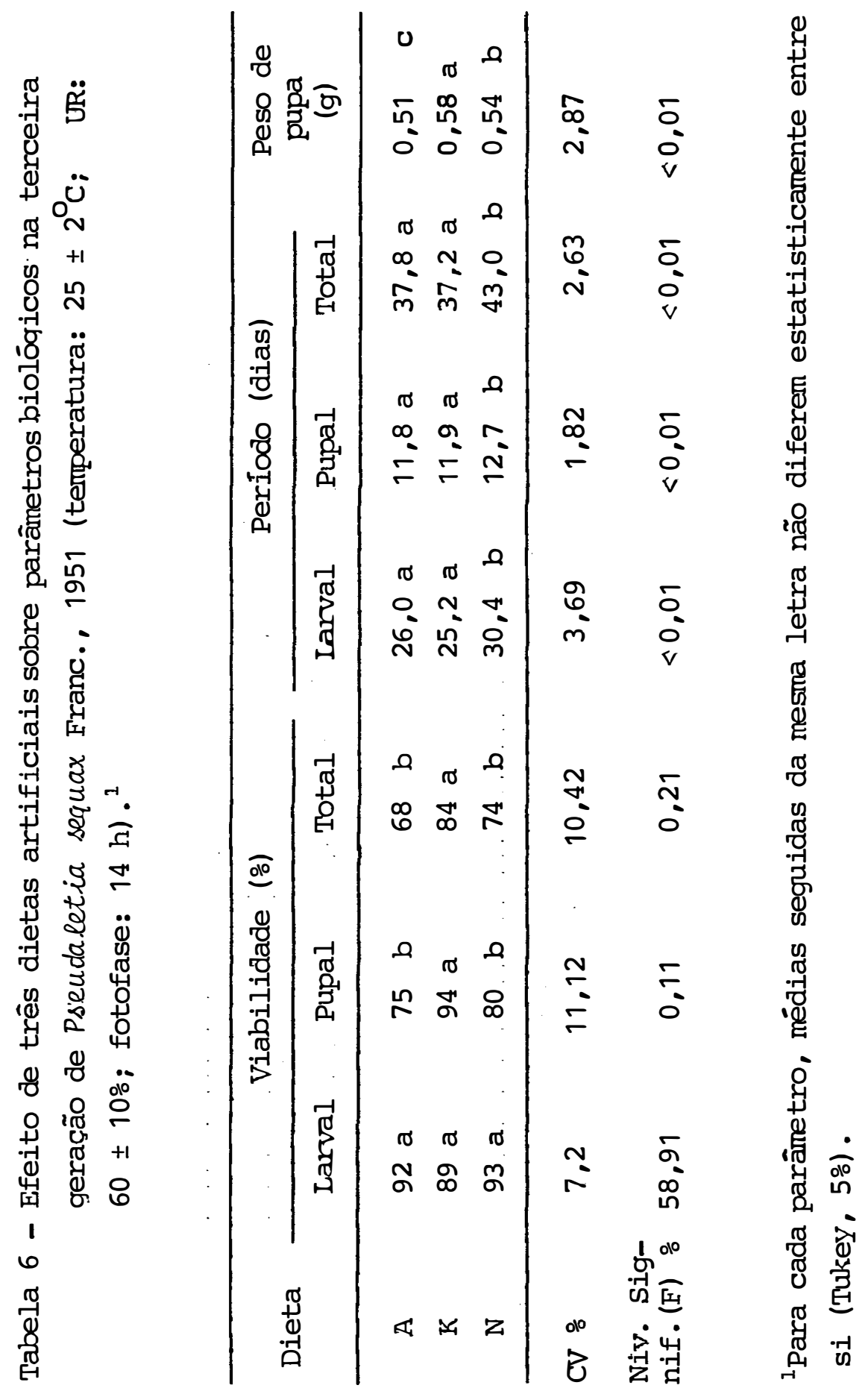




\section{- Gerações sucessivas}

A viabilidade das fases larval e pupal foi afetada pelas diferentes gerações de $P$. sequax (Tabela 7 e Figura 1). Nas três dietas a viabilidade decresceu da primeira para a terceira geração, sendo que na dieta $N$ este decréscimo já se configurou na segunda geração. Este resul tado indica uma superioridade das dietas $A$ e $\mathrm{K}$ em relação à N. A viabilidade média das três geraçōes foi maior na dieta K (90\%), seguida pela dieta A (85\%) e N (77\%), embora estas diferenças não tenham sido testadas estatisticamente.

A duração do período lagarta-pupa também so freu o efeito da geração dos insetos. Como pode ser observa do na Tabela 7 e Figura 2, a variação obedeceu a um mesmo padrão nas dietas $A$ e $K$, onde o desenvolvimento foi mais rápido na terceira geração; na dieta $\mathrm{N}$ esta situação se inverteu. Tomando-se os vialores médios das três gerações, embora sem uma confrontação estatística, verifica-se que a duração do período lagarta-pupa aumentou da dieta $\mathrm{K}$ para a A e desta para a N. A maior diferença foi observada quando se comparou a dieta $\mathrm{N}$ com as demais.

O peso de pupas variou significativamente de acordo com as gerações consideradas (Tabela 8 e Figura $3)$. Nas três dietas, este parâmetro decresceu claramente da primeira para a terceira geração. 0 peso médio nas três gerações foi maior na dieta $K(0,60 \mathrm{~g})$ em relação ao consta tado nas dietas A e $N$, cujos valores foram praticamente iguais $(0,55$ e 0,56 , respectivamente).

A razão sexual não foi afetada significativamente ao longo das três geraçẽ̃es nas três dietas (Tabẹ la 8). 
.47

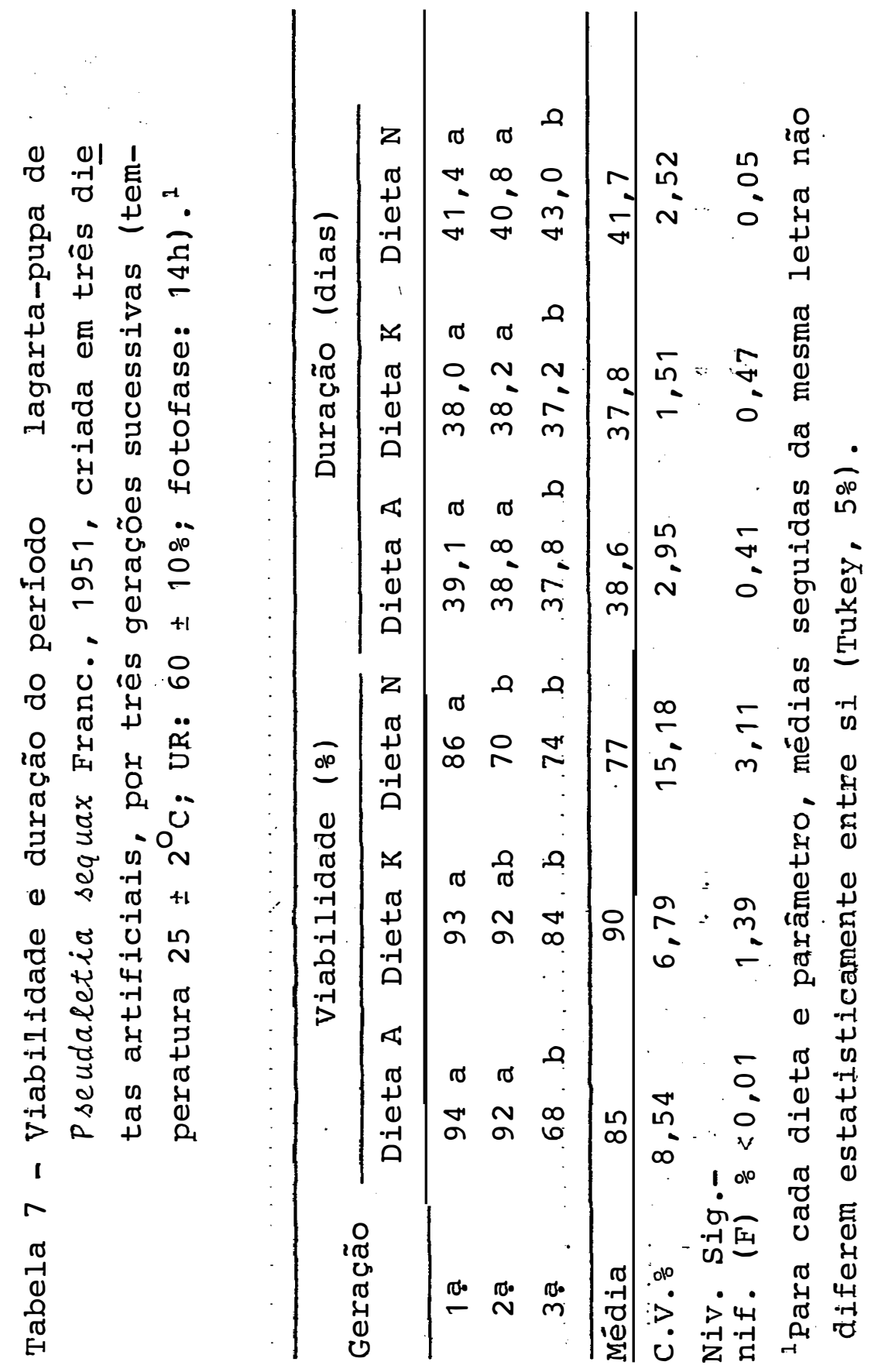




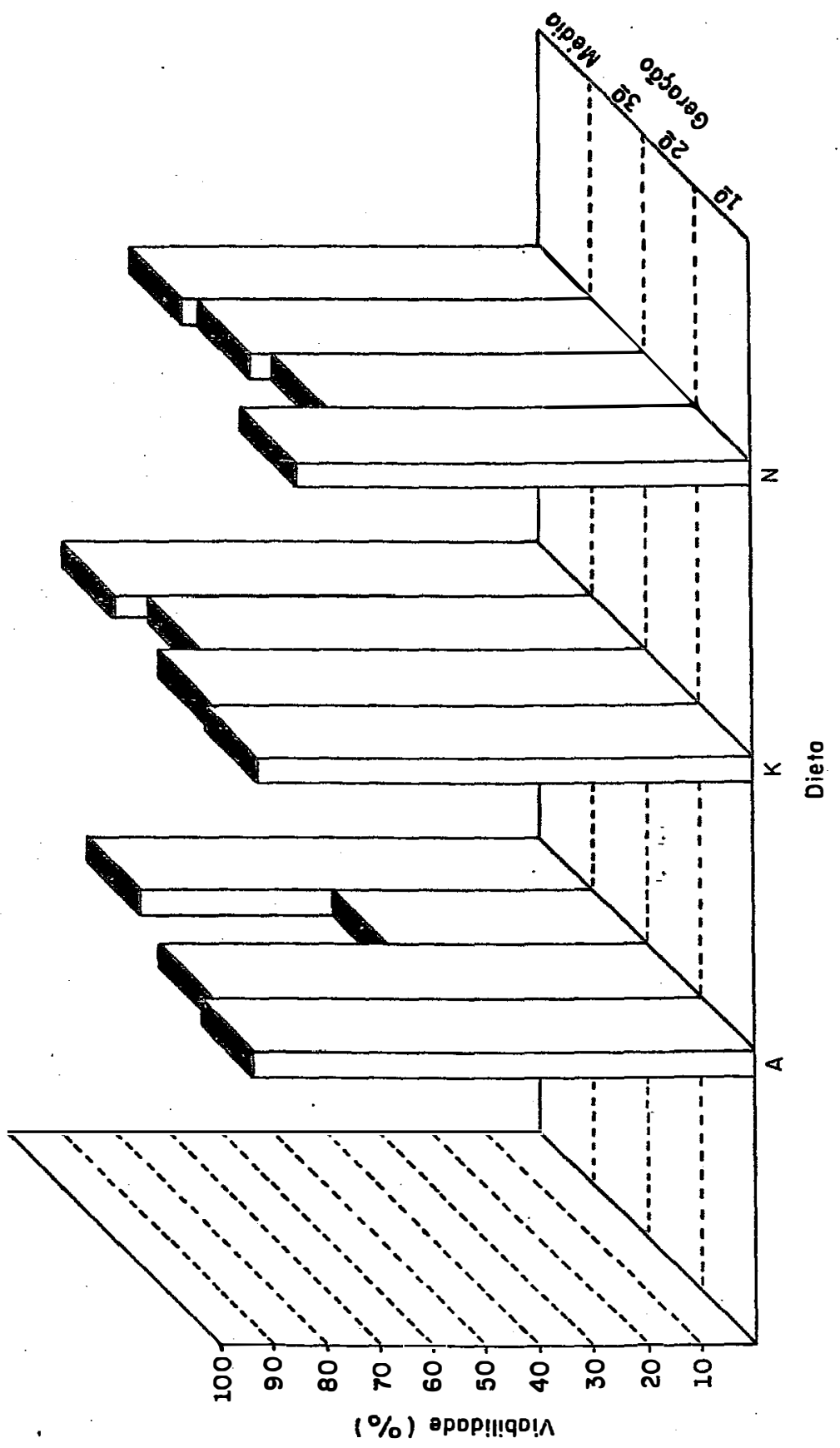

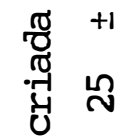

ถูก

ก

i

㝴

出

క్ర

ช

सू

క్ర ఫ్

a

8

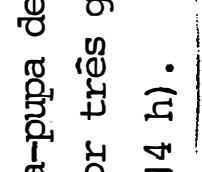

范

ర్ర

응

건

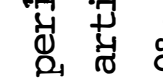

$\mathrm{O}$

1

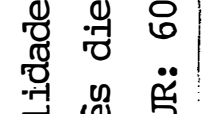

望题

疍

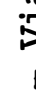

-

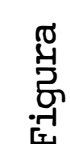



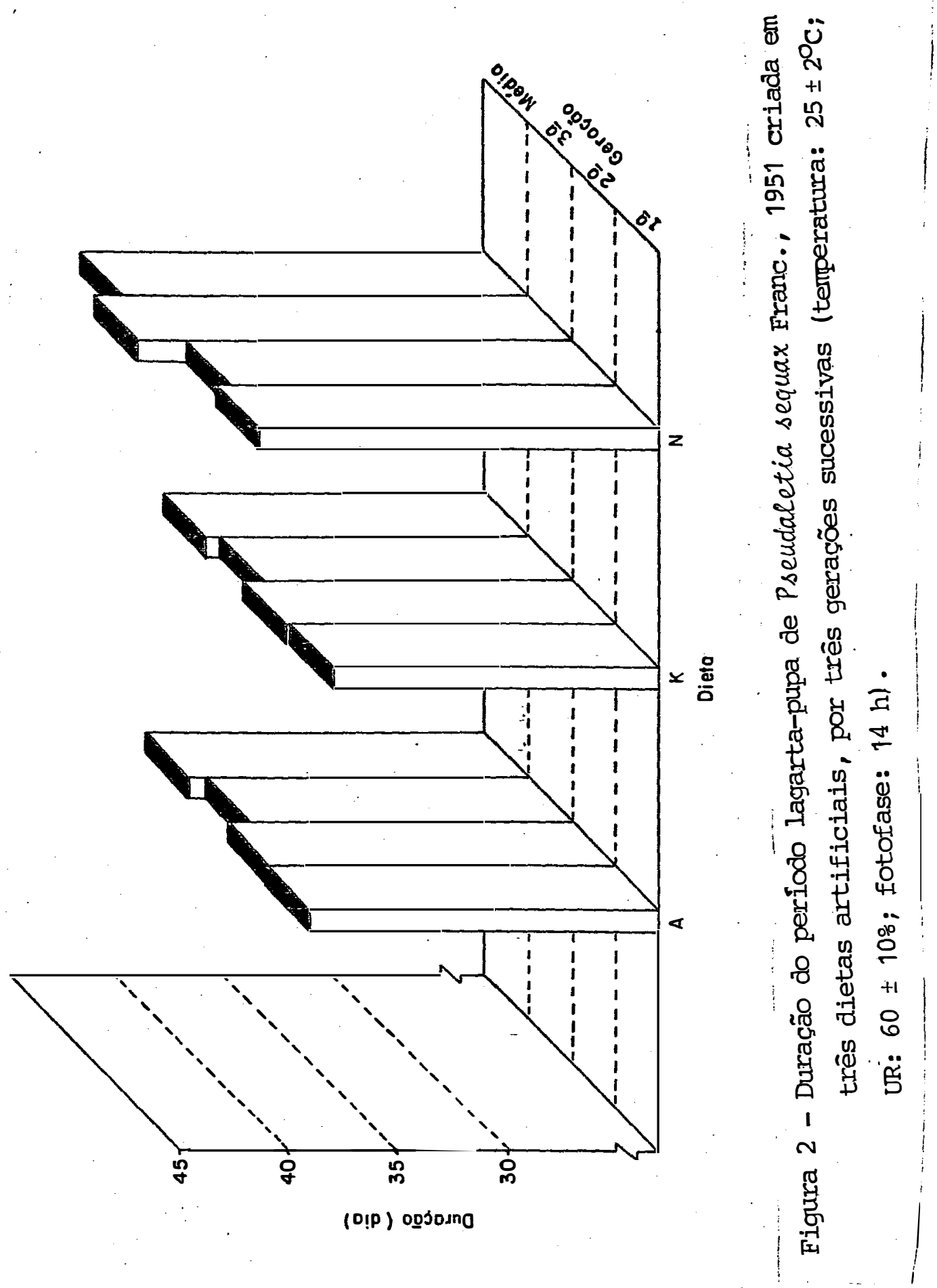


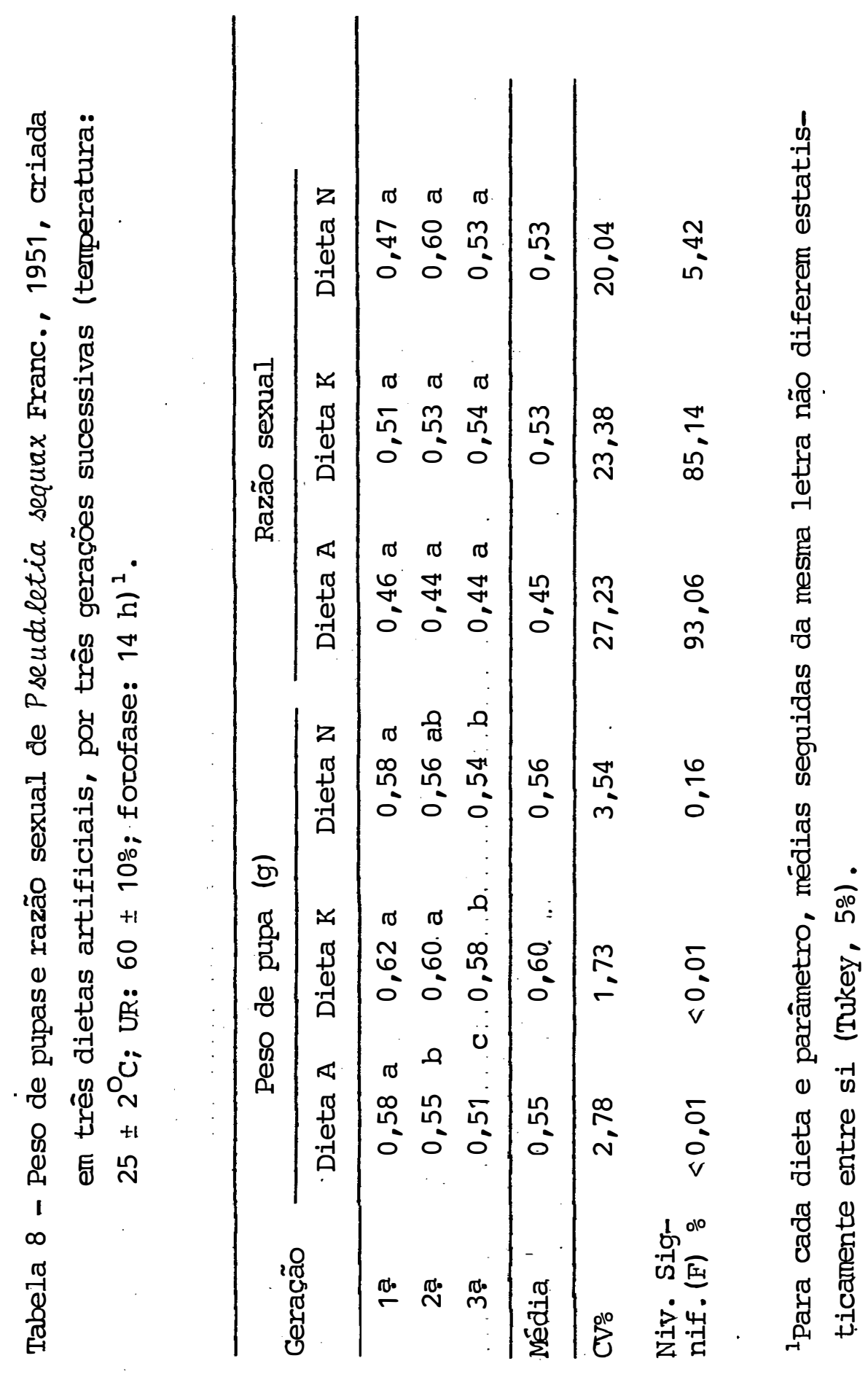

.50 


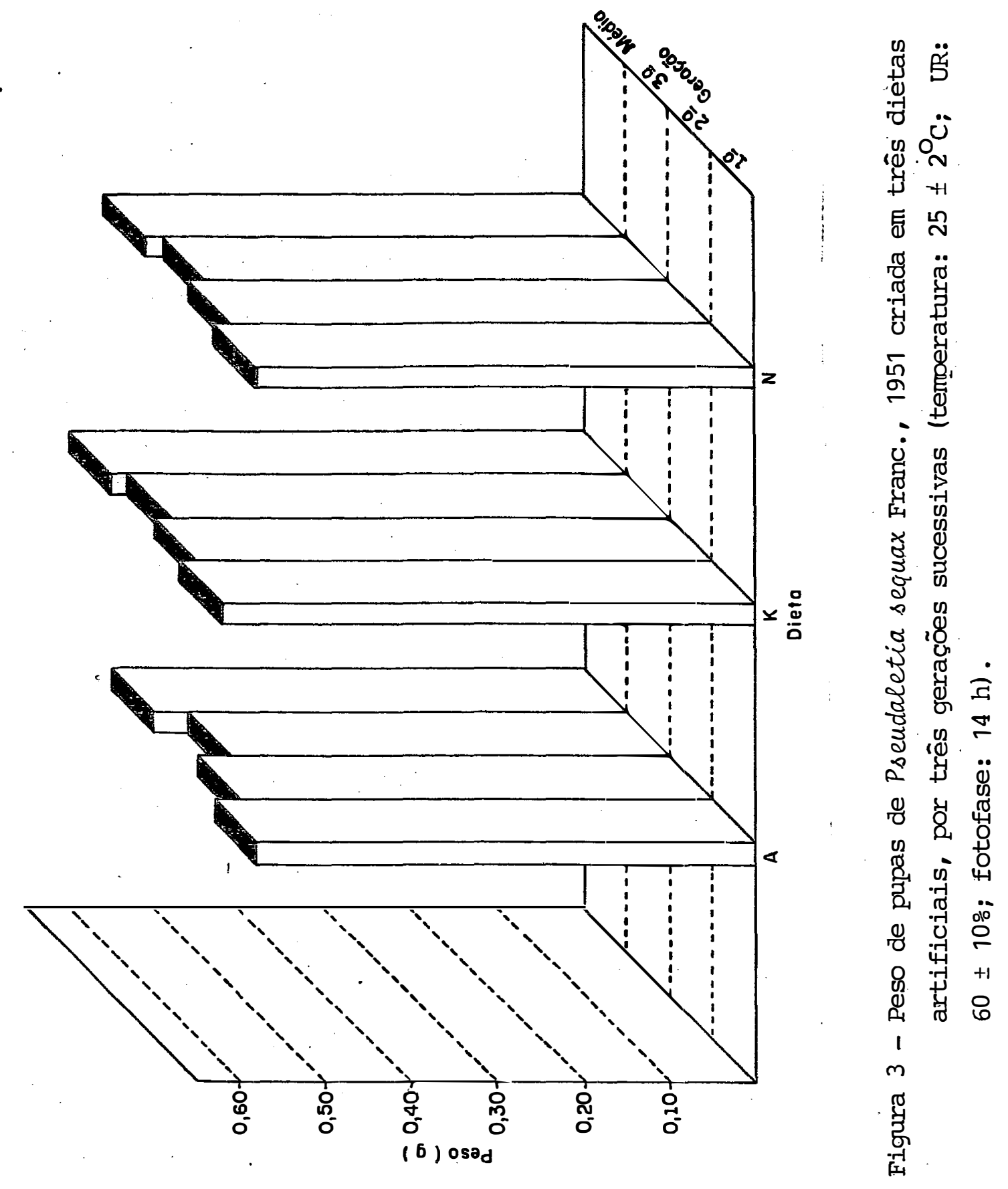


A porcentagem de pupas e adultos deformados tendeu a aumentar da primeira para a terceira geração, nas três dietas (Tabela 9). Embora estes resultados não tenham sido submetidos a análise de variância, constatou-se uma considerável deformação de pupas nas dietas A e.N. O grau de deformação de adultos foi relativamente baixo e semelhante nas três dietas.

O decréscimo da viabilidade e no peso de pupas, bemcomo a tendência de aumento da deformação de pupas e adultos, que em linhas gerais ocorreram da primeira para a terceira geração, podem ser considerados indicativos do início de um processo degenerativo. Conforme MACKAUER (1972), os mecanismos que mais contribuem para a decadência genéti ca ṇa criação de insetos em laboratório, são o efeito da colônia inicial, o cruzamento entre irmãos e a seleção.

No presente estudo, esta provável decadência, pode ser conseqüencia da origem do material e do cruzamento entre irmãos. A utilização de insetos oriundos de uma $\underline{\mathrm{u}}$ nica fêmea e o cruzamento dos descendentes podem ser apontadoś como causas deste fenômeno.

Observou-se, porem, que enquanto na dieta $\mathrm{N}$ esta tendência de declínio é mais clara, uma vez que a viabilidade decresceu já na segunda geração e a velo cidade de desenvolvimento também diminuiu na terceira gera ção, nas dietas A e $\mathrm{K}$ ela não é tão evidente. Nestas dietas, a provável degeneração indicada pelo aumento da mortạ lidade ao longo das gerações, não é confirmada pela duração do período lagarta-pupa que, por sua vez diminuiu. Assim, o incremento na velocidade de desenvolvimento dos insetos neste período, também poderia ser interpretado como um princípio de adaptação dos mesmos às dietas A e $K$, contrariando a hipótese de degeneração. 
53.

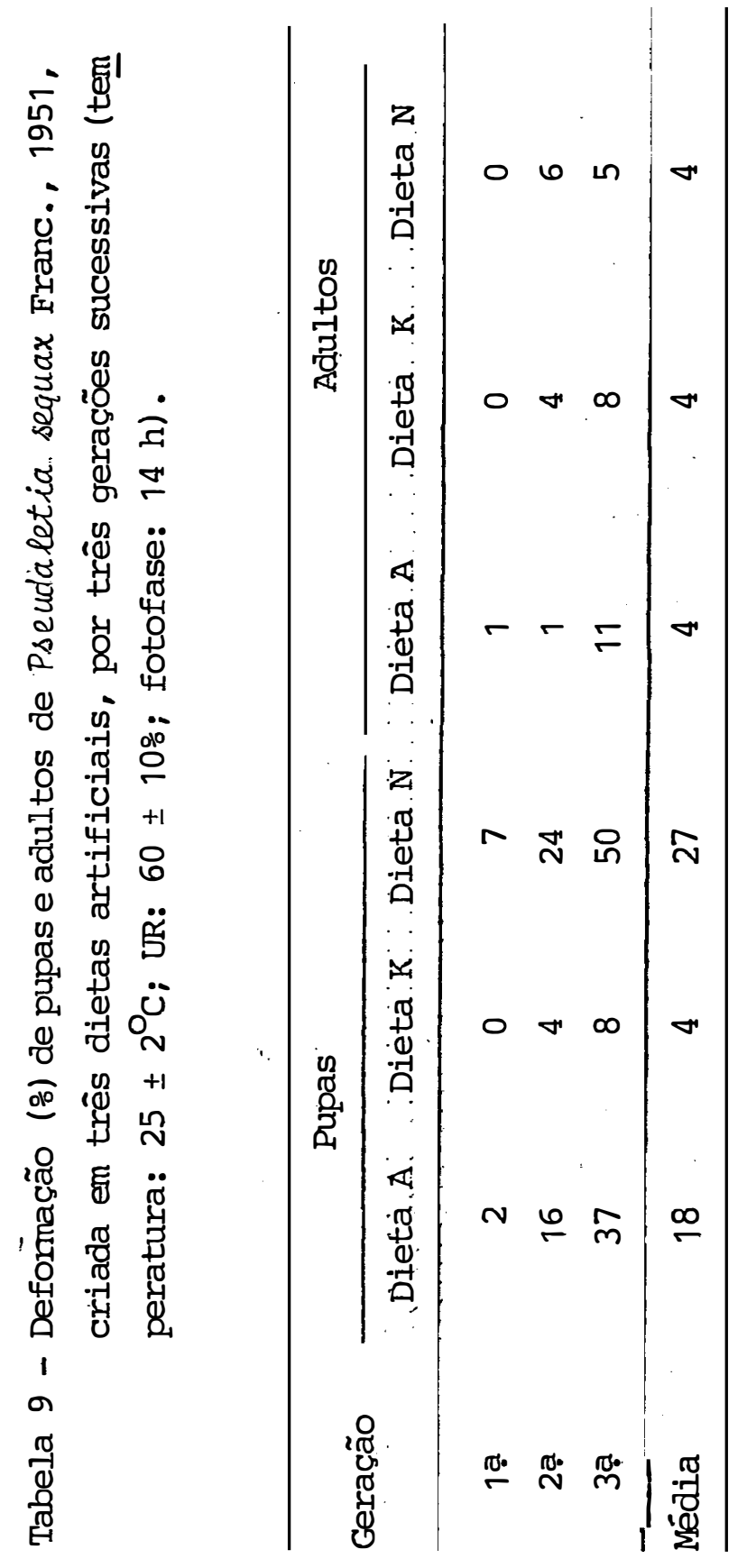


A propósito disso, BOLLER (1972) mencionou que em insetos trazidos para criação em laboratório, a pro dução de uma linhagem para esta condição pode ser baixa ou mesmo declinar no início do processo, para depois aumentar após 5 ou 7 gerações. Com base nesta afirmação, poder - se-ia levantar a possibilidade de que a mortalidade crescente verificada da primeira para a terceira geração, nas três dietas em estudo, decorreu de um processo adaptativo dos insetos aos substratos alimentares.

Na realidade, com as informações obtidas nestes experimentos, não é possível ir além de conjeturas. Pa ra a obtenção de dados mais consistentes e conclusivos sobre o desempenho das dietas ao longo de gerações sucessivas, seria necessário estender o estudo para um maior núme ro de gerações, como também ampliar as observações, incluin do parâmetros que indiquem o potencial de reprodução dos insetos (fecundidade, fertilidade, etc...).

\subsubsection{Comparação das dietas artificiaiais quanto ao seu consumo e utilização pelos insetos}

A quantidade ingerida, assimilada e metabolizada nas dietas $A, K$ e $N$, a quantidade de fezes produzidas e o ganho de biomassa, bem como a duração do periodo larval no qual estes parâmetros foram levantados, estão condensados na Tabela 10.

Todos estes parâmetros, inclusive a velocidade de desenvolvimento das lagartas, sofreram efeito significativo das dietas artificiais. 
.55 .

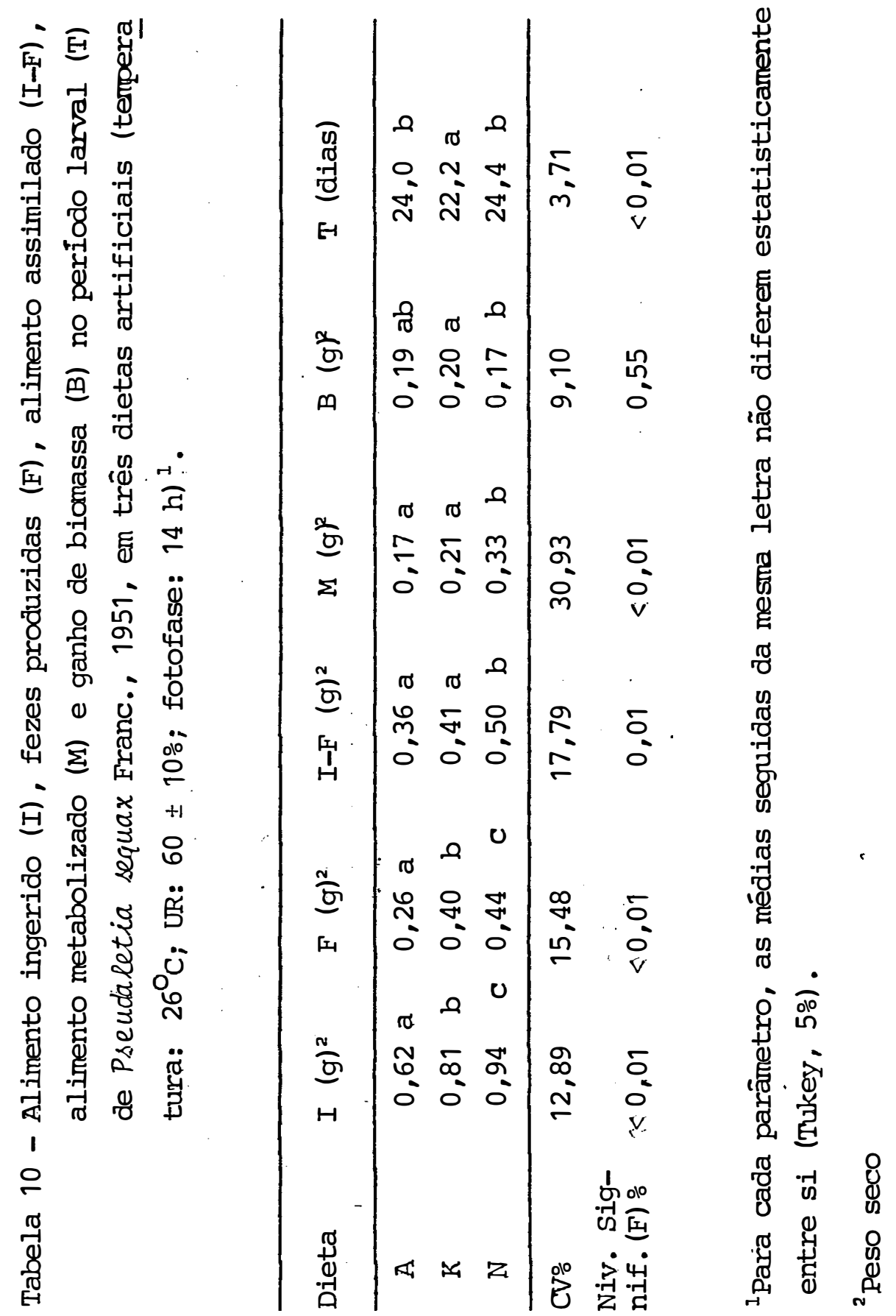


O alimento ingerido (I) e as fezes produzidas (F) apresentaram um mesmo tipo de variação em rẹlação às dietas. Ambos foram menores na dieta $A$, intermediários na dieta $\mathrm{K}$ e mais elevados na dieta $\mathrm{N}$. Nesta última, a quanti dade de alimento assimilado (I-F) ou seja, o alimento trans formado em energia e/ou em biomassa, foi maior em relação as outras duas dietas.

Observando-se o ganho de biomassa (B) apresen tado pelos insetos, verifica-se que a utilização do alimento para crescimento foi maior na dieta $\mathrm{K}$, intermediário na dieta $A$ e menor na dieta $N$. Através da análise do alimento metabolizado (M), que representa a quantidade de alimento utilizado na forma de energia metabólica, constatou-se que na dieta $\mathrm{N}$ uma maior proporção da mesma foi dirigí da a este fim, em detrimento do crescimento das lagartas.

O tempo necessário para que as lagartas atingissem o tamanho máximo, foi menor na dieta $\mathrm{K}$, em rela ção às dietas $A$ e $N$, indicando uma melhor adequação da mes ma em termos de velocidade de desenvolvimento. MUKERJI e GUPPY (1970) observaram que $P$. unipuncta é capaz dé acele rar o desenvolvimento, incrementando o consumo. No entanto no presente experimento, não há evidências de que esta tenha sido a causa do desenvolvimento mais rápido das lagartas criadas na dieta $\mathrm{K}$. Possivelmente, o fato esteve relacionado a composição das dietas.

Os parāmetros I, M e B, expressos em unidades de peso, podem ser transformados em indices se divididos pelo produto entre o peso médio das lagartas $(\bar{B})$ e o tempo (T) no qual as mesmas atingiram o tamanho máximo. Obtem-se assim a taxa de consumo relativo (RCR), a taxa metabólica relativa (RMR) e a taxa de crescimento relativo (RGR), ex- 
pressas em unidade de peso/peso.tempo. Por outro lado, a eficiência de utilização do alimento é expressa em porcentagem, através dos indices de digestibilidade aproximada $(A D)$, eficiência de conversão do alimento ingerido (ECI) e do digerido (ECD) .

Estes Indices (Tabela 11 e Figura 4), permitem uma análise comparativa mais adequada, quanto ao consu mo e a utilização do alimento.

A RCR foi diferente nas très dietas em estudo, sendo menor na dieta $A$, intermediária na $K$ e maior na N. Entretanto, a RGR foi maior na dieta $\mathrm{K}$, em relação às dietas $A$ e $N$, que não diferiram entre si. Assim, na dieta $A$, mesmo ingerindo uma quantidade de alimento inferior em 34\%, as lagartas apresentaram crescimento comparável ao verificado na dieta $N$. Por outro lado, na dieta $K$, as lagartas consumiram 14\% a menos, mas apresentaram um ganho de peso maior que na dieta $\mathrm{N}$.

Estes dados indicaram uma superioridade das dietas $\mathrm{A}$ e $\mathrm{K}$ em relação à dieta $\mathrm{N}$, quanto ao pesó adquirido pelas lagartas de $P$. sequax, em relação à quantidade de alimento consumido. Isto decorreu, provavelmente, das diferenças quālitativas e quantitativas na composição das dietas.

A RMR não diferiu nas dietas A e $\mathrm{K}$, mas foi maior na dieta $\mathrm{N}$, evidenciando que nesta, os insetos utili zaram uma maior parte do alimento como energia metabólica, em detrimento do crescimento. 
.58 .

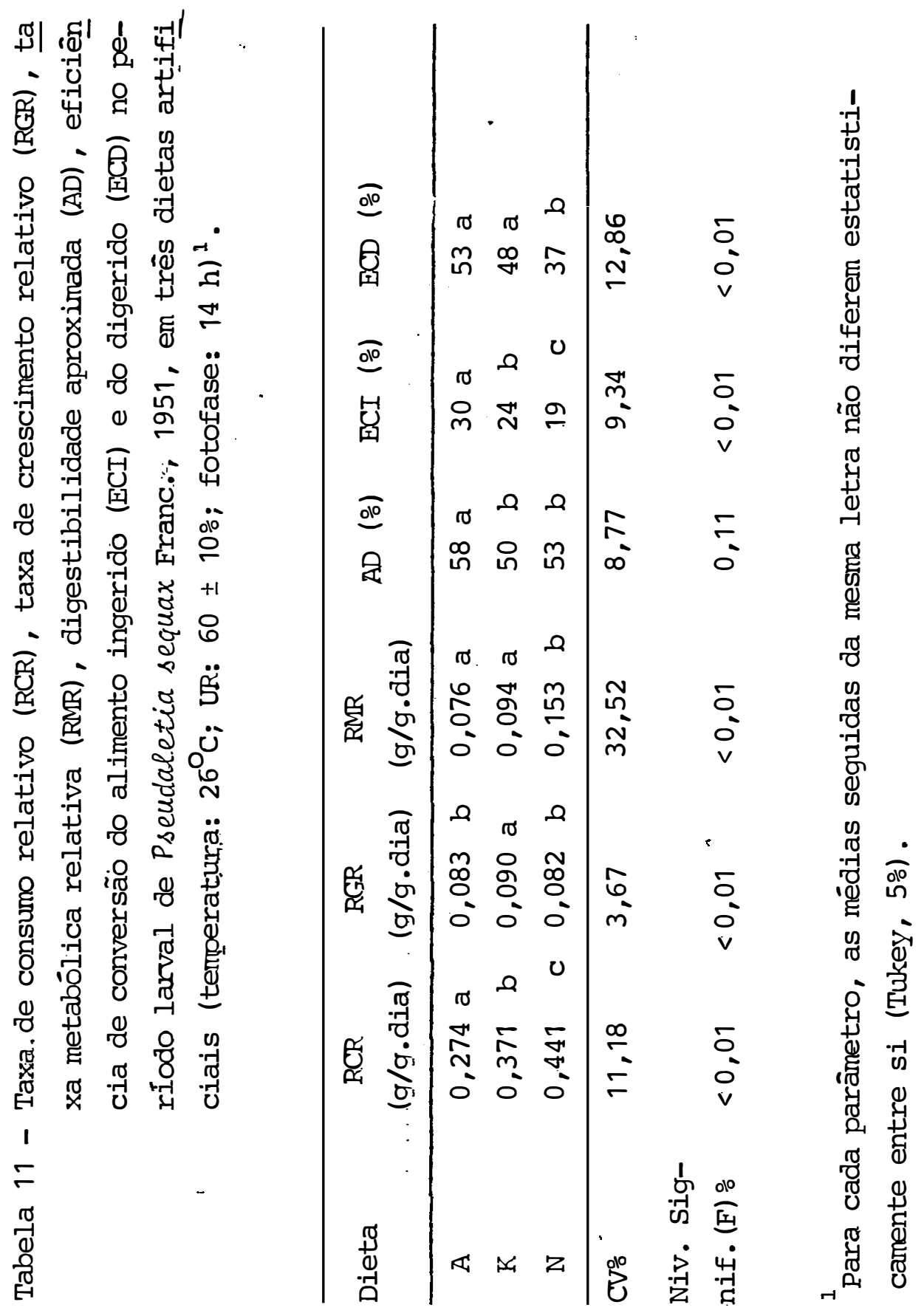




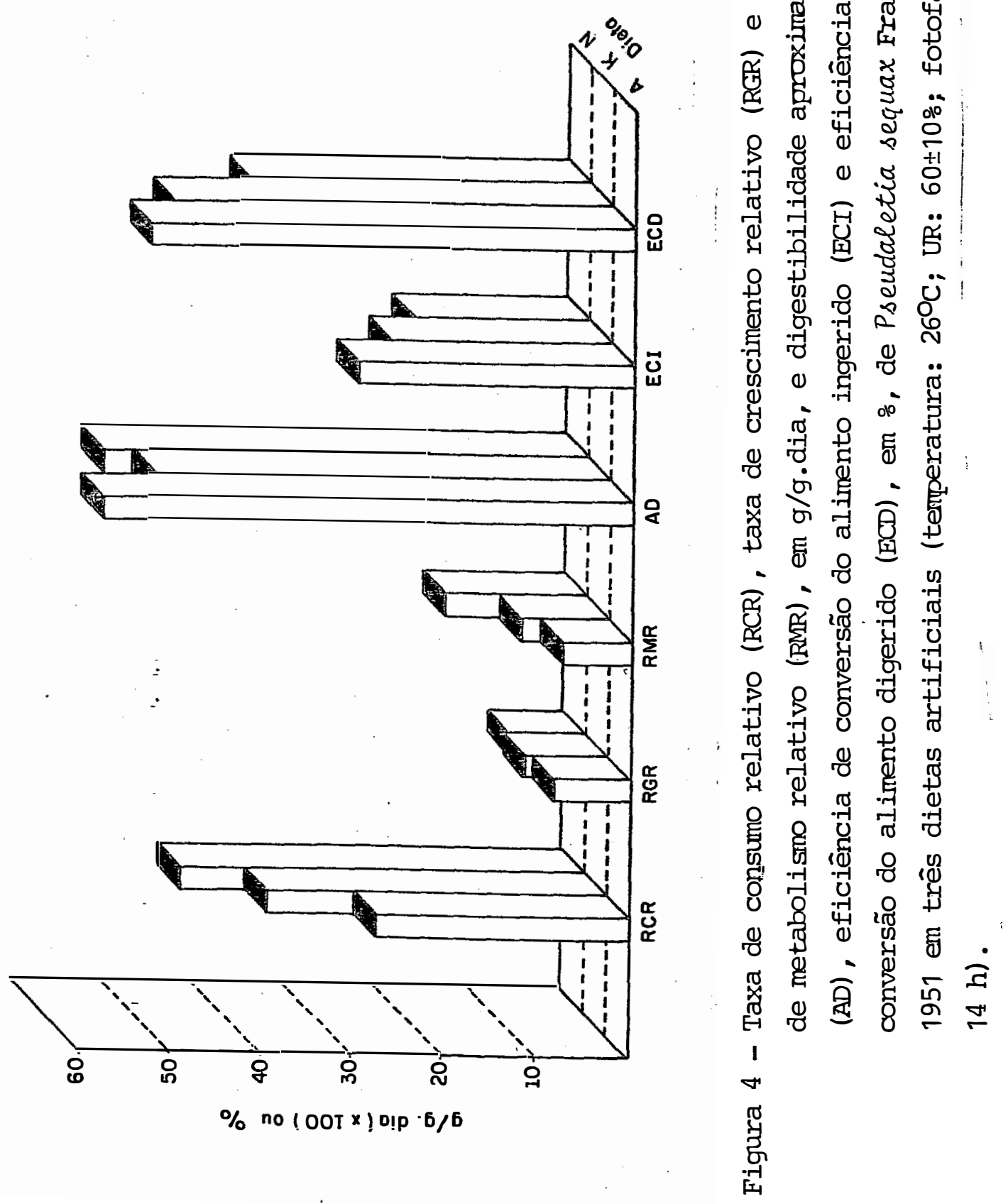


A digestibilidade aproximada (AD), representa a porcentagem do alimento que foi efetivamente assimilada. E dita aproximada, pelo fato da urina dos insetos estar computada nos valores de excreção utilizadas para o seu cál culo. Este indice äemonstra que a assimilação foi mais eficiente na dieta $A$, em relação às dietas $\mathrm{K}$ e $\mathrm{N}$.

A eficiência de conversão do alimento ingerido (ECI), ou taxa bruta de eficiência, foi diferente nas três dietas em estudo. Deste modo, a proporção do alimento ingerido que foi utilizado para ganho de biomassa, foi maior na dieta $A$, intermediària na $\mathrm{K}$ e menor na $N$. Por outro lado, a eficiência de conversão do alimento digerido (ECD), ou taxa líquida de eficiência, foi superior nas die tas $A$ e $K$, que por sua vez não diferiram entre si. Isto de monstra um melhor aproveitamento da porção digerível destas duas dietas para conversão em substância corpórea, por parte dos insetos.

o custo metabólico (100-ECD) foi maior na dieta $N$ (63\%), confirmando que uma maior quantidade desta dieta łoi metabolizada em energia, para manutenção da vida. Esta energia pode ter sido gasta para a neutralização de substâncias desfavorāveiś à fisiologia dos insetos (SCHOONHOVEN e MEERMAN, 1978). Pode-se levantar a hipótese, que o ocorrido esteja associado à maior quantidade relativa de feijão da dieta $N$, em relação às demais (Tabela 2) . PARRA e CARVALHO (1984) discutiram a presença de fatores antifisiológicos e de a.lelogúímicos, bem como a baixa digestibilidade de proteînas, em feijão.

Com base nos indices nutricionais discutidos, espe cialmente no ECD, considerado para Diatraea saccharalis (Fabr. 1794) como o que melhor explica a adequação nutricional de dietas artificiais (MARTINS, 1983), constatou-se que as dietas A e K são mais ade 
quadas que a $\mathrm{N}$, para. a lagarta do trigo.

\subsubsection{Custo do inseto produzido nas dietas artificiais}

Na Tabela 12 está apresentado o custo de pro-

dução de $P$. sequax nas dietas $A, K$ e $N$, calculado a partir do consumo das lagartas e preço dos ingredientes, uma vez que a viabilidade larval foi estatisticamente igual nas três dietas (Tabelas 4,5 e 6 ).

O custo das dietas variou diretamente com a complexidade relativa das mesmas em termos de número e concentração de ingredientes (Tabela 1). Assim, para uma mesma quantidade, a dieta $A$ foi mais cara que a $K$ e esta, mais cara: do que a N. Por outro lado, o consumo variou de forma inversa, sendo menor na dieta $A$, intermediário na $\mathrm{K}$ e menor na $\mathrm{N}$.

Estas variações em sentidos opostos, dos dados utilizados na estimativa do custo/inset'o produzido, ge raram uma compensação nos valores obtidos. Desta forma, o custo de produção foi bastante próximo para as três dietas.

O diferencial mais expressivo foi observado na comparação da dieta $N$ com as demais. Os insetos produzidos nesta dieta custaram cerca de 10 e $12 \%$ menos do que os produzidos os nas dietas $K$ e $A$, respectivamente. Considerando-se apenas o aspecto econômico, esta diferença poderá ter maior ou menor importância de acordo com o número de insetos a serem produzidos. 


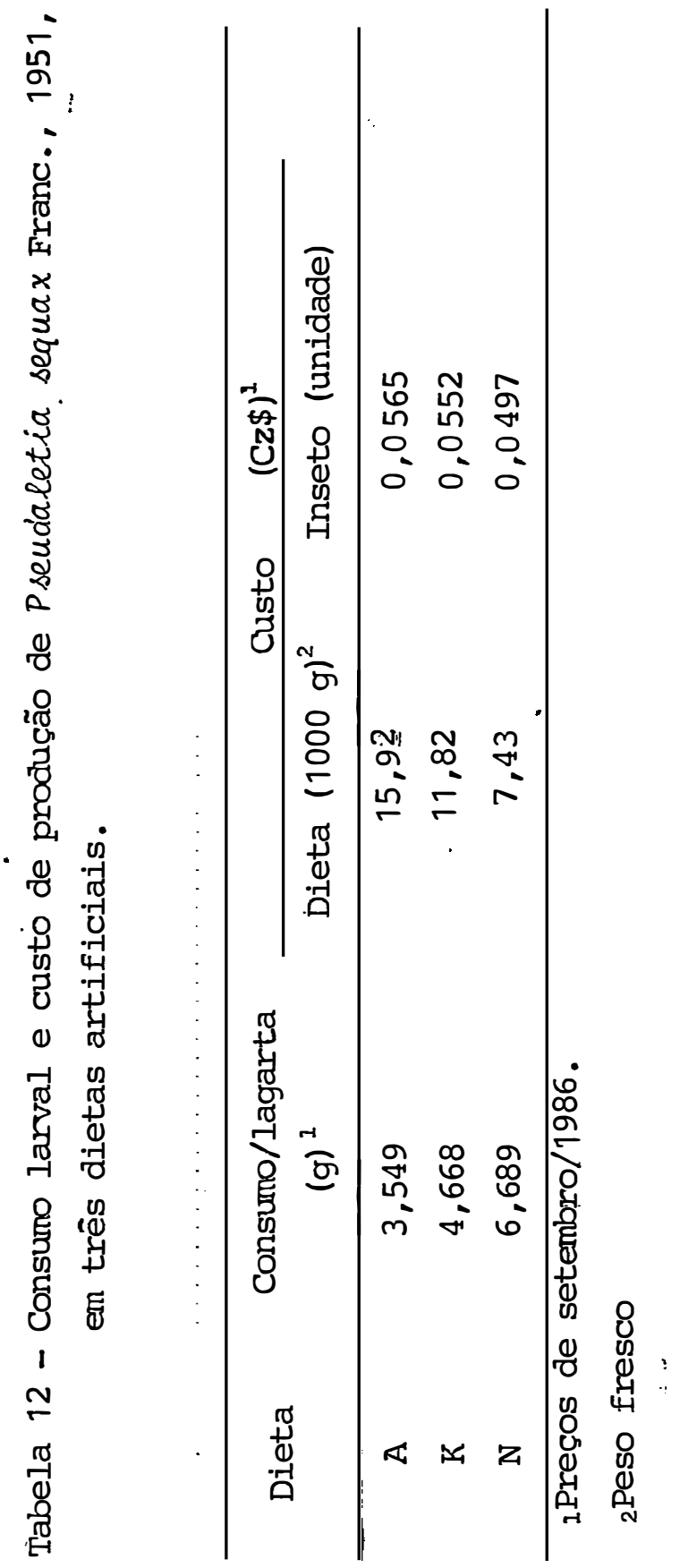




\subsection{Biologia COMPARADA DE P.: sequax EM DIETAS NATURAL E ARTIFICIAIS}

\subsubsection{VIABILIDADE DAS PASES IMATURAS}

Os resultados referentes à viabilidade das fases de ovo, lagarta e pupa, nas dietas $A, K, N$ e folhas de trigo, estão apresentados na Tabela 13 .

\section{- Viabilidade de ovos}

Observou-se um efeito significativo do alimento ingerido na fase larval, na viabilidade dos ovos. Este resultado não coincide com os obtidos por PADIAL (1980), que não constatou tal efeito para diferentes dietas (milho e trigol.

As dietas A e $\mathrm{K}$ proporcionaram viabilida de de ovos igual à verificada em trigo (85\%). Na dieta $N$, apenas 21\% dos ovos foram fêrteis. Em todas as dietas, observou-se que a viabilidade de ovos variou de 0 a 100\%, ao longo de período de oviposição. Situação semelhante foi re gistrada por PADIAL (1980) que encontrou uma oscilação de 0 a $98,54 \%$. Nas dietas $A$ e $K$, isto foi constatado mais para o final do período (observação complementar):; enquanto que na $\mathrm{N}$ ocorreu já nas primeiras posturas, nas quais foram to madas as amostras para os testes de viabilidade. Portanto, é possivel que resultados diferentes poderiam ter sido encontrados, caso fosse considerado, para as três dietas, a viabilidade de todo o período de oviposição.

A viabilidade média de $85 \%$ registrada pa ra as dietas $A, K$ e trigo, pode ser considerada alța. se comparada com a viabilidade de $53,17 \%$ encontrada por PA- 
DIAL $(1980)$, a $25^{\circ} \mathrm{C}$, em ovos de insetos criados em trigo. o valor obtido situa-se porēm, numa posição intermediária entre os 77,1\% encontrado em trigo por LESCHE (1984), e os $89,91 \%$ encontrado em capim quicuio por PEREIRA (1978).

Para outras espécies de Pseuda letia, a viabilidade dos ovos mencionada na bibliografia é relativa mente baixa. BREELAND (1958) citou uma viabilidade de 67,5\% para $P$. unipuncta, enquanto que TERRA e ZERBINO (1983a) re gistraram viabilidade de $46 \%$ para $P$. adultera.

\section{- Viabilidade larval}

Quando avaliada no primeiro instar larval a qual expressa, também, o efeito fagoestimulante do alimento, a viabilidade foi igual em todas as dietas, atin gindo valores próximos de 100\% (Tabela 13).

Tomada, no entanto, para todo'o período larval, a viabilidade foi significativamente afetada pelos tratamentos, sendo maior nas dietas artificiais do que no trigo. As dietas artificiais foram estatisticamente iguais quanto à estes parâmetros com viabilidade de $93 \%$ na dieta $\mathrm{K}$ e de $96 \%$ nas dietas $A$ e $N$.

A influência do alimento natural sobre a viabilidade das lagartas de $P$. s sequax já fora constatada : por PEREIRA (1978) e PADIAL (1980). TERRA e ZERBINO (1983a) re gistraram uma menor sobrevivência de lagartas de $P$. a dulte ra alimentadas em folhas-bandeiras, em relação a folhas tenras de trigo.

A maior mortalidade ocorrida na dieta natural, pode ser atribuída à manipulação diária das lagar 
tas para troca do alimento e limpeza do recipiente de cria ção.

Por outro lado, a viabilidade de $84 \%$ obtida no trigo, é superion à registrada por outros autores, no mesmo substrato alimentar. PEREIRA (1978) e PADIAL (1980) citaram uma viabilidade larval em torno de 60 e $81 \%$, respectivamente.

\section{- Viabilidade pupal}

Constatou-se que o alimento fornecido às lagartas interferiu na viabilidade das pupas. Este fato já havia sido apontado por PADIAL (1980) que, alimentando lagartas de $P$. sequax com milho, trigo e capim quicuio, encontrou uma mortalidade de aproximadamente $11 \%$ nas pupas provenientes da última dieta.

Na presente avaliação as três ḋietas artificiais superaram o trigo, o qual propiciou uma viabilidade de $81 \%$. A maior viabilidade pupal foi registrada nas dietas A (98\%) e K (100\%) que não diferiram entre si, e mostraram-se superiores à dieta $\mathrm{N}$ na qual a viabilidade foi de $90 \%$ (Tabela 13).

\section{- Viabilidade total}

Tomando-se a porcentagem de insetos que, a partir dos ovos viáveis, chegaram à fase adulta, ou seja, computando-se a viabilidade dos períodos larval e pupal, constatou-se que as dietas $A, K, N$ e trigo proporcionaram, respectivamente, sobrevivências de 94, 93, 86 e …68\% (Tabela 13). Os valores obtidos nas dietas artificiais superaram a viabilidade mínima de $75 \%$, preconizada por SINGH 
.66.

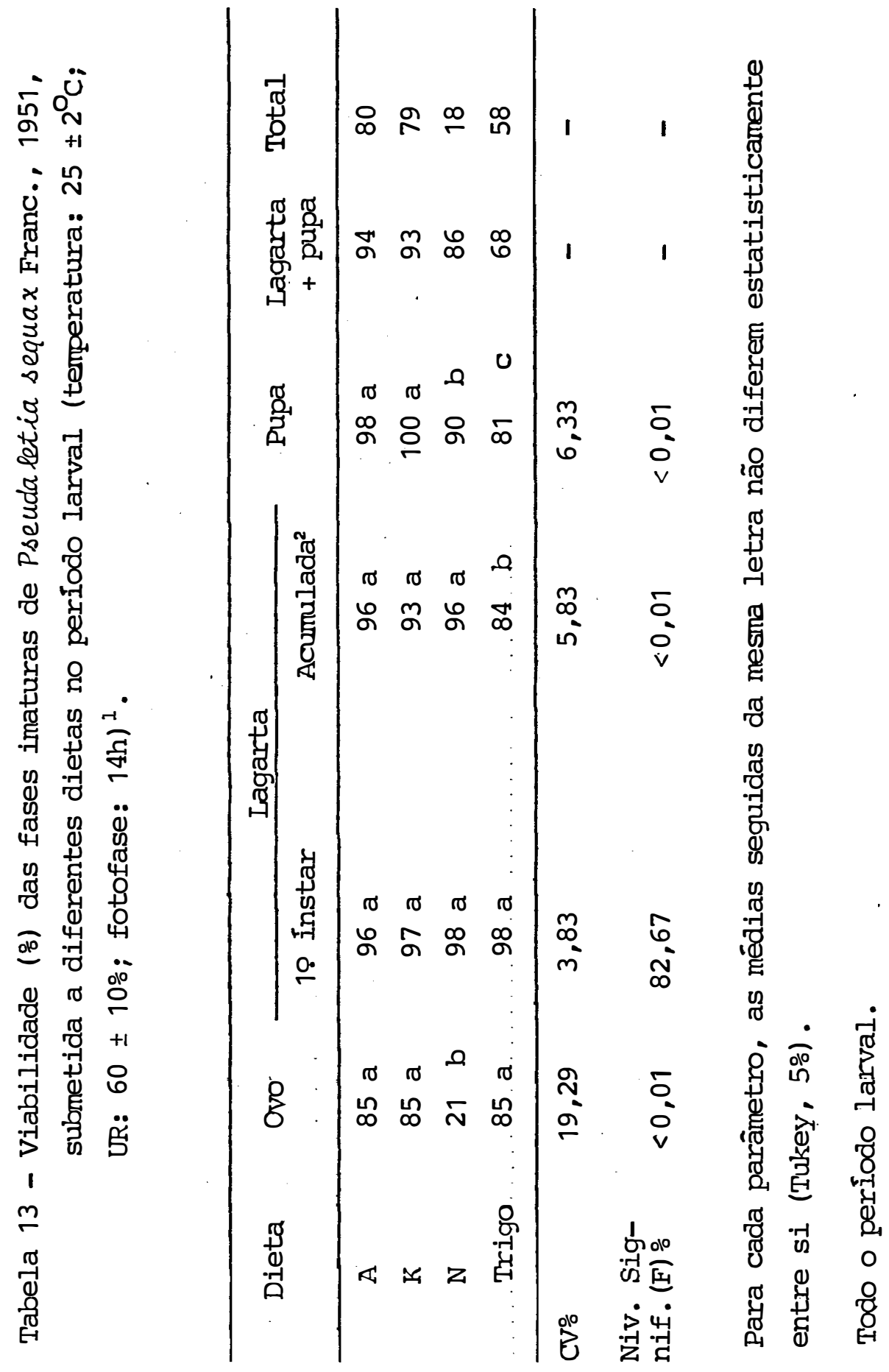


(1983), para que uma dieta artificial seja considerada satisfatória.

Incluindo-se neste cômputo a viabilidade de ovos, percebe-se que cerca de $80 \%$ dos insetos chegaram à fase adulta, nas dietas A e $\mathrm{K}$. No trigo este valor "chegou a $58 \%$ e, na dieta N.; atingiu apenas $18 \%$.

\subsubsection{DURAÇ̃̃O DO DESENVOLVIMENTO}

Os dados relativos à duração das fases $\underline{i}$ maturas de $P$.: sequax, nas dietas artificiais e no trigo, encontram-se na Tabela 14 , e estão representados na Figura 5 .

- Período de incubação

Não houve efeito significativo do alimen to ministrado às lagartas na duração do desenvolvimento em brionário, o que está de acordo com os resultados obtidos por PADIAL (1980).

Tanto para as dietas $A, K$ e $N$, como para o trigo, o periodo de incubação esteve em torno de 4 dias. Este dado ratifica o resultado encontrado por PEREIRA (1978), e situa-se dentro do intervalo de 4 a 6 dias, referido por LESCHE (1984), a $20^{\circ} \mathrm{C}$, condição de temperatura inferior a do presente experimento. '.

- Pexíodo larval

A duração da fase larval foi afetada pe- 
lo alimento ingerido durante a mesma (Tabela 14 e ..Figura 5). Isto confirma as observações de PEREIRA (1978) e PADIAL (1980) que constataram o efeito de diferentes hospedeiros sobre a velocidade de desenvolvimento larval em $P$. sequax. TERRA e ZERBINO (1983a) registraram efeito seme lhante em $P$. adultera.

A velocidade de desenvolvimento foi maior na dieta $\mathrm{K}$ e no trigo, nos quais o periodo larval durou 24,0 dias. A dieta A proporcionou uma duração intermediária (25,3 dias), e na dieta $\mathrm{N}$ ocorreu o maior período larval $(27,3$ dias $)$.

Os resultados verificados na dieta $A$, $K$ e trigo são compativeis com os citados por PADIAL (1980) que, em trigo, encontrou um periodo larval entre 24 e 25 dias. Coincidem, também, com o resultado encontrado por LESCHE (1984) (24,4 dias), embora este tenha sido obtido a $20^{\circ} \mathrm{C}$. Por outro lado, em termos gerais, são inferiores aos resultados constatados por PEREIRA (1978), que registrou uma duração de 31 a 34 dias para o período larval.

\section{- Período pupal}

A duração do periodo pupal, independente mente do sexo, também foi afetada pelo alimento fornecido às lagartas (Tabela 14 e Figura 5), ratificando a citação de PADIAL (1980). O resultado obtido no trigo $(13,0$ dias) é numericamente inferior ao encontrado por PADIAL (1980) e superior ao referido por PEREIRA (1978). 


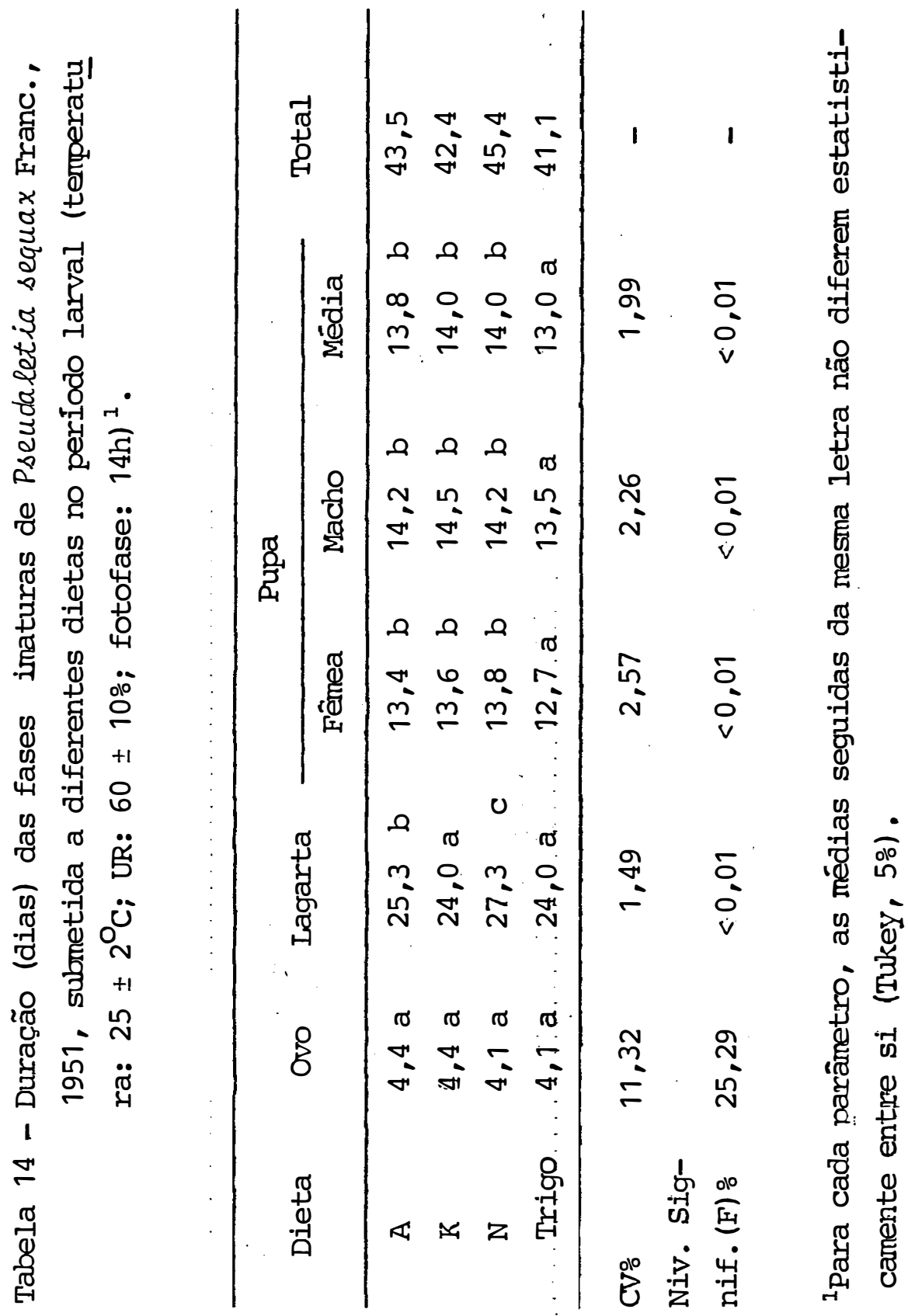


As três dietas artificiais proporciona ram um periodo pupal estatisticamente igual e, em geral, a penas um dia mais longo ợe o verificado no trigo.

Quando considerados isoladamente, ambos os sexos mostraram a mesma variação na duração do periodo pupal, em função das dietas. Em todos os tratamentos,o periodo pupal foi ligeiramente superior nos machos em relação às femeas, embora esta diferença não tenha sido testada estatisticamente.

- Ciclo total (ovo-emergência do adulto)

Embora este parâmetro não tenha sido sub metido à análise de variância, observou-se que a sua duração média variou em função do alimento (Tabela 14 e Figura 5). A diferença mais expressiva foi constatada entre o trí: go $(41,1$ dias) e a dieta $\mathrm{N}(45,4$ dias). A dieta $\mathrm{K}$ apresentou um resultado de 42,4 dias e a dieta $A$ de 43,5 dias, di ferindo do alimento natural em cerca de 1 e 2 dias, respec tivamente.

Os resultados obtidos em termos de velocidade de desenvolvimento das fases imaturas, revelam uma equivalência das dietas artificiais, especialmente das die tas $A$ e $K$, com o trigo.

\subsubsection{RAZÃO SEXUAL}

Conforme pode ser constatado na Tabela 15, a razão sexual não foi afetada pelo alimento :ingerido pelas lagartas. Nas quatro dietas em avaliação, a razão se xual foi próxima a 0,50 . Este mesmo valor foi registrado por PEREIRA (1978), utilizando capim quicuioe trigo para 
criação das lagartas. No entanto, neste mesmo trabalho o autor observou a influência do alimento na razão sexual, pois esta foi 0,67 em insetos criados em cevada. Ainda em trigo, PADIAL (1980) encontrou uma razão sexual de 0,41, dado este confirmado por LESCHE (1984).

PADIAL' (1980) considerou pequena a influência do alimento ingerido pelas lagartas sobre a razão sexual, registrando valores de 0,56 em capim quicuio, 0,50 em milho e 0,41 em trigo.

\subsubsection{PESO DE PUPAS}

O peso de pupas foi afetado significativa mente pelos tratamentos (Tabela 15). O resultado reforça as citações de PADIAL (1980) para $P_{\text {. }}$ sequax e de TERRA e ZERBINO (1983a) para $P$. adultera, quanto ao efeito da alimentação das lagartas sobre o peso de pupas. Entretanto, PADIAL (1980) não considerou o peso pupal como indicativo de adequação da dieta; comparando, nesse sentido, capim quicuio (onde as pupas foram mais pesadas), triǵo e milho, concluiu pela melhor adaptação da espécie a esse último, baseado na maior velocidade de desenvolvimento e na menor ocorrência đe înstares adicionais nas lagartas. Da mesma forma, TERRA e ZERBINO (1983a), comparando dois alimentos naturais, verificaram que o mais adequado do ponto de vis ta da duração e da viabilidade de fases imaturas de $P$. adultera, proporcionou um menor pesó de pupas.

No presente experimento verificou-se que, tanto nos machos como nas fêmeas, o peso de pupas foi maior na dieta. $K$ (média de $0,62 \mathrm{~g}$ ) (Tabela 15). As dietas $A$ e $N$, igualaram-se quanto a este parâmetro (média de $0,58 \mathrm{~g}$ ), supe rando o trigo (média de $0,50 \mathrm{~g}$ ). Em todas as dietas o peso 
de pupas foi maior nas fêmeas em relação aos machos, embora. a diferença não tenha sido testada estatisticamente.

O peso das pupas oriundas do trigo, foi maior que os encontrados para a mesma espécie por PADIAL (7980) $(0,45 \mathrm{~g})$ e LESCHE $(\$ 984)$, que registrou $0,34 \mathrm{~g}$ para fê meas e $0,32 \mathrm{~g}$ para machos.

Tabela 15 - Razão sexual e peso de pup̣as de Pseudaletia sequax Franc. 1951; submetida a diferentes dietas no período larval (temperatura: $25 \pm 2^{\circ} \mathrm{C}$; UR: $60 \pm 10 \%$; fotofase: $\left.14 \mathrm{~h}\right)^{2}$.

\begin{tabular}{|c|c|c|c|c|}
\hline \multirow{2}{*}{ Dieta } & \multirow{2}{*}{$\begin{array}{l}\text { Razão } \\
\text { sexual }^{2}\end{array}$} & \multicolumn{3}{|c|}{ Peso de pupas (g) } \\
\hline & & Fêmea & Macho & Média \\
\hline$A$ & $0,46 \mathrm{a}$ & $0,60 \quad b$ & $0,56 \mathrm{~b}$ & $0,58 \quad b$ \\
\hline $\mathrm{K}$ & $0,51 \mathrm{a}$ & $0,64 a$ & $0,59 a$ & $0,62 \mathrm{a}$ \\
\hline $\mathrm{N}$ & $0,47 \mathrm{a}$ & $0,59 \quad b$ & $0,57 \quad b$ & $0,58 \quad \mathrm{~b}$ \\
\hline Trigo & $0,54 \mathrm{a}$ & 0,51 & 0,49 & $0,50 \quad c$ \\
\hline CVo & 22,08 & 3,78 & 13,19 & 2,38 \\
\hline $\begin{array}{l}\text { Niv. Sig- } \\
\text { nif. (F) \% }\end{array}$ & 32,58 & $<0,01$ & $<0,01$ & $<0,01$ \\
\hline
\end{tabular}

${ }^{2}$ Para cada parâmetro, médias seguidas da mesma letra não diferem estatisticamente entre si (Tukey, 5\%).

$2 \frac{q}{q+0^{\circ}}$ 


\subsubsection{ADULTO}

Os resultados sobre longevidade, periodos de pré-oviposição e de oviposição e capacidade de postura das fêmeas são apresentados na Tabela 16, para os insetos alimentados na fase larval com as dietas $A, K, N$ e trigo. A Figura 5 condensa os dados de longevidade, prê-oviposição e oviposição com os de duração das fases de desenvolvimento. Para a comparação das dietas, agruparam-se os casais mantidos a $25 \pm 2{ }^{\circ} \mathrm{C}$ e a $28 \pm 2{ }^{\circ} \mathrm{C}$, uma vez que não houve diferença estatística entre as dietas, dentro de cada condição de temperatura.

Todos os parâmetros relativos à fase àdulta foram bastante variáveis, conforme atestam os respec tivos coeficientes de variação (C.V.\%). Isto tem sido observado para outras espécies de Pseudaletia, e foi constatado por PEREIRA (1978) para P.: sequax.

\section{- Longevidade}

Tanto considerada separadamente para cada sexo, como em conjunto, verificou-se que a longevidade não foi afetada pelo alimento consumido pelas lagartas. Si tuação semelhante já havia sido relatada, para o caso de alimentos naturais, em $P_{\text {. }}$ sequax (PADIAL, 1980) e em $P$. adultera (TERRA e ZERBINO, 1983a). No entanto, em termos de longevidade, mais importante que a alimentação da fase la val é o alimento do próprio adulto, conforme estabeleceram GUPPY (1961) para P. unipuncta e TERRA e ZERBINO (1983a), para $P$. adultera.

No trigo, a longevidade foi de 15,6 dias para fêmeas e 18,1 dias para machos, inferior à encontrada em capim quicilo por PEREIRA (1978), que foi de 26 : a 22 dias para fêmeas e machos, pela ordem. Foi superior, porém, à longevidade verificada em trigo por LESCHE (1984), 


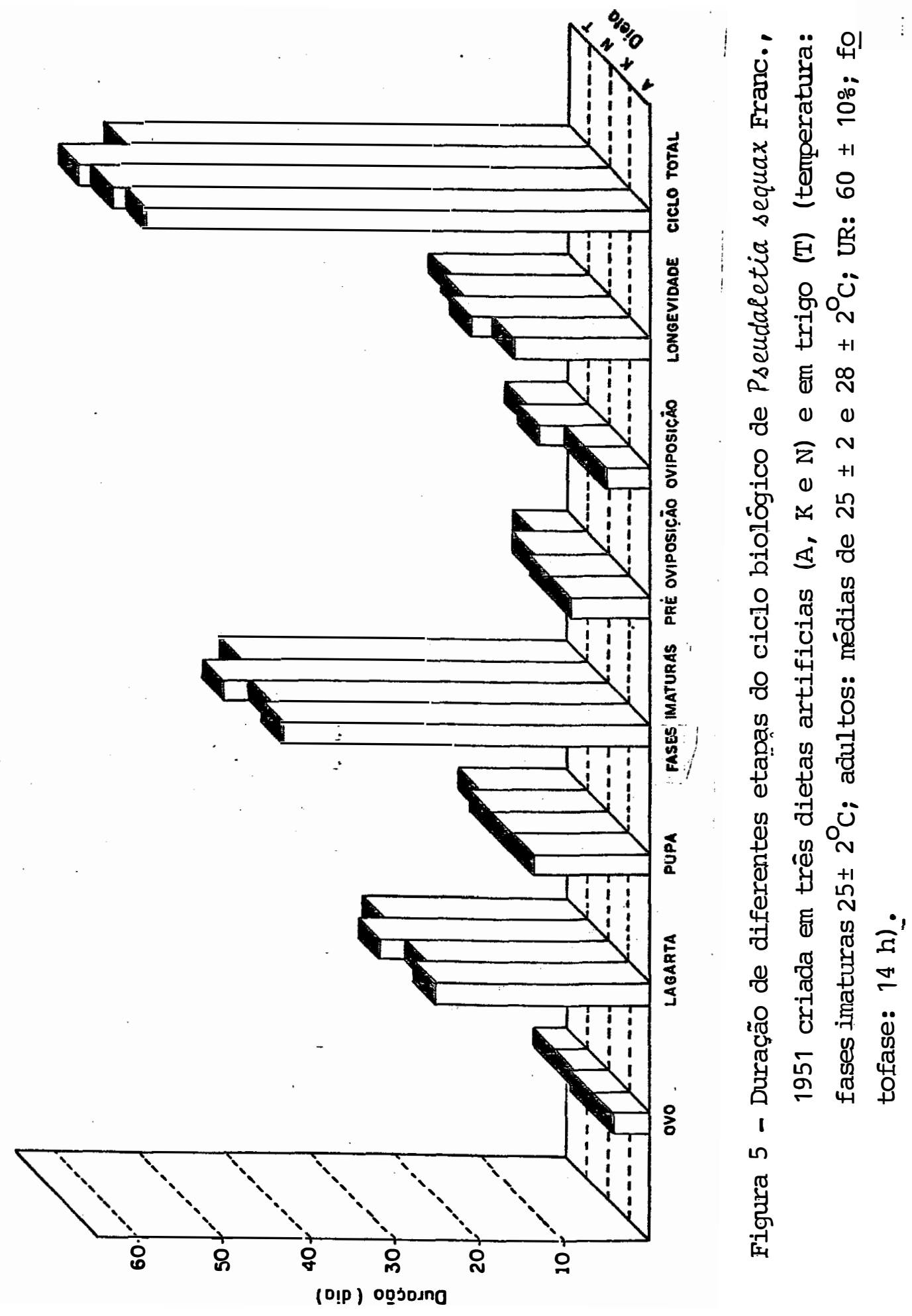


qual foi de 13,1 e 12,5 dias, para fêmeas e machos, respec tivamente. A longevidade média, independente do sexo, foi de 16,6 dias, cerca de 4 dias maior que a citada por PADIAL (1980).

Em todos os substratos alimentares a lon gevidade variou expressivamente. Nas fêmeas flutuou de 6 a 22 dias, e nos machos de 8 a 28 dias. Uma grande variação deste parāmetro também foi mencionada por PEREIRA (1978) para P. sequax, ELmSHERIF (1972) para Leucanialoreyi Dup. e BINDRA e SINGH (1975), para Mythimna separata (Wlk.). O mesmo pode ser inferido para $P$. unipuncta, através da análise dos dados de BREELAND (1958) e POND (1960).

Embora não tenha sido comparada estatisticamente, observou-se a tendência da longevidade dos machos ser superior à das fêmeas, em todos os alimentos testados. Tomando-se a mêđia destes, a longevidade foi de 19,5 e 15,5 dias, para machos e fêmeas, respectivamente. PADIAL (1980) não encontrou diferença significativa entre a Lonqevidade de machos e fêmeas de P. sequax. 0 mesmo fato foi relatado por TERRA e ZERBINO (1983a), para $P$. a du $\ell$ tera. Para $P$. unipuncta, os resultados são contraditórios, pois SREEIARD, (1958) e POND (1960) constataram uma maior longevidade das fêmeas, enquanto que GUPPY (1961) verificou o oposto. SINGH e RAI (1977) registraram que à fêmeas de $M$. separata têm vida mais longa do que os machos. 


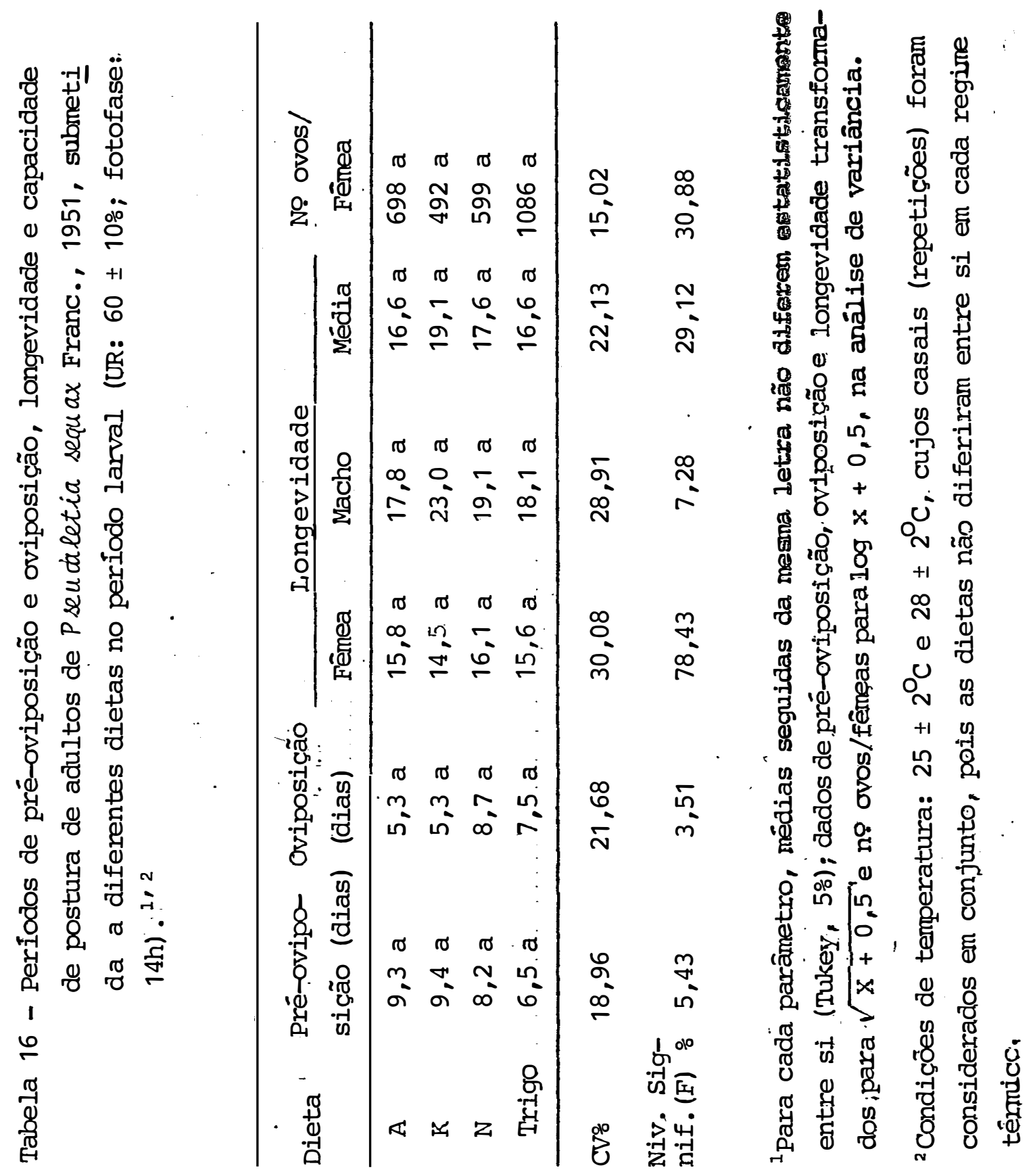




\section{- Períodos de pré-oviposição e oviposi- ção}

Assim como ocorreu com a longevidade das fêmeas, os períodos de pré-oviposição e de oviposição não foram afetados pelo alimento ingerido na fase larval, (Tabela 16). As dietas artificiais $A, K$ e $N$ mostrar?m-se comparâveis à dieta natural, em relação a estes parâmetros.

O valor encontrado, nos insetos criados no.trigo, para o período de pré-oviposição $(6,5$ dias) é superior aos obtidos por PADIAL (1980) (3 dias) e LESCHE (1984) (3,5 dias). Quanto ao período de oviposição $(7,5$ dias), o resultado foi semelhante aos encontrados por PADIAL (1980) (8 dias) e por LESCHE (1984) (7,1 dias). No entanto, ambos são inferiores àqueles constatados por PEREI RA (1978) que foram de, aproximadamente, 14 dias para $\circ$ perỉodo de pré-ơviposição. e 10 dias, pará o de oviposição.

Em todos os alimentos, a variação destes parâmetros foi expressiva. Em geral, independentemente da dieta, o período de pré-oviposição variou de,3 a 15 dias, e o de oviposição de 3 a 16 dias. Grande variação in dividual quanto a estes parâmetros, já fora observada por PEREIRA (1978) e, para P. unipuncta, por GUPPY (1961). POND

(1960), verificou que o período de pré-oviposição de $P$. unipuncta pode situar-se entre 1 e 15 dias.

\section{- Capacidade de postura}

Não se apurou diferença estatisticamente significativa entre o nûmero de ovos colocados por fêmeas oriundas das dietas $A, K, N$ e trigo. Este resultado está de acordo por PADIAL (1980). Faz-se necessário ressaltar, no entanto, a grande variação individual que existiu quan- 
to a este parâmetro $(\mathrm{CV}=62,85 \%$, sem transformação ' dos dados), o que pode ter contribuido para a não rejeição da hipótese de nulidade para estes tratamentos.. A variação na capacidade de postura/fêmea foi de 149 a 2687 ovos no trigo (média = 1086 ovos), de 107 a 1415 ovos na dieta A (média = 698 ovos), de 55 a 1347 ovos na dieta $\mathrm{N}$ (média = 599 ovos) e de 129 a 985 ovos na dieta $\mathrm{K}$ (média = 492 ovos).

Uma grande variação na capacidade de pos tura individual de $P$. sequax, foi registrada na literatura.' PEREIRA (1978), para insetos criados en capim quicuio, encontrou uma média de aproximadamente 872 ovos/fêmea, variando de 83 a 2231 ovos.

Para insetos criados en milho e en trigo, PADIAL (1980) referiu uma variação de 5 a 2535 ovos/fêmea, com uma média de aproximadamente 1139 ovos en milho e 1248 ovos, em trigo. Una capacidade de postura de 564 ovos/fêmea crịada en trigo, foi citada por IESCHE (1984), sem referir-se à existência de variação. 0 : fato também foi mencionado para outras espécies de Pseudaletia (POND, 1960; ALAM, 1961; GUPPY, 1961; TERRA e ZERBINO, 1983a e ETCHECIURY et alii, 1985) e para L. Loneyi (ELSHERTF, 1972).

Foi observado ainda, que independente do alimento fornecido na fase larval, muitas fêmeas mor reram com ovas no abdome, sem manifestarem seu potencial pleno de oviposição. A esse respeito, PADIAL (1980) observou que as fêmeas de $P$.: sequax criadas em trigo a $25^{\circ} \mathrm{C}$, retiveram cerca de $7,5 \%$ dos ovos que poderiam colocar. POND (1960) observou que em $P$. unipuncta, não ocorreu . acasalia mento quando a temperatura mêdia foi de $17^{\circ} \mathrm{C} e$, embora alguma movimentação e atividade alimentar tenham ocorrido, o corpo das fêmeas apresentou-se distendido com ovos, os quais não foram colocados. No presente estudo constatou-se que pelo menos $47 \%$ das fêmeas morreram com quantidade variável de ovos no abdome. 
De 64 casais observados, verificou-se - que $14 \%$ dos mesmos não conseguiram separar-se após a cópula per manecendo; em geral, acoplados até a morte. Este fenômeno foi relatado em $P$. unipuncta por CALLAHAN e CHAPIN (1960)-e GUPPY (1961) .

\subsubsection{DEFORMAÇÃO DE PUPAS E ADULTOS}

A mal formação de pupas e adultos é um parâmetro morfológico que pode ser utilizado para avalia ção de dietas, pois podelı decorrer de deficiência ou inade quação nutricional.

No presente experimento, embora cs dados não tenham sido analisados estatisticamente, verificou - se uma maior deformação em pupas e adultos provenientes do trigo, em relação às dietas artificiais (Tabela 17) .

Na dieta $K$ não foram registradas deforma ções, e na dieta. $\AA$, estas ocorreram empnoporção bastante baixar atingindo $2 \%$ na's pupas e 1\% nos adultos. Nas dietas artifi ciais o maior grau de deformação foi constatado na $\mathrm{N}$, com 7\% de deformação pupal.

\subsubsection{CONTAMINAČ̃O DAS DIETAS ARTIFICIAIS POR MI- CRORGANISMOS}

Em termos gerais a contaminação das dietas $A, K$ e $N$ pode ser considerada inexpressiva (Tabela 17). Apenas a dieta $\mathrm{N}$ foi contaminada nor fungos, em 2\% dos tubos observados. 
Tabela 17 - Deformação de pupas e adultos de Pseudaletia sequax Franc. 1951, sutmetida a diferentes dietas no período larval e contaminação das dietas axtificiais por microrganismos (tem

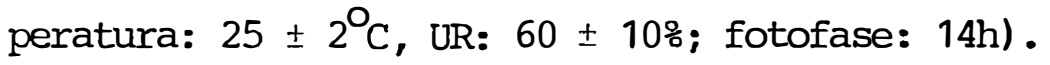

\begin{tabular}{lccc}
\hline \multirow{2}{*}{ Dieta } & \multicolumn{2}{c}{ Deformação $(\%)$} & Contaminação $(\%)^{2}$ \\
\cline { 2 - 3 } & Pupas & Adultos & \\
\hline A & 2 & 1 & 0 \\
K & 0 & 0 & 0 \\
N & 7 & 0 & 2 \\
Trigo & 12 & 4 & - \\
\hline
\end{tabular}

1 Fungos

\subsubsection{TABELAS DE VIDA DE FERTILIDADE}

Os dados de fertilidade, duração e sobre vivência de $P$. sequax nas dietas $A, K, N$ e trigo foram con densados através de tabelas de vida de fertilidade (Tabela 18) .

A duração média de uma geração $(T)$, ou seja, o perĩodo de tempo entre o nascimento dos pais e o de seus descendentes, foi menor no trigo (52,5 dias). Nas dietas artificiais, este periodo aumentou para 56,$1 ; 57,9$ e 59,3 dias nas dietas $K, A$ e $N$, pela ordem.

A capacidade de aumento populacional da espécie a cada geração, estimada atravês da taxa "Iíquida de reprodução (Ro), foi maior no trigo. Comparando-se, porêm, as três dietas artificiais, constatou-se que a dieta $\mathrm{N}$ proporcionou a menor taxa líquida de reprodução, enquan- 
to que o valor desta nas dietas $\mathrm{A}$ e $\mathrm{K}$ foi relativamente mais próximo ao verificado no trigo. Ainda quanto a este parâmetro, registrou-se uma pequena superioridade da dieta $\mathrm{K}$, em relação a dieta A. Os dados demonstraram que após uma geração, a população de fêmeas aumentou 346,$84 ; 310,20 ; 282,63$ e 54,14 vezes nas dietas: trigo, $K, A$ e $N$, respectivamente.

A razão finita de aumento $(\lambda)$ foi maior no trigo, em comparação com as dietas artificiais. Entre estas, a dieta $\mathrm{K}$ foi a que proporcionou valores de $\lambda$ mais - próximos aos verificados no trigo, seguida pelas dietas A e $N$, na ordem decrescente. Uma melhor visualização destas diferenças pode ser obtida estimando-se o número de indiví duos que as fêmeas criadas nas diferentes dietas, podem adicionar à população, num mesmo período de tempo. Isto é possivel, elevando-se a razão finita de aumento a um expoen te dado por: um período de tempo $(t)$ qualquer $\left(\lambda^{t}\right)$.

Assim, lançando-se mão do artifício de elevar os valores de $\lambda$ ao expoente 41,3 dias, período no qual uma fêmea criada em trigo adicionaria a população 100 indivíduos fêmeas, verificou-se que, por sua 'vez, as fêmeas provenientes das dietas $\mathrm{A}, \mathrm{K}$ e $\mathrm{N}$ poderiam acrescentar 56,68 e 16 individuos, respectivamete. 
Tabela 18 - Taxa líquida de reprodução (Ro), duração média de cada geração (T), capacidade inata de aumentar em número (rm) e razão finita de aumento $(\lambda)$ de Pseudaletia sequax Franc., 1951, em diferentes dietas (temperatura: fases imaturas $25 \pm 2^{\circ} \mathrm{C}$, adultos - médias de $25 \pm 2{ }^{\circ} \mathrm{C}$ e $28 \pm 20^{\circ} \mathrm{C}$; UR: $60 \pm 10 \%$; fotofase: $14 \mathrm{~h})$.

\begin{tabular}{lrccc}
\hline Dieta & Ro & T (dias) & rm & $\lambda$ \\
\hline A & 282,63 & 57,9 & 0,097481 & 1,10239 \\
K & 310,20 & 56,1 & 0,102268 & 1,10768 \\
N & 54,14 & 59,3 & 0,067314 & 1,06963 \\
Trigo & 346,84 & 52,5 & 0,111409 & 1,11785 \\
\hline
\end{tabular}

\subsection{EfEITO DA temperatura NA Biologia E EXIGÊnCias tÉr MICAS DE $P$. s sequax}

\subsubsection{SOBREVIVENCIA DAS FASES IMATURAS}

Os resultados obtidos para as fases de ovo, lagarta e pupa de $P$. sequax, submetidas a temperaturas de $18,20,22,26,30$ e $32^{\circ} \mathrm{C}$, são apresentados na Tabe la 19. Estesrevelaram que a temperatura afetou a sobrevivência dos insetos em todas as suas fases imaturas.

A temperatura de $32^{\circ} \mathrm{C}$ foi letal para to dos os embriões, enquanto que a $18^{\circ} \mathrm{C}$ a sobrevivência destes foi de apenas 12\%. Este resultado concorda, em parte, com o de POND (1960), o qual constatou o efeito letal da temperatura média de $17^{\circ} \mathrm{C}$, sobre ovos de $P$. unipuncta. Nas demais temperaturas, não houve diferença em termos de viabị lidade do período embrionário; a 20 e a $22^{\circ} \mathrm{C}$ a sobrevivência dos ovos foi de 88 e 90\%, respectivamente; tanto a 26 como a $30^{\circ} \mathrm{C}$, a sobrevivência dos ovos foi de $96 \%$ 
Tabela 19 - Sobrevivência (\%) das fases imaturas de Pseuda letia sequax

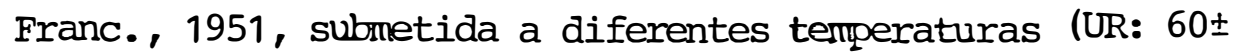
10\%; fotofase: $14 \mathrm{~h})^{2}$.

\begin{tabular}{|c|c|c|c|c|c|}
\hline $\begin{array}{l}\text { Terperatura } \\
\left(O^{\circ}\right)\end{array}$ & Ovo. & 19 Instar & Lagarta & Pupa & Total \\
\hline 18 & $12 \mathrm{~b}$ & 91 & $78 \mathrm{ab}$ & $71 \mathrm{ab}$ & 6 \\
\hline 20 & $88 \mathrm{a}$ & 87 & $72 \mathrm{~b}$ & . $60 \mathrm{ab}$ & 38 \\
\hline 22 & $90 \mathrm{a}$ & 87 & $58 \mathrm{~b}$ & $48 \quad b$ & 25 \\
\hline 26 & $96 a$ & 100 & $93 a$ & $95 \mathrm{a}$ & 85 \\
\hline 30 & $96 a$ & 84 & $50 \quad b$ & $34 \mathrm{~b}$ & 16 \\
\hline 32 & $0 \mathrm{~b}$ & 89 & $0 \quad \mathrm{C}$ & - & - \\
\hline$C V 8$ & 47,04 & - & 20,05 & 32,07 & - \\
\hline $\begin{array}{l}\text { Niv. Sig- } \\
\text { nif. (F) } \%\end{array}$ & $<0,01$ & - & $<0,01$ & 0,13 & - \\
\hline
\end{tabular}

${ }^{2}$ Para cada parânètro, as médias seguidas da mesina letra não diferem es tatisticamente entre si (Tukey, 5\%); dados transformados para arco seno $\sqrt{\mathrm{x} / 100}$ na análise da variância.

${ }^{2}$ A sobrevivência dos ovos foi determinada com material de outra geração.

A sobrevivência no 19 instar larval foi bastante grande em todas as temperaturas, tendo atingido valor mais elevado $(100 \%)$ a $26^{\circ} \mathrm{C}$. Nas demais temperaturas esteve entre 84 e $91 \%$.

Em relação a todo o período larval a sobrevivência foi maior a $26^{\circ} \mathrm{C}$, em oposição a $32^{\circ} \mathrm{C}$ onde a mortalidade foi total. Nas demais temperaturas, a sobrevivência atingiu valores intermediârios, variando de 50 a 78\%. Em linhas gerais, este resultado não está de acordo com PADIAL $(1980)$ que, a $25^{\circ} \mathrm{C}$, observou uma sobrevivência larval de $70 \%$, e não constatou diferença entre 20 e $25^{\circ} \mathrm{C}$. 
Por outro lado, está de acordo com o resultado encontrado por GUPPY (1961), que registrou alta mortalidade larval a $29^{\circ} \mathrm{C}$ e efeito letal da temperatura de $31^{\circ} \mathrm{C}$ para as lagartas de $P$. unipuncta.

Assim como no período larval, foi possivel constatar que a máxima sobrevivência de pupas ocorreu a $26^{\circ} \mathrm{C}$, atingindo 95\%. Os resultados pertinentes ao periodo pupal, não confirmam os obtidos por PADIAL (1980). Este autor constatou uma sobrevivência pupal de $100 \%$ a $20^{\circ} \mathrm{C}$ e de aproximadamente $90 \%$ a $25^{\circ} \mathrm{C}$.

Analisando-se os resultados de :sobrevivência em toda a fase imatura (Tabela 19), cons tatou-se que a melhor temperatura para $P$. sequax, em termos de sobrevivência, foi a de $26^{\circ} \mathrm{C}$. Nesta temperatura, 85\% dos ovos deram origem a indivíduos adultos.

\subsubsection{DURAÇÃO DO DESENVOLVIMENTO}

1 Os dados referentes ao efeito de cinco temperaturas $\left(18,20,22,26\right.$ e $\left.30^{\circ} \mathrm{C}\right)$ na duração das fases imaturas de $P$. sequax, são apresentados na Tabela 20. Grafi camente, estes dados estão representados na Figura 6, em termos de tempo e taxa de desenvolvimento de ovos, lagartas, pupas e ciclo total: (ovo-emergência do adulto), em função da temperatura. Constatou-se que a duração das fases imaturas do inseto foi afetada significativamente pela temperatura, decrescendo com o aumento desta. A velocidade de desenvolvimento em função da temperatura, ajustou-se ao modelo linear obtido através da recíproca da equação : da hipérbole (Tabela 21). 
Tabela 20 - Duração (dias) das fases imaturas de Pseudaletia sequax Franc., 1951, suhnetida a diferentes temperaturas. (UR: $60 \pm 10 \%$; fotofase: $14 \mathrm{~h})^{2}$.

\begin{tabular}{|c|c|c|c|c|}
\hline $\begin{array}{c}\text { Termeratura } \\
\left({ }^{\circ} \mathrm{C}\right)\end{array}$ & Ovo & Iagarta & Pupa & Total \\
\hline 18 & - & $61,8 \mathrm{a}$ & $31,7 \mathrm{a}$ & - \\
\hline 20 & $7,1 \mathrm{a}$ & $42,0 \quad b$ & $23,6 \mathrm{ab}$ & $72,7 \mathrm{a}$ \\
\hline 22 & $6,4 \quad b$ & $39,4 \quad b$ & $19,8 \quad b$ & $65,6 a$ \\
\hline 26 & $4,3 \quad c$ & $27,1 \quad c$ & $13,5 \quad c$ & $44,9 \quad b$ \\
\hline 30 & $4,0 \quad c$ & $25,1 \quad c$ & $10,2 \quad c$ & $39,2 \quad b$ \\
\hline $\mathrm{CV}$ \% & 8,76 & 8,25 & 7,12 & 7,97 \\
\hline $\begin{array}{l}\text { Niv. Sig- } \\
\text { nif. (F) } \%\end{array}$ & $<0,01$ & $<0,01$ & $<0,01$ & $<0,01$ \\
\hline
\end{tabular}

${ }^{1}$ Para cada parâmetro, médias seguidas da mesma letra não diferem estatisticamente entre si (Tukey, 5\%). 

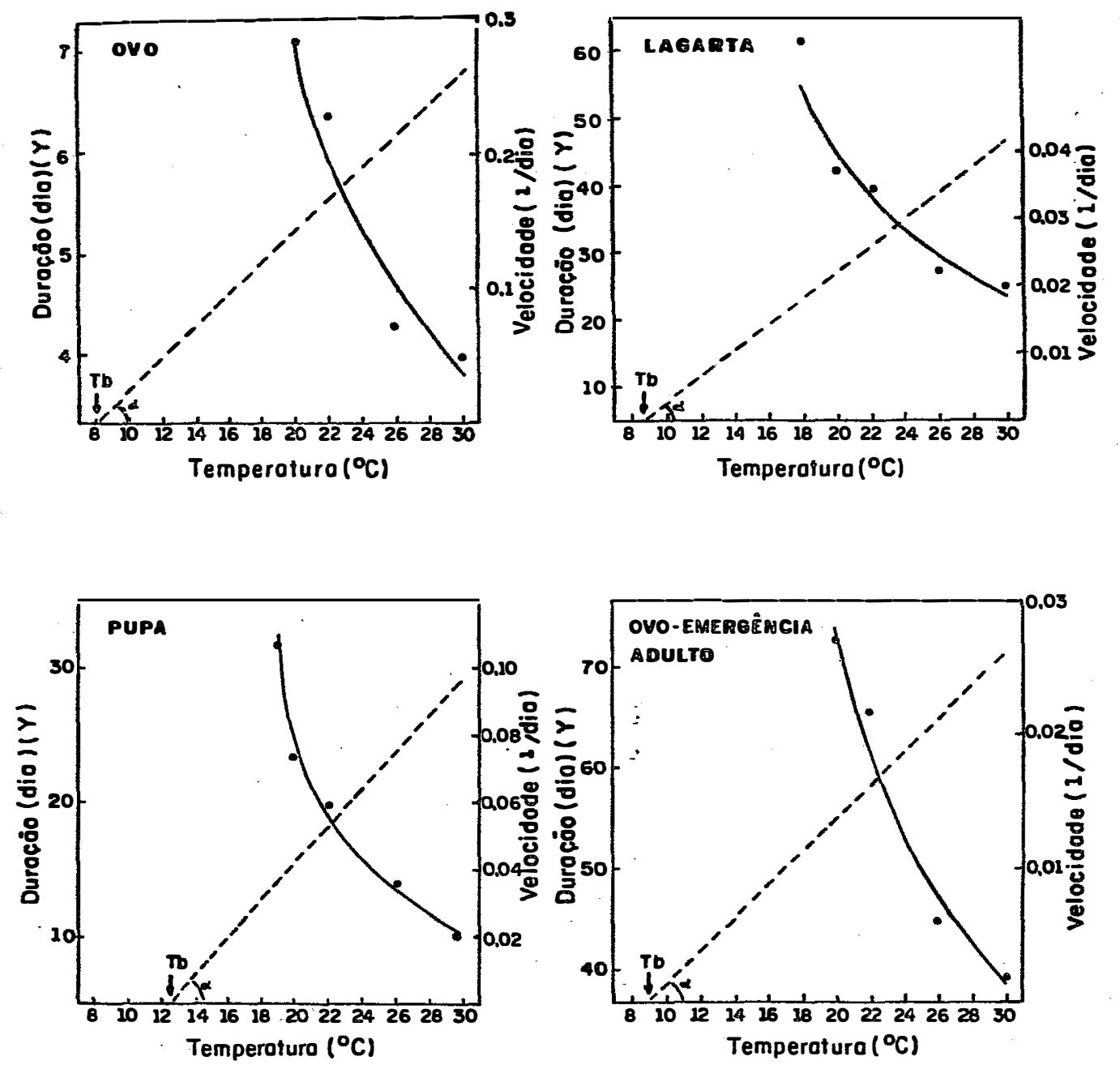

Figura 6 - Reliação da termeratura com a duração $(\stackrel{-}{\longrightarrow}$ e com a velocidade de deșenvolvimento (- - ) de diferentes fases do ciclo biológico de Pseudaletia sequax Franc., 1951 (UR: 60 $\pm 10 \%$; fotofase: $14 \mathrm{~h})$. 
Tabela 21 - Temperatura base (Tb), constante tērmica (K), equação da velocidade do desenvolvimento (1/D) e respectivo coeficiente de determinação $\left(R^{2}\right)$ para as fases imaturas de Pseudaletia sequax Franc., :1951, criada em dieta artificial.

\begin{tabular}{lrrccc}
\hline Fases & $\ldots \mathrm{Tb}\left({ }^{\circ} \mathrm{C}\right)$ & $\mathrm{K}(\mathrm{GD})$ & Equação $^{2}$ & $\mathrm{R}^{2}(\circ)$ \\
\hline Ovo & 8,1 & 84,4 & $1 / \mathrm{D}=-0,0955182+0,0118544 \mathrm{~T}$ & 93,5 \\
Larva & 8,8 & 505,9 & $1 / \mathrm{D}=-0,0174398+0,0119768 \mathrm{~T}$ & 94,8 \\
Pupa & 12,5 & 180,6 & $1 / \mathrm{D}=-0,0691531+0,0055371 \mathrm{~T}$ & 99,7 \\
\hline Total & 9,1 & 804,4 & $1 / \mathrm{D}=-0,0112792+0,0012432 \mathrm{~T}$ & 97,3 \\
\hline
\end{tabular}

${ }^{2} \mathrm{D}=$ duração (dias) $; \mathrm{T}=$ temperatura $\left({ }^{\mathrm{O}} \mathrm{C}\right)$.

O período de incubação decresceu com 0 aưmento de temperatura na fáixa de 20 a $30^{\circ} \mathrm{C}$, atingindo 0 valor de 7,1 e 4,0 dias, respectivamente. Entretanto, a di ferença entre os dados encontrados a 26 e $30^{\circ} \mathrm{C}$, não foi significativa. Esta mesma tendência foi observada para $P$. unipuncta na faixa de 10 a $29^{\circ} \mathrm{C}$ (GUPPY, 1969) e para M. se parata, na faixa de 15 a $30^{\circ} \mathrm{C}$ (SINCHAISRI e SÓGAWA, 1969).

A duração da fase larval decresceu com o incremento da temperatura, variando de 61,8 dias $\left(18^{\circ} \mathrm{C}\right)$ a $25,1\left(30^{\circ} \mathrm{C}\right)$. A 20 e a $22^{\circ} \mathrm{C}$, o periodo larval foi estatisti camente igual, atingindo 42,0 e 39,4 dias, respectivamente. O desenvolvimento mais ránido ocorreu nas temperaturas de $26^{\circ} \mathrm{C}(27,1$ dias $)$ e $30^{\circ} \mathrm{C}(25,1$ dias $)$, as quais não diferiram estatisticamente entre si. O efeito da temperatu ra na duração do período pupal seguiu, praticamente, o mes mo padrão verificado para o período larval.

Uma relação inversa entre temperatura e a duração do período de desenvolvimento de $P$. sequax tam- 
bém foi constatada por PADIAL (1980); este autor encon trou um periodo larval em torno de 24 dias a $25^{\circ} \mathrm{C}$, e de 27 dias a $20^{\circ} \mathrm{C}$ e um periodo pupal de aproximadamente, 13 e 15 dias, em ambas as temperaturas, respectivamente. Re lação semelhante também foi registrada para o período pupal de M.: separata (SINCHAISRI e SÕGAWA, 1969) e $P$. unipuncta (GUPPY, 1969), e para o período larval desta última (BREELAND, 1958 e POND, 1960). EL-SHERIF (1972) e HIRAI (1975) citaram que a duração do desenvolvimento de $L$ loreyi, variou inversamente com a temperatura.

Considerando-se o tempo necessário para que os insetos atinjam a fase adulta, observou-se que 0 mesmo decresceu com o aumento da temperatura (de 20 a $30^{\circ} \mathrm{C}$ ). As temperaturas de 20 e $22^{\circ} \mathrm{C}$ porém, não diferiram entre. si, ocorrendo o mesmo para as temperaturas de 26 e $30^{\circ} \mathrm{C}$.

Através destes resultados, constatou-se que a duração do ciclo de $P$. sequax variou com a temperatura e, por consecuinte, deve variar com a reaião e com a época do ano. Isto faz com que a temperatura possa ter importante papel em termos do número de gerações anuaiss des ta espécie. Na América do Norte, já foi demonstrado este tipo de influência para $P$ : unipuncta (BREELAND,-1958; CALLAGHAN e CHAPIN, 1960; GUPPY, 1961 e MCLAUGLHLIN, 1962).

Através dos resultados obtidos sobre 0 efeito da temperatura na duração do desenvolvimento de $P$. sequax, foram estimadas a temperatura base (Tb) e a constante térmica $(K)$ para ovos, lacartas, punas e para o ciclo total (ovo-emergência do adulto) (Tabela 21 e Figura 6). 
micas são diferentes para cada fase do desenvolvimento: no entanto, a Tb para as fases de ovo e lagarta foram bastante próximas. Os valores de $\mathrm{Tb}\left({ }^{\circ} \mathrm{C}\right)$ diferem ligeiramente dos citados por SINCHAISRI \& SOIGAWA (1969) para M. separata, en quanto que os de $K$ (GD) diferem mais acentuadamente em relação aos citados por estes autores. O fato pode ser consi derado normal, pois são dados obtidos para espécies e regiões diferentes.

Os resultados encontrados, quanto aos limiares térmicos inferiores de $P$. sequax e graus dias necessários para completar o seu desenvolvimento, podem ser utilizados na estimativa do número de gerações anuais e na elaboração de modelos de previsão de ocorrência da espécie, bem como no płanejamènto de criações de laburatório.

\subsubsection{PESO DE PUPAS}

Como pode ser observado na Tabela 24 , o peso de pupasfoi afetado significativamente pela temperatu ra. O maior peso de pupas foi registrado a $26^{\circ} \mathrm{C}$, com $0,57 \mathrm{~g}$. Nas demais temperaturas o valor variou de 0,46 a $0,50 \mathrm{~g}$, sem diferirem estatisticamente entre si.

Este resultado está coerente com o relatado por PADIAL (1980), que também constatou o efeito da temperatura neste parâmetro, que foi maior a $25^{\circ} \mathrm{C}$ do que a $20^{\circ} \mathrm{C}$.

\subsubsection{ADULTO}

Os dados de longevidade de adultos $P$. sequax, sem alimentação, submetidos às diferentes tempe 
peraturas são apresentados na Tabela 22. Devido à insuficiência de dados para considerar fêmeas e machos separadamente, a análise de variāncia foi aplicada sobre a longevi dade média total.

A longevidade decresceu com o aumento da temperatura, sendo maior a 18 e $20^{\circ} \mathrm{C}$, e menor a 26 e $30^{\circ} \mathrm{C}$. A variação da longevidade pella temperatura, ajustou ao modelo linear da equação de primeiro grau (Figura 7).

Tabela 22:-Longevidade (dia) de Pseudaletia sequax Franc., 1951 , submetida a diferentes temperaturas constantes desde a fase larval e não alimentada na fase adulta (UR: $60 \pm 10 \%$; fotofase: $14 \mathrm{~h})$.

\begin{tabular}{|c|c|c|c|}
\hline $\begin{array}{l}\text { Temperatura } \\
\left({ }^{\circ} \mathrm{C}\right)\end{array}$ & Fêmea ${ }^{2}$ & Macho ${ }^{2}$ & Média ${ }^{2}$ \\
\hline 18 & 12,9 & 16,4 & $14,9 \mathrm{a}$ \\
\hline 20 & 11,9 & 15,2 & $13,8 \mathrm{a}$ \\
\hline 22 & 13,6 & 9,3 & $12,0 \mathrm{ab}$ \\
\hline 26 & 5,8 & 4,6 & $5,2 \mathrm{~b}$ \\
\hline 30. & 3,0 & $5,5$. & $\ldots 4,7 \mathrm{~b}$ \\
\hline CV\% & - & - & 43,50 \\
\hline $\begin{array}{l}\text { Niv. Sig- } \\
\text { nif. }(F) \%\end{array}$ & - & - & $<0,01$ \\
\hline
\end{tabular}

${ }^{1}$ Não submetido à anâlise de variância por insuficiência de dados.

${ }^{2}$ Médias seguidas da mesma letra não diferem estatisticamente entre si (Tukey, 5\%) . 


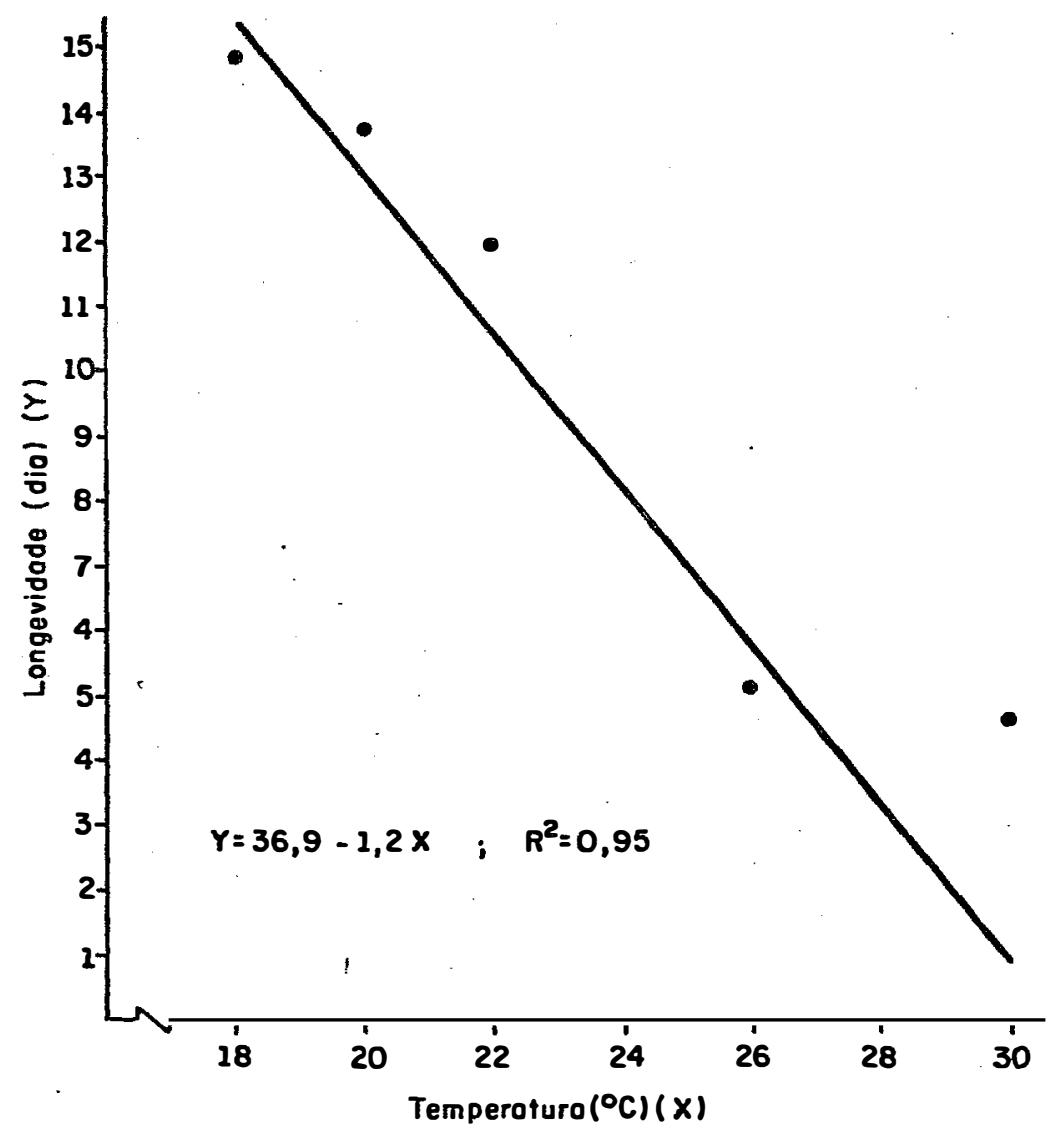

Figura 7 - Relação entre temperatura e longevidade (média de machos e fêmeas) de Pseudaletia sequax Franc., 1951 (UR: 60 $\pm 10 \%$; fo tofase: $14 \mathrm{~h}$ ). 
Na Tabela 23, são apresentados os resultados relativos aos períodos de pré-oviposição, longevidade e capacidade de postura de insetos adultos mantidos em duas condições de temperatura $\left(25 \pm 2{ }^{\circ} \mathrm{C}\right.$ e $\left.28 \pm 2{ }^{\circ} \mathrm{C}\right)$, e que foram alimentados com solução de mel a $10 \%$.

Todos estes parâmetros relativos à fase adulta foram afetados pela temperatura; apresentando maiores valores à $25 \pm 2{ }^{\circ} \mathrm{C}$ do que a $28 \pm 2{ }^{\circ} \mathrm{C}$. As diferenças fo ram estatisticamente significativas (5\% de probabilidade), apenas para o período de pré-oviposição, longevidade das fêmeas e da média de fêmeas e machos, e número de ovos por fêmea. No entanto a diferença em termos do período de oviposição e da longevidade dos nachositambémi foram significatị vas ao nível de $10 \%$ de probabilidade.

Os dados revelam que o aumento da temperatura diminuiu a longevidade e o período de pré-oviposição. Provavelmente, houve uma aceleração das reacões orgânicas das mariposas e/ou um maior gasto de energia através de mecanismos termoreguladores. Ficou claro o efeito negativo da alta temperatura sobre a capacidade de postura, que foi de 731 ovos/fêmea a $25 \pm 2{ }^{\circ} \mathrm{C}$, e de 576 ovós/fêmea à $28 \pm 2{ }^{\circ} \mathrm{C}$.

Estes resultados estão de acordo com os relatos de alguns autores, em relação ao efeito da tempera tura sobre os adultos de M.: separata. SINCHAISRI e SOGAWA (1969) constataram o efeito da temperatura na Iongevidade das fêmeas e na capacidace de postura. DHALIWAL e BATNS (1978) sugeriram que o maior número de ovos colocados em temperaturas mais baixas, deveu-se ao aumento na longevidade dos insetos, que foi verificado nesta condição. 
Tabela 23 - Períodos de pré-oviposição e oviposição, longevidade e capacidade de postura de adultos de Pseuáaletia sequax Franc. 1951, alimentados com solução de mel a 10\%, em duas condições de temperaturas (UR:: $60 \pm 10 \%$; fotofase: $14 \mathrm{~h})^{2}$.

\begin{tabular}{|c|c|c|c|c|c|c|}
\hline \multirow{2}{*}{$\begin{array}{c}\text { Termperatura } \\
{ }^{\circ} \mathrm{C}\end{array}$} & \multirow{2}{*}{$\begin{array}{c}\text { Pré-oviposição } \\
\text { (dia }\end{array}$} & \multirow{2}{*}{$\begin{array}{l}\text { Oviposição } \\
\text { (dia) }\end{array}$} & \multicolumn{3}{|c|}{ Longevidade (dia) } & \multirow{2}{*}{$\begin{array}{l}\text { No ovos/ } \\
\text { Fêmea }\end{array}$} \\
\hline & & & Fêmea & Macho & Média & \\
\hline $25 \pm 2$ & $10,5 \mathrm{a}$ & $6,57 \mathrm{a}$ & $18,9 a$ & $21,3 a$ & $20,2 a$ & $731 \mathrm{a}$ \\
\hline $28 \pm 2$ & $6,9 . b$ & $5,08 \mathrm{a}$ & $13,6 \mathrm{~b}$ & $18,3 a$ & $16,1 \mathrm{~b}$ & b $576 \mathrm{~b}$ \\
\hline Vo & 34,6 & 31,79 & 24,83 & 31,34 & 19,33 & 30,60 \\
\hline $\begin{array}{l}\text { Niv. Sig- } \\
\text { nif. (F) \% }\end{array}$ & $<0,01$ & 9,03 & $<0,01$ & 7,49 & $<0,01$ & 3,77 \\
\hline
\end{tabular}

${ }^{1}$ Para cada parânetro, médias seguidas da mesma letra não diferem estatisticamente entre si (teste $F, 5 \%$ ) ; dados transformados para $\sqrt{x+0,5}$ (oviposição) e $\log x+0,5$ (nọ ovos/fêmea), na análise da variância.

A influência prejudicial da alta tempera tura nas funções vitais dos insetos, também ficou evidente nas aberrações verificadas no comportamento de oviposição. Considerando-se como tal, os casos de fêmeas que não ovipositaram ou que o fizeram em número reduzido (inferior a 50 ovos), constatou-se que a $28 \pm 2^{\circ} \mathrm{C} 21 \%$. de fêmeas apresentaram anormalidades. A $25 \pm 2{ }^{\circ} \mathrm{C}$, não houve casos de fêmeas que não ovipositaram e apenas $8 \%$ delas colocaram ovos em número considerado anormal. 


\subsubsection{DEFORMAÇÃO DE PUPAS E ADULTOS}

A ocorrência de pupas e adultos deformados, nas diferentes temperaturas em estudo é apresentada na Tabela 24. Embora não tenham sido submetidos à análise estatistica, estes parâmetros morfológicos foram influenciados pela temperatura. Em experimento anterior (Tabela 17), constatou-se que na dieta $K$, utilizada no presente teste, não ocorreram deformações em pupas e a-adultos a temperatura de $25 \pm 2{ }^{\circ} \mathrm{C}$.

A temperatura constante que propiciou as menores porcentages de deformação, foi $26^{\circ} \mathrm{C}$. No outro extremo, observou-se que a $30^{\circ} \mathrm{C}$ a deformação de pupas foi de $100 \%$ e a de adultos de 50\%. A quantidade de pupas defórma das também foi alta a 20 e $22^{\circ} \mathrm{C}$. atingindo valores de 33 e $44 \%$, respectivamente. Além disso, a $22^{\circ} \mathrm{C}$, a deformação de adultos também foi expressiva, perfazendo $20 \%$.

\subsubsection{CONTAMINACÁOO DA DIETA ARTIFICIAL POR MI CRORGANISMOS}

Quanto à contaminação da dieta (Tabela 24)., verificou-se que a mesma foi elevada nas temperaturas de 22 e $30^{\circ} \mathrm{C}$, sendo devida exclusivamente a fungos. Este fato pode ser considerado como uma das possiveis causas da baixa sobrevivência de pupas e lagartas (Tabela 19), observada nestas temperaturas. 
Tabela 24 - Peso de pupas, defonmação de pupas e adultos de Pseudalé tia sequax Franc., 1951 e contaminacão da dieta, artificial, por microrganismos em diferentes temperaturas constantes (UR: $60 \pm 10 \%$; fotofase: $14 \mathrm{~h}$ ).

\begin{tabular}{|c|c|c|c|c|}
\hline \multirow{2}{*}{$\begin{array}{c}\text { Temperaturas } \\
\qquad\left({ }^{\circ} \mathrm{C}\right)\end{array}$} & \multirow{2}{*}{$\begin{array}{l}\text { Peso de pu } \\
\text { pas }(g)^{3}\end{array}$} & \multicolumn{2}{|c|}{ Deformação (\%) } & \multirow{2}{*}{$\begin{array}{c}\text { Contaminação } \\
\left(\frac{(\%)^{2}}{}\right.\end{array}$} \\
\hline & & Pupa & Adulto & \\
\hline 18 & $0,50 \mathrm{~b}$ & 15 & 16 & 0 \\
\hline 20 & $0,50 \mathrm{~b}$ & 33 & 5 & 6 \\
\hline 22 & $0,49 \mathrm{~b}$ & 44 & 20 & 31 \\
\hline 26 & $0,57 \mathrm{a}$ & 8 & 5 & 0 \\
\hline 30 & $0,46 \mathrm{~b}$ & 100 & 50 & 39 \\
\hline 32 & - & $\because$ & $\therefore$ & 3 \\
\hline C.V. $\%$ & 7,04 & - & - & - \\
\hline Nív. signif. (F) & 0,20 & $=$ & - & - \\
\hline
\end{tabular}

1 Médias seguidas da mesma letra não diferem estatisticamente entre si (Tukey 5\%).

2 Fungos.

4.4. CONSIDERAC̣̃ES SOBRE UMA CRIACÃO MASSAL DE P. sequax

A críação massal de insetos caracterizan - se pela produção de indivíduos em quantidade suficiente e de qualidade comparável aos da natureza, dentro de uma rer lação custo/benefício aceitável, de acordo com o fim a que os insetos se destinam.

Sem dúvida, um dos princịpaìs componentes do conjunto de conhecimentos que viabilizam uma criação 
com estas caracteristicas é, na maioria das vezes, a exis tência de uma dieta artificial que substitua o alimento na tural do inseto. Num mesmo nível de importância, está a temperatura sob a qual a criação é mantida, em virtude da sua grande influência sobre o desenvolvimento e comportamento dos insetos.

Além destes dois fatomes, os quais foram bjeto de investigação no presente trabaliho, o dominio de $\underline{u}$ ma série de outras informações complementares è necessário para o estabelecimento de um programa de criação de in setos bem sucedido. Entre estas, podem-se citar aquelas re lacionadas com as demais exigências ambientais da espécie (umidade, fotoperíodo, etc.), tamanho de recipientes e gaio las de criação, obtenção de ovos, alimentação de adultos e cuidados assépticos.

\subsubsection{DIETA ARTIFICIAL}

A experimentação realịzada em termos de dietas artificiais, permitiu levantar dados sobre o rendimento potencial e a economicidade de produção de $P$. sequax em laboratório. Além disso, tambén foi avaliada a qualidade dos insetos produzidos, através da comparação com indivíduos criados no trigo e do acompanhamento biológico, ao longo de três gerações sucessivas.

Para efeito de discussão dos resultados ob tidos com as dietas $A, K$ e $N$, quanto à possibilidade de utilização num programa de crịação massal de $P$. : sequax, supôs-se a necessidade de se produzirem 20.000 lagartas/dia. Esta è a produção atual de lagartas de Anticarsia gemmatalis Hueb., principalmente para o programa de Baculovirus an 
ticar sia em desenvolvimento no Brasil (MOSCARDI*).

Uma produção massal de lagartas de $P$. sequax poderá vir a ser absorvida, por exemplo, em programas de resistência de plantas ou na produção de entomopa tógenos, pois recentemente foi registrada a incidência de um virus de poliedrose nuclear nas lagartas desta espécie (TONET e KITAJIMA, 1984; e LAZZARI e IAZZARI, 1985).

- Quantidade e qualidade dos insetos

A possibilidade de ser produzida uma maior ou menor quantidade de lagartas depende muito da viabilidade das diversas fases de desenvolvimento do inseto, prin cipalmente da viabilidade larval.

As três dietas artificiais podem proporcio nar um rendimento aceitável, acima do limite mínimo precô nizado por SINGH (1983) (75\% das lagartas originando adul tos), e superior ao obtido no trigo (Tabela 13). Desta forma, mesmo que a produção sobre o alimento natural reunisse características satisfatôrias de praticidade e economicidade, ela seria quantitativamente desvantajosa em relação às dietas artificiais.

As três dietas artificiais, apresentaram um alto potencial de produção de lagartas superando, inclusive, o obtido na criação massal de A. gemmatalis no CNPSO/EMBRAPA que é de 90\% (CAMPO et alii, 1985). A viabilidade larval médiạ, em três gerações consecutivas, foi de 94,93 e 93: nas dietas $A, K$ e $N$, respectivamente.

* moscardi, p. (embrapa, Centro nacíarag de Pesquísa de soja (CNPSo), Londririal. Comunicação péssoál, 1986. 
Outros parâmetros que podem interferir indiretamente no número de lagartas produzidas são capacida de postura e a viabilidade dos ovos. Em relação a esta última, as dietas A e $\mathrm{K}$ apresentaram desempenho satisfató rio e igual ao trigo, atingindo 85\% (Tabela 13). Em termos de ca pacidade de postura, as três dietas artificiais não diferiram do trigo (Tabela 16).

Considerando-se a viabilidade de todo o pe ríodo de desenvolvimento, verificou-se que as dietas $A$ e $\mathrm{K}$ superaram 0 trigo e a dieta $\mathrm{N}$, quanto ao número de inse tos que atingiram a fase adulta (Tabela 13, Figura 8).

Quando se trata de produção de entomopatógenos, a lém do nưmero, o peso das lagartas tem particular importância. Tam bém neste aspecto as dietas artificiais mostraram diferenças entre si. Lagartas mais pesadas foram obtidas nas dietă A e K com 0,19 e $0,20 \mathrm{~g}$, em seu tamanho máximo, respectivamente, "contra $0,17 \mathrm{~g}$ na dieta N (Tabela 10).

Avaliando-se as fases de lagarta e de pupa por três gerações sucessivas, nas dietas $A, K$ e $N$, observou-se a tendência de decréscimo na qualidade dos insetos, através da análise da viabilidade (Tabela 7), . peso de pupas (Tabela 8) e deformação de pupas e adultos (Tabela 9).

Em termos gerais, entretanto, as dietas A e $K$ mostraram-se sempre superiores à $N$, quanto a estes pa râmetros. Há que se acrescentar, também, que nas dietas A e $\mathrm{K}$. a velocidade de desenvolvimento aumentou da primeira para a terceira geração (Tabelá 7 ), contmariando a hipóte se de uma possível degeneração ao longo das três primeíras gerações. 
Pelo exposto, constatanse que os dados obtidos não são suficientemente conclusivos a respeito do padrão de qualidade dos insetos nas gerações estudadas. No entanto, permitem inferir que as dietas $A$ e $K$ podem, no minimo, sustentar a crìação de lagartas de $P_{\text {. }}$ s sequax por três gerações consécutivas, com uma viabilidade larval mé dia superior a $90 \%$.

A qualidade dos insetos produzidos nas die tas artificiais, tambêm pode ser discutida comparando-os através de parâmetros biológicos, com os produzidos no trigo. Nesse sentido, verificou-se que quanto à velocidade de desenvolvimento, as dietas $A$ e $K$ foram as que mais se aproximaram do trigo (Tabela 14, Figura 8). Em relação ao peso de pupas (Tabela 15), as três dietas, artificiais apresentaram resultados superiores ao do trigo; o mesmo ocorreu em ter mos de deformação de pupas e adultos, para as dietas A e K (Tabela 17).

A longevidade e a duração dos períodos de pré-oviposição e de oviposição, registradas nas dietas arrtificiais, foram comparáveis aos obtidos no trigo (Tabela 16, Figura 15). Como já foi discutido, as dietas.A :e.K igualaram-se 'ao trigo quanto à viabilidade de ovos 'e númenò destes

No entanto; a grande variação na capacidade individual de postura pode ter contribuido para: que não se detectasse diferenças estatísticas entre as dietas, quanto ao número de ovos por fêmea. Ressalta-se, pon tanto, a necessidade de novos e mais completos estudos sobre o potencial de reprodução de $P$. sequax, em dietas artificiais. 
.100

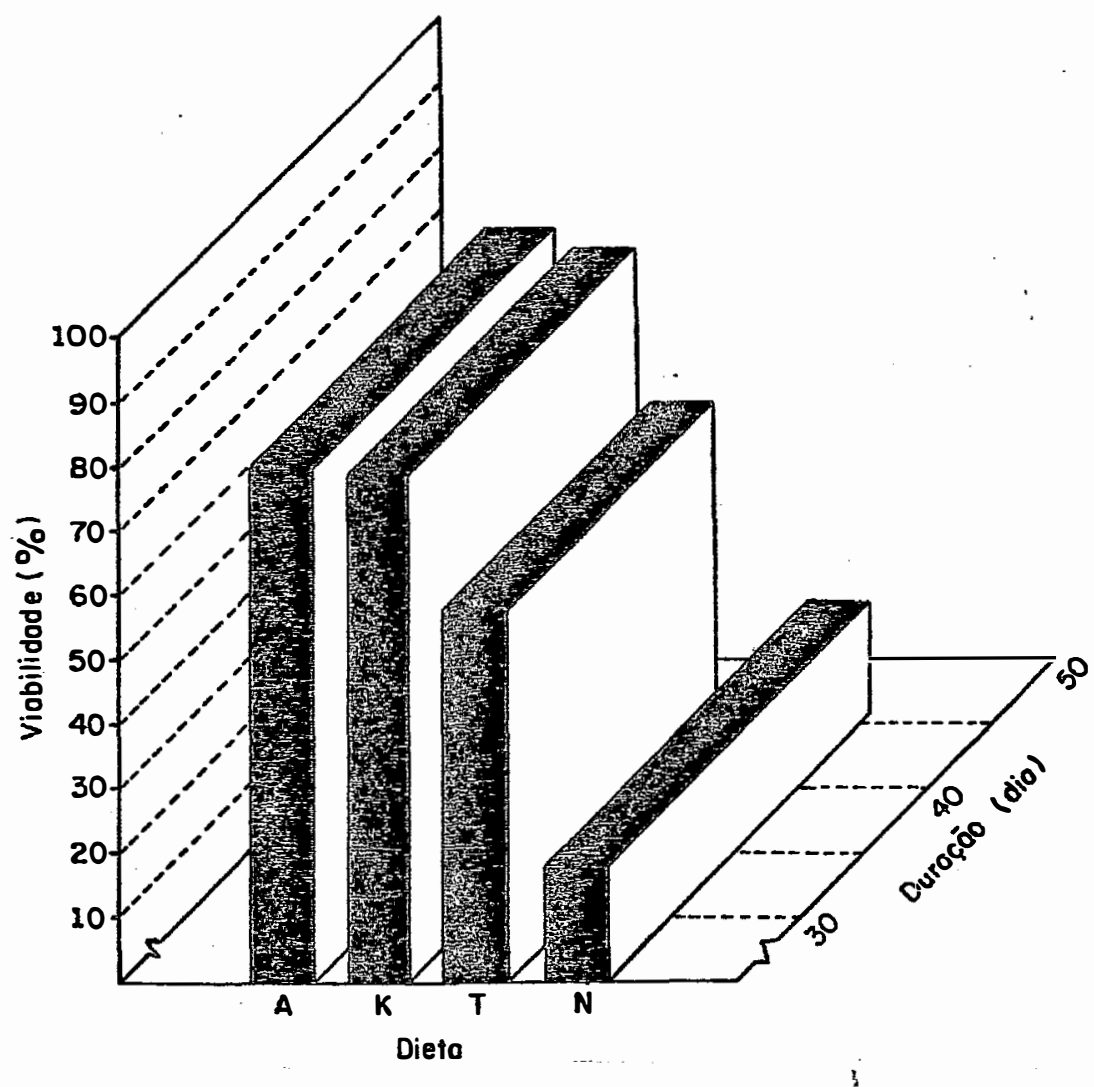

Figuna 8 - Viabilidade e duração das fases imaturas de Pseudaletia sequax Franc., 1951 criada em três dietas artificiais $(A ; K$ e N) e em tri go (T) (termeratura: $25 \pm 2{ }^{\circ} \mathrm{C}$; UR: $60 \pm 10 \%$; fotofase: $14 \mathrm{~h}$ ). 


\section{- Custo e benefício da criação}

A relação custo/benefício de uma criação massal de insetos só pode ser devidamente avaliada dentro de uma situação real, baseando-se em dados concretos. Não obstante, é bastante fácil de serem reconhecidos, em termos gerais, os beneficios decormentes de uma criação massal. O principal deles è a agilização das pesquisas básicas e aplicadas, devido à disponibilidade de material biológico em quantidade suficiente e a qualquer tempo.

o custo dos insetos produzidos nas dietas A, K e $\mathrm{N}$ não apresentou diferenças expressivas (Tabela 12). Raciocinando-se em termos de produção de 20.000 lagartas, o gasto com as dietas seria da ordem de 1130,00, 1104,00 e 994,00 cruzados, nas dietas A, K e N, respectivamente, levando-se em consideração apenas o custo da die ta, independentemente das outras despesas (mão-de-obra, etc.).

Considerando-se que a viabilidade larval é praticamente igual nas trềs dietas artificiais (Tabela. 13), a dieta $\mathrm{N}$ forneceria o menor custo de produção. No entanto, como já foi discutido, esta dieta se mostrou inferior às demais, em termes da quantidade e da qualidade dos insetos produzidos.

A maior economicidade e praticidade da uti lização de dietas artificiais, toma-se evidente quando se considera que no presente trabalho;para a manutenção de uma criação de cem lagartas com trigo, foram necessárias $2 \mathrm{~h} / \mathrm{homem} / \mathrm{dia}$ apenas para troca de alimento e limpeza dos recipientes de criação, na fase larval. Nessas conđições, seria praticamente impossivel produzirem-se 20.000 lagartas/dia. Esta afirma 
ção torna-se ainda mais sustentável, ao se levar em conta que a viabilidade lanval em trigo, foi inferior à das die tas artificiais (Tabela 13).

Em termos globais as dietas $\mathrm{A}$ e $\mathrm{K}$ evidenciaram-se superiores à dieta $N$, para a criação de $P_{\text {.: se- }}$ quax. Quando comparadas ao trigo revelaram-se, quanto a al guns parâmetros, semelhantes a este e, quanto a outros, su periores ou inferiores.

A utilização da dieta $\AA$ ou da $K$, poderá, ser feita alternativamente, conforme as circunstancias de terminadas pelo preço e de disponibilidade de componentes, ou por fatores que alterem a relação custo/beneficio em favor de uma delas.

\section{4,2. TEMPERATURA ḌE CRIAC̣Ão}

O estudo do efeito de diferentes temperatu ras constantes $\left(18,20,22,26,30\right.$ e $\left.32^{\circ} \mathrm{C}\right)$ sobre a biologia de $P$. sequax, permitiu constatan que o melhor desenvolvimento dos insetos ocorreu a $26^{\circ} \mathrm{C}$ (Tabelas 19, 20 e 24, Figura 9). Esta temperatura também se mostrou menos adequada à ocorrêncíia de mìcronganismos contaminantes, na dieta, a qual foi nula nesta condição (Tabeila 24).

Para os parâmetros da fase adulta, a rela ção inversa entre a temperatura e a longevidade (Tabela 22 e Figura 7) mostrou que este fator pode ter grande importância no processo de criação massal, e que deve exis tir uma faixa têrmica ótima para o desempenho reprodutivo da espécie. De fato, isto foi ratificado quando se avaliou a longevidade, a duração dos periodos de prê-oviposi ção e de oviposição e a capacidade de postura, em dois re 


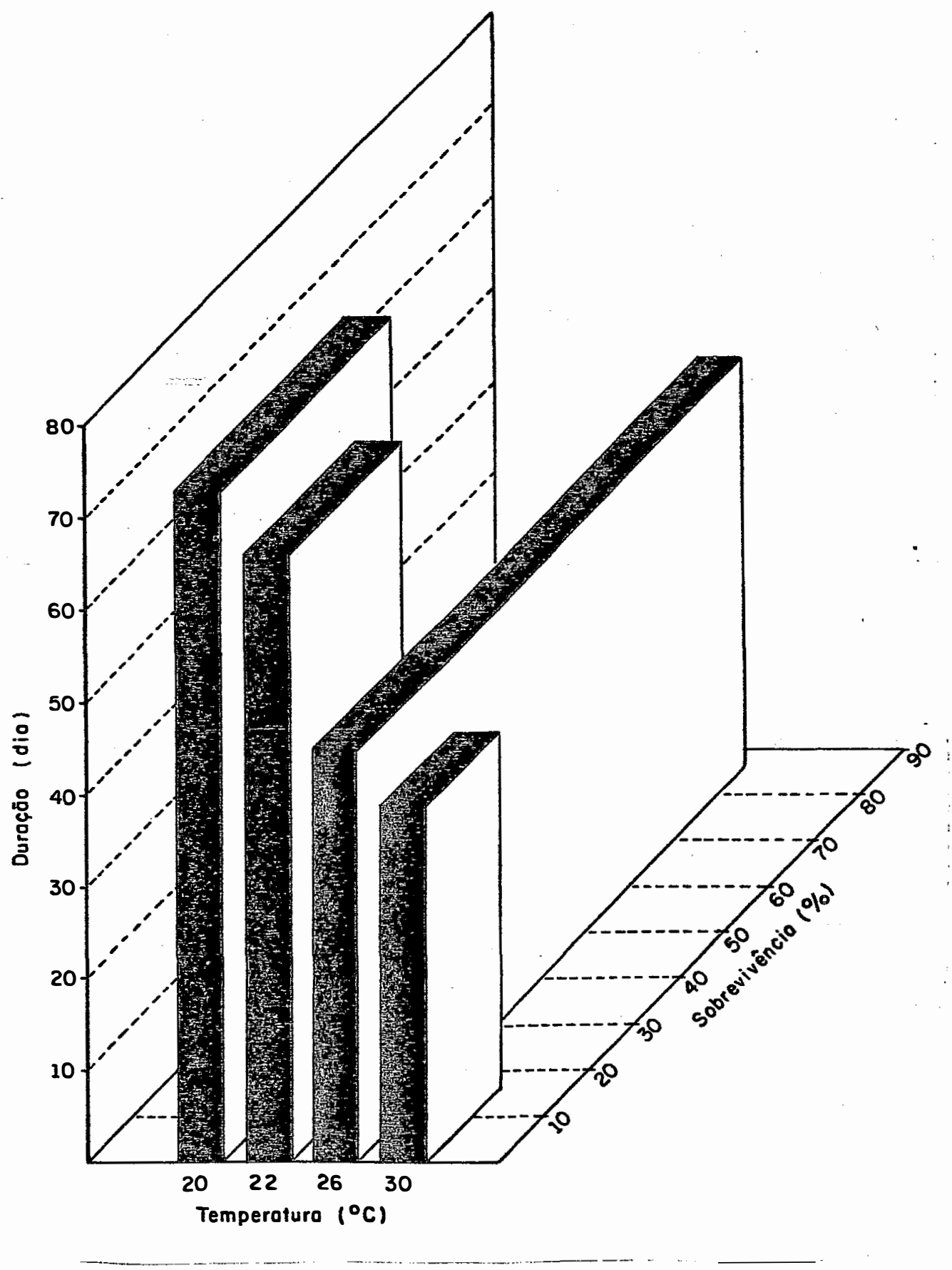

Figura 9 - Sobrevivência e đuração das fases imaturas de. Pseudaletia sequax Franc., 1951 submetida a diferentes temperaturas (UR: 60 $\pm 10 \%$; fotofase: $14 \mathrm{~h})$. 
gimes térmicos distintos (Tabela 23). Os resultados alcan çados em relação a estes parâmetros, demonstraram uma melhor adequação da temperatura de $25 \pm 2{ }^{\circ} \mathrm{C}$, do que a de $28 \pm 2{ }^{\circ} \mathrm{C}$.

Estes dados mostram a necessidade de que 0 efeito da temperatura na fase adulta seja melhor pesquisa da, especialmente no sentido da definị̧ão de condições téx micas ideais para cópula e oviposição.

\subsubsection{OUTROS CONHECIMENTOS NECESSÁRIOS À CRIAÇÃO}

Alēm da dieta artifician e da temperatura, que foram as variáveis estudadas experimentalmente neste trabalho, os demais componentes da técnica de criação utị lizada, foram definidos previamente.

Para tanto, foram realizadas adaptações de técnicas empregadas para a crịação de outras espécies de lepidópteros no Laboratôrio de Biologia do Depto. de Ento mologia da ESALQ. Alguns procedimentos utilizados, resultaram de testes exploratórios, conduzidos preliminarmente com este fim.

O material e os métodos utilizados para criação de $P$. sequax no presente estudo, poderão ser èmpregados como técnica básica de um programa de icriação massal. Provavelmente, maiores ou menores modificações se mostrarão necessárias em conseqüêncịa da maior quantidade de insetos a ser produzida, e em favor da maior praticida de e economicidade operacionais. Desde logo, pode-se adrni. tir que um dos principais ajustes metodológicos a ser efe tivado, será a substîtuição dos tubos de vidino por recí pientes descartâveìs, para a manutenção das lagartas. 
Esta e outras eventuais adaptações, deverão ser devidamen te testadas e aprovadas experimentalmente, antes de serem incorporadas ae processo de criação. 


\section{CONCLUSÕES}

Os resultados obtidos no presente trabalho, permitem as seguintes conclusões:

- Duas dietas artificiais, uma à base de feijão, caseina, farinha de soja, germe de trigo e levedu ra de cerveja (dieta $A$ ) e outra à bse de feijão, germe de trigo e levedura de cerveja (dieta $K$ ), podem ser utilizadas em substituição a folhas de trigo para criação de $P$. sequax.

- $O$ alimento ingerido pelas lagartas influencia a viabilidade das fases de ovo, lagarta e pupa, a duração dos períodos larval e pupal, o peso de pupas, a taxa líquida de reprodução (Ro) e a razão finita de aumento ( $\lambda$ ). Não tem efeito, porém, sobre a razão sexual, longevidade de machos e de fêmeas, duração dos períodos de pré-oviposição e de ovipo sição e capacidade de postura.

- As dietas artificiais são consumidas e u tilizadas em quantidades diférentes pelas lagartas, sendo a eficiência de conversão menor no alimento menos adequado.

- A sobrevivência e a duração das fases de ovo, lagarta e pupa, bem como, o peso de pupas, são afetados pela temperatura. O efeito da temperatura na sobrevivência depende da fase de desenvolvimento. Na faixa de 20 a $30^{\circ} \mathrm{C}$ para a fase de ovo e de 18 a $30^{\circ} \mathrm{C}$ para as fases larval e pupal, a duração do desenvolvimento decresce com. o aumento da temperatura, sendo que a velocidade de desen volvimento em função da temperatura, ajusta-se ao modelo linear obtido através da recîproca da equação da hipêrubole. 
- A temperatura base e a constante térmica são de $8,1^{\circ} \mathrm{C}$ e $84,4 \mathrm{GD}$ para a fase de ovo, $8,8^{\circ} \mathrm{C}$ e 505,9 GD para a fase larval, $12,5^{\circ} \mathrm{C}$ e $180,6 \mathrm{GD}$ para a fase pupal e de $9,1^{\circ} \mathrm{C}$ e $804,4 \mathrm{GD}$, para todo o periodo de desenvolvimento.

- A longevidade, a duração dos periodos de pré-oviposição e de oviposição e a capacidade de postura são afetadas pela tempenatuna, sendo que o regime térmico de $25 \pm 2{ }^{\circ} \mathrm{C}$ é mais adequado à espécie do que o de $28 \pm 2{ }^{\circ} \mathrm{C}$. Na faixa de 18 a $30^{\circ} \mathrm{C}$, a longevidade mêdia de machos e fêmeas decresce linearmente com $\odot$ aumento da temperatura.

- A condição têrmica mais adequada para a criação de $P$.: sequax é entre 25 e $26^{\circ} \mathrm{C}$. 


\section{REFERÊNCIAS BIBLIOGRÁFICAS}

ALAM, M.z. On the biology of rice ear-cutting caterpillar, Pseudaletia unipuncta (Haworth) in East Pakistan. Agriculture Pakistan, Karachi, 1ㅡ(4): 560-72, 1961.

AMANTE, E. Sugestões para controle de várias pragas do trigo: Laphygma frugiperda, Mocis repanda, Pseudaletia unipuncta, Elasmopalpus lignosellus e Lycophotia sp. O Biológico, são Paulo, 28(9): 267-8, 1962.

AMARAL, J.F. do. Lagarta do trigo. O Biológico, São Pau $10,15(11): 209-15 ; 1949$.

BAUCKE, O. Lagarta do trigo. A Granja, Porto Alegre, 11. (102): 63-8, 1955.

BE, F.C. A new artificial diet for the armyworm Leucania separata (Wlk.). Acta Entomologica Sinica, Beijing, $\underline{24}(4): 379-83,1981$.

BERTELS, A. Entomologia agrícola sul-brasileira. Rio de Janeiro, Serviço de Informação Agrícola/Ministērio da Agricultura, 1956. 458p. (Série didática, 16).

BERTELS, A. Pragas do trigo no campo e seu combate. Pesquisa Agropecuária Brasileira. Sērie Agronomia, Rio de Janeiro, $\underline{5}$ : 81-9, 1970. 
BERTELS, A. \& BAUCKE, O. Segunda relação das pragas das plantas cultivadas no Rio Grande do Sul. Pesquisa Agropecuária Brasileira. Série Agronomia, Rio de Janei ro, $1: 17-46,1966$.

BERTELS, A. \& FERREIRA, E. Levantamento atualizado dos insetos que vivem nas culturas de campo do Rio Grande do Sul. Pelotas, Universidade Católica de Pelotas, 1973. 17p. (Publicação científica, 1).

BERTHOLDI, R.E.B. \& BIEZANKO, C.M. Principais noctuídeos prejudiciais às plantas cultivadas em arredores de Pelotas. Ciència e Cultura, São Paulo, $\underline{2}(4): 304,1950$.

BIEZANKO, C.M. \& RUFFINELLI,A. Fauna de lepidoptera del Uruguay; X. Agaristidae, Noctuidae et Thyatiridae. Montevideo, Centro de Sanidad Vegetal, 1971. 30p. (Pu blicação técnica, 2) .

BIEZANKO, C.M.; RUFFINELLI, A.; LINK, D. Plantas y otras substancias alimenticias de las orugas de los lepidopteros uruguayos. Revista do Centro de Ciências Rurais, Santa Maria, $\underline{4}(2): 107-47,1974$.

BINDRA, O.S. \& SINGH, J. Bionomics of the army-worm Mythimna separata (Walker) (Lepidoptera: Noctuidae), at Ludhiana, Punjab. Indian Journal of Agricultural Science, New Delhi, 43(3): 299-303, 1973.

BOLLER, E. Behavioral aspects of mass rearing of insects. Entomophaga, Paris, 17(1): 9-25, 1972. 
BOWLING, C.C. Rearing of two lepidopterous pests of rice on a common artificial diet. Annals of the Entomological Society of America, Columbus, 60: 1215-6, 1967.

BREELAND, S.G. Biological studies on the armyworm Pseuda letia unipuncta (Haworth) in Tennessee (Lepidoptera: Noctuidae). Journal of Tennessee Academic Science, Na shville, 33(4): 263-347, 1958.

BRUES, C.T. Insect dietary, a account of the food habits. of insects. Cambridge, Harvard University Press, 1946. $466 \mathrm{p}$.

BURTON, R. Mass rearing the corn earworm in the laboratory. Tifton, USDA/Agricultural Research Service, 1969. 8p. (ARS 33-134).

CALLAHAN, P.S. \& CHAPIN, J.B. Morphology of the reproduc tive systems and mating in two representative members of the family Noctuidae, Pseudaletia unipuncta e Peridroma margaritosa, with comparison to Heliothis zea. Annals of the Entomological Society of America, Colum bus, 53: 763-82, 1960 .

CAMPO, C.B.H.; OLIVEIRA, E.B. de; MOSCARDI; F. Criação. massal da lagarta da soja (Anticarsia gemmatalis). Lon drina, Centro Nacional de Pesquisa de Soja/EMBRAPA, 1985. 23p. (Documentos, 10).

CORSEUIL, E. Pragas do trigo. Agrotecnia, Porto Alegre, $\underline{2}(4): 51-67,1958$. 
CORSEUIL, E. \& CRUZ, F.Z. da. Insetos nocivos à cultura do trigo no Rio Grande do sul. Revista da Faculdade de. Agronomia da UFRGS, Porto Alegre, $\underline{I}(1): 19-28,1975$.

COSTA, R.G. Alguns insetos e outros pequenos animais que danificam as plantas cultivadas no Rio Grande do Sul. Porto Alegre, Secretaria do Estado dos Negócios da Agricúltura, Indústria e Comércio, 1958. 296p. (SIPA, 172).

CosTA, R.G. Lagarta nos trigais. Boletim Agronômico, Porto Alegre, $\underline{9}(105 / 106): 20-22,1945$.

CRUZ, M.S. \& FOERSTER, L.A. Aspectos biológicos de Pseudaletia sequax Franclemont, 1951 (Lepidoptera, Noctuidae) em trigo, alface e espinafre. In: CONGRESSO BRA -SILEIRO DE ENTOMOLOGIA, 10, Rio de Janeiro, 1986. Resumos. Rio de Janeiro, Sociedade Entomológica do Bra sil, 1986. p.29.

DAVIS, J.J $;$ \& SATTERTHWAIT, A.F. Life-history studies of Cirphis unipuncta, the true army worm. Journal of. Agricultural Research, Washington, $\underline{6}(21): 7.99-812,1916$.

DHALIWAL, Z.S. \& BAINS, S.S. Effect of temperature on the development, survival and the rate of increase of armyworm, Mythimna separata (walker) (Noctuidae, Lepidoptera). Indian Journal of Ecology, Ludhiana, $\underline{5}(2)$ : 240-9, 1978 .

EL-SHERIF, S.I. On the biology of Leucania loreyi Dup. (Lepidoptera, Noctuidae). Zeitschrift Fuer Angewandte. Entomologie, Hamburg, 71: 104-11, 1972. 
ETCHECHURY, M.B.; ORIHUELA, J.A.; TORTEROLO, M.C. ; TERRA, A.L.; ZERBINO, M.S. Efecto de la alimentacion sobre características biologicas y consumo foliar de Mythimna (= Pseudaletia) adultera Schaus (Lepidoptera: Noctu idae). In: JORNADAS DE ZOOLOGIA DEL URUGUAY, Montevideo, 1985. Actas. Montevideo, 1985. p.i.

FAGUNDES, A.C. Principais insetos que atacam a cultura do trigo no R.G. do Sul. In: REUNIÃO LATINO-AMERICANA DE TRIGO, Porto Alegre, 1974. Anais. Porto Alegre, 1974. p.201-3.

FRAENKEL, G. Nutritional value of green plants for insec ts. In: SYMPOSIA OF THE INTERNATIONAL CONGRESS OF ENTOMOLOGY, 9 , Amsterdam, 1953. Proceedings. p.90-100.

FRANCLEMONT, J.G. The species of the Leucania unipuncta group, with a discussion of the generic names for the various segregates of Leucania in North America; (Lepi doptera, Phalaenidae, Hadeninae). Proceedings of the Entomological Society of Washington, Washington, 53(2) : $57-85,1951$.

FRANZMANN, B.A. Food consumption of larvae of the common armyworm (Pseudaletia convecta (Walk.)). Queensland Journal of Agricultural and Animal Sciences, Brisbane, 30: 157-9, 1973 .

GALLO, D.; NAKANO, O.; WIENDL, F.M.; SILVEIRA NETO, S.; CARVALHO, R.P.L. Manual de entomologia - pragas das plantas e seu controle. São Paulo, Agronômica Ceres, 1970. 858p. 
GALLO, D. ; NAKANO, O.; SILVEIRA NEIO, S.; CARVALHO, R.P.L .; BATISTA, G.C.; BERTI FILHO, E.; PARRA, J.R.P.; ZUCCHI, R.A.; ALVES, S.B. Manual de entomologia agrícola. S. Paulo, Agron. Ceres, 1978. $531 \mathrm{p}$.

GASSEN, D.M. Caracterização das espēcies do gênero Pseudaletia Franc., 1951 (Lep., Noctuidae) ocorrentes no Rio Grande do Sul. Porto Alegre, 1983. 18p. (Especia lização - Instituto de Bio-Ciências/PUC-RS).

GASSEN, D.N. Insetos associados à cultura do trigo no. Brasil. Passo Fundo, Centro Nacional de Pesquisa de Trigo/EMBRAPA, 1984. 39p. (Circular técnica, 2).

GOODWIN, R.H. Axenic culture of the armyworm Pseudaletia unipuncta (Haworth) on a meridic diet. Nature, London, 212: 799-800, 1966 .

GREENE, G.L.; LEPPLA, N.C.; DICKERSON, W.A. Velvetbean caterpillar: a rearing procedure and artificial medium. Journál of Economic Entomology, Baltimore, 69(4) : 4878, 1976 :

GUAGLIUMI, P. Lagartas desfolhadoras. In: Pragas da cana-de-açúcar; nordeste do Brasil. Rio de Janeiro, Ins tituto do Açúcar e do Álcool, 1972/73. 622p.

GUPPY, J.C. Life history and behaviour of the armyworm. Pseudaletia unipuncta (Haw.) (Lepidoptera: Noctuidae), in Eastern Ontário. The Canadian Entomologist, Ottawa, 93: 1141-53, 1961 .

GUPPY, J.C. Some effects of temperature on the immature stages of the armyworm, Pseudaletia unipuncta (Lepidop tera: Noctuidae), under controlled conditions. The Canadian Entomologist, Ottawa, 101: 1320-27, 1969. 
HADDAD, M.L. \& PARRA, J.R.P. Mētodos para estimar os li-. mites térmicos e a faixa ótima de desenvolvimento das. diferentes fases do ciclo de desenvolvimento de insetos. Piracicaba, Fundação de Estudos Agrários "Luiz de Queiroz", 1984. 12p. (Sērie Agricultura e Desenvol vimento).

HAMBLETON, E.J. Alguns dados sobre lepidópteros brasilei ros no Estado de Minas Gerais. Revista de Entomologia, Petrópolis, $\underline{5}(1): 1-7,1935$.

HATTORI, M. \& ATSUSAWA, S. Mass-rearing of the cabbage armyworm Mamestra brassicae (L.) and the common armyworm Mythimna separata (Wlk.) (Lepidoptera, Noctuidae) on a simple artificial diet. Japanese Journal of Applied Entomology and Zoology, Tokyo, 24(1): 36-39, 1980.

HENSLEY, S.D. \& HAMMOND, 'A.M. Laboratory techniques for rearing the sugar cane borer on an artificial diet. Journal of Economic Entomology, Baltimore, 61: 1742-3, 1968.

HIRAI, K. The influence of rearing temperature and densi ty on the development of two Leucania species, L. Loreyi Dup. and L. separata Walker (Lepidoptera: Noctuidae). Applied Entomology and Zoology, Tokyo, 10(3) : 234-7, 1975 .

HIRAI, K. A simple artificial diet for mass rearing of the armyworm Leucania separata Walker (Lepidoptera: Noc tuidae) - Applied Entomology and Zoology, Tokyo, 11(4): $278-83,1976$. 
HOUSE, H.I. Nutrition. In: ROCKSTERN, M. ed. The physiology of insecta. New York, Academic Press, 1974. p.1-62.

KOGAN, M. Criação de insetos: bases nutricionais e aplicações em programas de manejo de pragas. In: CONGRESSO BRASILEIRO DE ENTOMOLOGIA, 6, Campinas, 1980. Anais. Campinas, Fundação Cargill, 1980. p.45-75.

KOGAN, M. \& PARRA, J.R.P. Techniques and applications of measurements of consumption and utilization of food by phytophagous insects. In: BHASKARAN, G.; FRIEDMAN, $\mathrm{S}$. \& RODRIGUEZ, J.G. ed. Current topics in insect endocrinology and nutrition. New York, Plenum Publishing Corporation, 1981. p.337-52.

KOJIMA, I. \& NAKAYAMA, I. Rearing of various lepidopterous larvae on artificial diet of identic compostion. Japanese Journal of Applied Entomology and Zoology, To kyo, 23 (4): 261-3, 1979 .

LARA, F.M.; SILVEIRA NETO, S.; PÉRECIN, D. Constância sị multânea de espécies de noctuídeos pragas de Jaboticabal e Piracicaba, São Paulo. Anais da Sociedade Entomológica do Brasil, Jaboticabal, 6 (1): 51-7, 1977.

LAZZARI, S.N. \& LAZZARI, F.A. Ocorrência de Pseudaletia sequax Franclemont, 7951 (Lepidoptera, Noctuidae) e seus inimigos naturais em cevada (Hordeum sp.), no Paraná. Anais da Sociedade Entomológica do Brasì, Porto Alegre, $14(1): 59-66 ; 1985$.

LESCHE, G.E. Biologia de Pseudaletia sequax Franclemont, 1.951 (Lepidoptera, Noctuidae), em trigo. In: CONGRESSO BRASILEIRO DE ENTOMOLOGIA, 9, Londrina, 1984. Resumos. Iondrina, Sociedade Entomológica do Brasil, 1984. p.21.

MACKAUER, M. Genetic aspects of insect production. Entiomophaga. Paris, 17(1): 27-48, 1972 . 
MARICONI, F.A.M. Insetos daninhos às plantas cultivadas. São Paulo, Nobel, 1969. 123p.

MARICONI, F.A.M. Inseticidas e seu emprego no combate às pragas. 3ạ ed., São Paulo, Nobel, 1976. v.2.

MARTINS, J.F. do S. Resistência de variedades de arroz à Diatraea saccharalis (Fabricius, 1794) (Lepidoptera-Py ralidae) e sua associação com características biofísicas e bioquímicas das plantas. Piracicaba, 1983. 139 p. (Doutorado - Escola Superior de Agricultura "Luiz de Queiroz"YUSP).

MCLAUGHLIN, R.E. The effect of temperature upon larval mortality of the armyworm, Pseudaletia unipuncta(Haw.). Journal of Insect Pathology, New York, $\underline{4}$ : 279-84,1962.:

MENDES, A.C. Métodos de criação de parasitos da broca da cana-de-açúcar, Diatraea saccharalis (Fabricius, 1794). In: CONGRESSO BRASILEIRO DE ENTOMOLOGIA, 6, Campinas, 1980. Anais. Campinas, Fundação Cargill, 1980. p.103132 .

MIHSFELDT, L.H. Comparação de dietas artificiais para crí ação de Diatraea saccharalis (Fabricius, 1794) (Lepidoptera-Pyralidae). Piracicaba, 1985. 120p. (Mestrado - Escola Superior de Agricultura "Luiz de Queiroz"/ USP) .

MUKERJI, M.K. \& GUPPY, J.C. A quantitative study of food consumption and growth in Pseudaletia unipuncta (Lepidoptera: Noctuidae). The Canadian Entomologist, Ottawa, 102: 1179-88, 1970 .

NAKANO, O.; SILVEIRA NETO, S.; ZUCCHI, R.A. Entomologia Econômica. Piracicaba, Livroceres, 1981. 314p. 
NEELGUND, Y.F. \& MATHAD, S.B. Comparative studies of development of the armyworm, pseudaletia separata (Wal-. ker), reared on Napier grass and artificial diet. Karnatak University Journal Science, India, 19: 7-3, 1974.

PADIAL, I. Estudo do efeito do alimento e da temperatura sobre Pseudaletia sequax Franclemont, 1951 (Lepidoptera: Noctuidae). Curitiba, 1980. 62p. (Mestrado - Uni versidade Federal do Paraná).

PARO Jr., L.A.; NAKANO, O.; ARAGÃO, P.F.; PESSINI, L.A. Controle da "lagarta do trigo" Pseudaletia adultera (S. chaus, 1894) (Lepidoptera-Noctuidae), com o inseticida endogan em atomização. O Solo, Piracicaba, 64 (1): 2932,1972 .

PARRA, J.R.P. Biologia dos insetos.: Piracicaba, Departa mento de Entomologia/ESALQ/USP, 1979. 383p. (Mimeogra fado) .

PARRA, J.R.P. Métodos para medir consumo e utilização de alimento por insetos. In: CONGRESSO BRASILEIRO DE ENTOMOLOGIA, 6, Campinas, 1980. Anais. Campinas, Funda ção Cargill, 1980. p. 77-102.

PẠRA, J.R.P. \& CARVALHO, S.M. de. Biologia e nutrição quantitativa de Spodoptera frugiperda (J.E.Smith, 1797) em meios artificiais compostos de diferentes variedades de feijão. Anais da Sociedade Entomológica do Bra- . sil, Porto Alegre, $\underline{13}(2)$ : 305-19, 1984. 
PEREIRA, R.P. Morfologia, biologia e influência da dieta alimentar no desenvolvimento de Pseudaletia sequax Fran clemont, 1951 (Lepidoptera: Noctuidae), em laboratörio. Curitiba, 1978. 82p. (Mestrado - Universidade Federal do Paranā).

PEREIRA, R.P. Influência da dieta no desenvolvimento lar val e pupal de pseudaletia sequax Franclemont, 1951 (Le pidoptera: Noctuidae). Anais da Sociedade Entomológica do Brasil, Jaboticabal, 9(2): 211-7, 1980.

POND, D.D. Life history studies of the armyworm, Pseudaletia unipuncta (Lepidoptera: Noctuidae), in New Bruns wick. Annals of the Entomological Society of America, Columbus, 53: 661-5, 1960 .

SALVADORI, J.R.; SILVA, J.J.C.; GOMES, S.A. Pragas do trigo no Estado de Mato Grosso do Sul. Dourados, UEPAE Dourados/EMBRAPA, 1983. 46p. (Circular técnica, 9).

SCHOONHOVEN, L.M. \& MEERMAN, J. Metabolic cost of changes in diet and neutralization of allelochemićs. Entomologia Experimentalis et Applicata, Amsterdam, 24 : 489-93, 1978.

SCRIBER, J.M. \& SLANSKY, F. The nutritional ecology of $\underline{i}$ mmature insects. Annual Review of Entomologv, Palo Alto, 26: 183-211, 1981 .

SHOREY, H.H. \& HALE, R.L. Mass rearing of the larvae of nine noctuid species on a simple artificial medium. Journal of Economic Entomology, Baltimore, 58(3): 522$4,1965$. 
SILVA, A.G.A.; GONÇALVES, C.R.; GALVÃO, D.M.; GONÇALVES, A.J.L.; GONES, J.; SILVA, M.N.; SIMONI, L. Quarto catálogo dos insetos que vivem nas plantas do Brasil, seus parasitos e predadores. Rio de Janeiro, Ministério da Agricultura, 1968. v.l.

SILVEIRA NETO, S.; LARA, F.M.; IGUE, T.; CARRÃO, C.A.B.

- Periodicidade de vôo de alguns noctuideos pragas deter minada com armadilha luminosa automática. Anais da Sociedade Entomológica do Brasil, Jaboticabal, $\underline{4}(1): 1$ $11,1975$.

SILVEIRA NETO, S.; NAKANO, O.; BARBIN, D.; VILLA NOVA, N. A. Manual de Ecologia dos Insetos. São Paulo, Agronô mica Ceres, 1976. 419p.

SINCHAISRI, N. \& SÕGAWA, K. The influence of temperature on the development of armyworm, Leucania separata wal ker (Lepidoptera: Noctuidae). Applied Entomology and Zoology, Tokyo, $\underline{4}(2): 102-3,1969$.

SINGH, D. \& RAI, L. Bionomics of the rice cutworm, Mythimna separata (Walker). Entomon, Trivandrum, $\underline{2}(2)$ : $141-44,1977$.

SINGH, P. Artificial diets for insects, mites and spidens. New York, IFI/Plenum, 1977. 594p.

SINGH, P. A general purpose laboratory diet mixture for rearing insects. Insect Science and its Application, Elmsford, $\underline{4}(4): 357-62,1983$. 
SINGH, P. Multiple species rearing diets. In: SINGH, P. \& MOORE, R.F. ed. Handbook of insect rearing. New York, Elsevier Science Publishers, 1985. v.l. p. 1945 .

TERRA, A.L. \& ZERBINO, M.S. Características biológicas de Mythimna (= Pseudaletia) adultera Schaus (Lep.; Noc tuidae: Hadeninae) frente a dos tipos de alimento. Mn tevideo, Ministerio de Agricultura y Pesca, Departamen to de Entomologia, Dirección de Sanidad Vegetal, 1983a. 16p. (Mimeografado).

TERRA, A.L. \& ZERBINO, M.S. Evaluacion de perdidas produ cidas por lagartas defoliadoras em trigo: I. Consumo fo liar de Mythimna (= Pseudaletia) adultera Schaus (Lepi doptera, Noctuidae, Hadeninae). In: CONGRESSO NACIONAL DE INGENIEROS AGRÔNOMOS, 3, Montevideo, $1983 \mathrm{~b}$.

Resumenes. Montevideo, Asociacion de Ingenieros Agrônomos del Uruguay, 1983. p.i.

TONET, G.L. \& KITAJIMA, E.W. Possĩvel ocorrência de um virus da poliedrose nuclear em Pseudaletia sp. (Lepidoptera-Noctuidae), lagarta do trigo, no Brasil. In : CENTRO NACIONAL DE PESQUISA DE TRIGO/EMBRAPA. Resul-. tados de pesquisa do CNPTrigo apresentados na XIII RENAPET, 1984. Passo Fundo, CNPTrigo/EMBRAPA, 1984. p. 252-4. (Documento, 7).

UVAROV, B.P. Insect nutrition and metabolism; a summary of the literature. Transactions of the Royal Entomological Society of London, London, 74: 255-343, 1928. 
VENDRAMIN, J.D.; SOUZA, A.R.R.; PARRA, J.R.P. Ciclo biológico de Heliothis virescens (Fabr., 1781) (Lepidopte ra, Noctuidae) em dietas com diferentes tipos de celulose. Anais da Sociedade Entomológica do Brasil, Jabo ticabal, $11(1): 3-11,1982$.

VERNALHA, M.M.; ROCHA, M.A.L.; GABARDO, J.C.; SILVA, R.P. Principais pragas das plantas cultivadas do Estado do Paraná. Curitiba, Diretório Acadêmico "Lycio Velloso", 1968. 264p.

WALDBAUER, G.P. The consumption and utilization of food by insects. Advances in Insect Physiology, New York, 9: 229-88, 1968 . 